\title{
Electrospray Ionization Mass Spectrometry: A Technique to Access the Information beyond the Molecular Weight of the Analyte
}

\author{
Shibdas Banerjee and Shyamalava Mazumdar \\ Department of Chemical Sciences, Tata Institute of Fundamental Research, Homi Bhabha Road, Colaba, Mumbai 400005, India \\ Correspondence should be addressed to Shyamalava Mazumdar, shyamal@tifr.res.in
}

Received 9 August 2011; Revised 23 October 2011; Accepted 9 November 2011

Academic Editor: Troy D. Wood

Copyright (C) 2012 S. Banerjee and S. Mazumdar. This is an open access article distributed under the Creative Commons Attribution License, which permits unrestricted use, distribution, and reproduction in any medium, provided the original work is properly cited.

The Electrospray Ionization (ESI) is a soft ionization technique extensively used for production of gas phase ions (without fragmentation) of thermally labile large supramolecules. In the present review we have described the development of Electrospray Ionization mass spectrometry (ESI-MS) during the last 25 years in the study of various properties of different types of biological molecules. There have been extensive studies on the mechanism of formation of charged gaseous species by the ESI. Several groups have investigated the origin and implications of the multiple charge states of proteins observed in the ESI-mass spectra of the proteins. The charged analytes produced by ESI can be fragmented by activating them in the gas-phase, and thus tandem mass spectrometry has been developed, which provides very important insights on the structural properties of the molecule. The review will highlight recent developments and emerging directions in this fascinating area of research.

\section{Introduction}

The basic concepts of chemistry originated from the quantitative estimation (e.g., weighing) of the constituents in a chemical reaction during the period of Lavoisier more than 200 years ago. Since then the analytical measurement of masses of the samples continuously evolved through the gravimetric analysis to weighing a single atom/molecule using the modern instrument called mass spectrometer. In mass spectrometry, a particular state of matter called gaseous ionic state is studied by transferring the analytes from condensed phase to the gas phase followed by their ionization. The success of the study of gas-phase ion chemistry and its application has been driven by the continuous advancement of the mass spectrometric technique since the studies were performed by Thomson [1]. As a result the mass spectrometry has become one of the most sensitive analytical methods for the structural characterization of molecules. Before the development of ESI-MS, there were several ionization methods (electron ionization, chemical ionization, etc.), but none of them could be able to overcome the propensity of the analyte fragmentation. In the mid 1980s, it became indispensable to precisely measure the molecular mass of the biologically important supramolecules like proteins [2]. But the proteins are polar, nonvolatile, and thermally labile molecules. So the ionization of the proteins by conventional ionization methods could lead to structural destruction. Although a technique called fast atom bombardment (FAB) [3] was available that time for the ionization of the biological samples, this technique produces predominantly singly charged ions of the analyte and the method works best for smaller species of mass below about $1000 \mathrm{Da}$. However, the available mass analyzers could not measure the high $\mathrm{m} / \mathrm{z}$ value of the singly charged high molecular weight proteins during those days. So the only way to analyze the protein mass was to digest the protein and then the analysis of the digest mixture by FAB-mass spectrometry.

All those problems were overcome in 1989 when Fenn introduced electrospray ionization, a soft ionization technique, to ionize intact chemical species (proteins) by multiple charging [4]. The ionization is soft in the sense that a very little residual energy is retained by the analyte, and generally 
no fragmentation occurs upon ionization. Not only that but also very weak noncovalent interactions are preserved in the gas phase [5]. Because of the multiple charging, the $\mathrm{m} / \mathrm{z}$ values of the resulting ions become lower and fall in the mass ranges of all common mass analyzers. Thus ESI became very useful in the production of gas-phase ions from large biologically important macromolecules like proteins and nucleic acids, and their subsequent mass spectrometric analysis for structural characterization as well as their rapid identification on the basis of molecular mass, a very specific property of the analyte. Gradually a systematic analysis of proteins with the mass spectrometry as the central tool led to a discrete subject called "Proteomics," one of the fastest growing research areas in the chemical sciences [6].

In 2002 Fenn, the inventor of ESI-MS shared the 4th Nobel Prize in mass spectrometry along with Koichi Tanaka (for the development of MALDI mass spectrometry, another soft ionization technique) and Kurt Wuthrich (for the work in NMR spectroscopy). "A few years ago the idea of making proteins or polymers "fly" by electrospray ionization (ESI) seemed as improbable as a flying elephant, but today it is a standard part of modern mass spectrometers" as stated by the Professor Fenn in his Nobel lecture [7]. Nowadays ESI-MS is not only being used as a balance to weigh protein molecules but also to gain a deeper understanding of the protein three-dimensional structures, noncovalent interaction, posttranslation modification, and amino acid sequence. Soft landing of the mass-selected multiply charged gaseous protein ions into liquids (after the mass spectrometric separation) was recently shown to retain the native structures and even the biological activities of some proteins $[8,9]$. Although the development of ESI-MS has had a major impact in biology and proteomics, its application has extended to a broad range of analytes including polar organic [10], inorganic [11], and metal-organic complexes [12]. Recently ESI efficiency scale of the different organic molecules with different polarities has been developed $[13,14]$. The best ESI response has been observed for the analytes with ionizable basic/acidic polar functional groups. High-performance liquid chromatography has been coupled with the ESI-MS for the molecular fractionation prior to mass-spectrometric analysis. Thus, HPLC/ESI-MS has become a very powerful technique capable of analyzing both small and large molecules of various polarities in a complex biological sample mixture.

Here we would briefly review the development of the ESIMS technique in last two and half decades not only for the mass access but also for the detailed understanding of the structural properties of the analyte in the different aspects of chemistry and biology including the fundamentals of the ionization mechanisms.

\section{The Historical Perspective}

There is an interesting history behind the development of ESI-MS. Although the process electrospray was known more than hundred years ago [15], the actual thought process on ESI-MS was initiated by Professor Dole, a physical chemist at Northwestern University. Much of the Dole's research focused on the polymerization chemistry. In the 1960s he was trying to characterize the size as well as mass distribution of some synthetic polymers (originally polystyrene) by mass spectrometric technique. But that time the troubles he encountered were the lack of a suitable ionization system which can produce molecular ions (without decomposing their structures) in the gas phase from the highly nonvolatile synthetic polymers and also the unavailability of the suitable detector system which can probe the appearance of the large molecular ions with high $m / z$ value. Accidently he discovered the existence of electrospray while visiting a car manufacturer, and he observed the car painting by a process called electrospray. Then he applied the electrospray process in the production of gas-phase polystyrene ions and their subsequent collection using a Faraday cage detector $[16,17]$. Although their experiments showed that the electrospray is a very promising soft ionization (no fragmentation of the analyte) technique, no mass spectrometer was available that time to separate and detect the ions of polystyrene molecules.

However, Dole's report $[16,17]$ on electrospray got the attention of Professor Seymour Lipsky and Professor Csaba Horvath at Yale Medical School [2]. That time (1970s) Professor Lipsky was thinking about the alternate ways of ionizing biopolymers like proteins, and Professor Horvath was to work on the development of HPLC known as highpressure liquid chromatography. They noticed that two of the Dole's reports referred the work of Fenn who was a professor in the Yale Engineering Department that time. Fenn was a specialist in the field of molecular beams and their production by nozzle-skimmer systems. Through those references Lipsky got in touch with Fenn. Fenn accepted the challenge of the production of biomolecular ions in the gas phase using his molecular beam apparatus even though he was approaching 65, typical retirement age [2]. Finally Fenn group's ground breaking discovery on the ionization and characterization of large biomolecules in the gas phase by electrospray ionization mass spectrometry [4] created a new dimension in the field of proteomics. After the Fenn's discovery of ESI-MS technique, the uses of the electrospray ionization continue to grow at an unprecedented rate (see Figure 1), and every day new applications are developed as the instrument continues to advance as fast as the need.

\section{Basic Architecture of the ESI-Mass Spectrometer}

Like other mass spectrometers, ESI-mass spectrometer is also composed of three basic components, for example, ion source, mass analyzer, and detector (see Figure 2). The intact molecular ions (not truly ions, see later) are produced in the ionization chamber where the ion source is kept, and then they are transferred in the mass analyzer region via several ion optics (electromagnetic elements like skimmer, focusing lens, multipole, etc.), which are basically kept to focus the ion stream to maintain a stable trajectory of the ions. The mass analyzer sorts and separates the ions according to their mass to charge ratio $(\mathrm{m} / \mathrm{z}$ value). The separated ions are then passed to the detector systems to measure their concentration, and the results are displayed on 


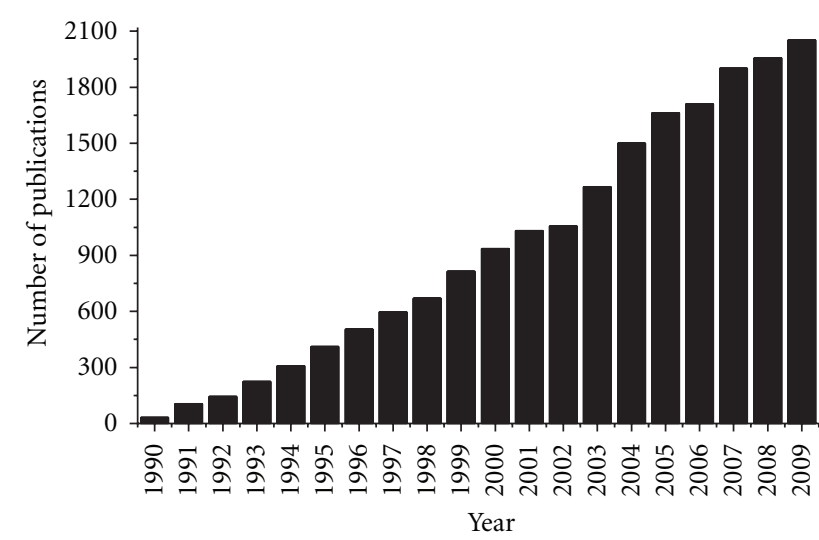

FIGURE 1: Yearly histogram of the papers dealing with the use of electrospray ionization after the Fenn's introduction of electrospray ionization mass spectrometry to ionize the biomolecules in 1989 . The information was obtained by searching ISI Web of Knowledge on 26.06.2011 for the term "Electrospray ionization."

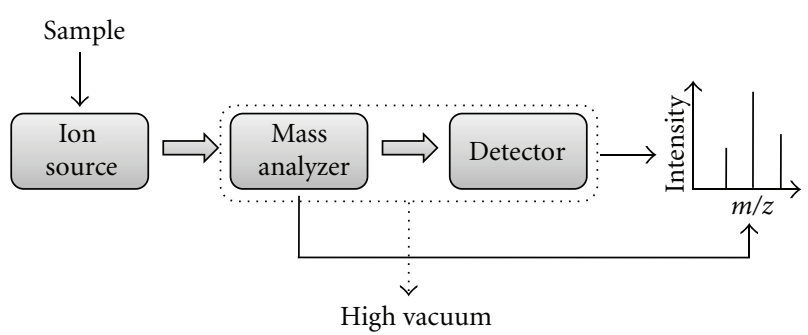

FIgURE 2: The basic components of the ESI-mass spectrometer.

a chart called a mass spectrum (see Figure 2). Since the ions in the gas phase are very reactive and often short lived, their formation and manipulation should be conducted in high vacuum. For this reason the ion optics, analyzer, and also the detectors are kept at very high vacuum (typically from $10^{-3}$ torr to $10^{-6}$ torr pressure). Mass spectrometers typically use either oil diffusion pumps or turbomolecular pumps to achieve the high vacuum required to operate the instrument. Generally the ion source is kept at atmospheric pressure, and a continuous pressure gradient and voltage gradient are used from source to the detector to help pump out the ions from source to the detector through the analyzer.

3.1. Ion Source. A suitable ESI source for the mass-spectrometric analysis was designed by the Fenn group in the mid 1980s [4, 18-20]. Later on it was modified by different research groups to improve the system's robustness [21-25]. Generally a dilute (less than $\mathrm{mM}$ in polar volatile solvent) analyte solution is injected by a mechanical syringe pump through a hypodermic needle or stainless steel capillary $(\sim 0.2 \mathrm{~mm}$ o.d and $\sim 0.1 \mathrm{~mm}$ i.d) at low flow rate (typically $1-$ $20 \mu \mathrm{L} / \mathrm{min})$. A very high voltage $(2-6 \mathrm{kV})$ is applied to the tip of the metal capillary relative to the surrounding source-sampling cone or heated capillary (typically located at $1-3 \mathrm{~cm}$ from the spray needle tip). This strong electric field causes the dispersion of the sample solution into an aerosol of highly charged electrospray (ES) droplets (see Figure 3). A coaxial sheath gas $\left(\right.$ dry $\left.\mathrm{N}_{2}\right)$ flow around the capillary results in better nebulization. This gas flow also helps to direct the spray emerging from the capillary tip towards the mass spectrometer. The charged droplets diminish in size by solvent evaporation, assisted by the flow of nitrogen (drying gas).

Finally the charged analytes are released from the droplets, some of which pass through a sampling cone or the orifice of a heated capillary (kept in the interface of atmospheric pressure and the high vacuum) into the analyser of the mass spectrometer, which is held under high vacuum. The heated capillary (typically $0.2 \mathrm{~mm}$ inner diameter, $60 \mathrm{~mm}$ in length and heated to $100-300^{\circ} \mathrm{C}$ ) causes the complete desolvation of the ions passing through it. The use of drying gas and the heated capillary can influence the system's robustness and reduce the degree of cluster ion formation [24]. The transfer of analyte ions from solution to gas phase is not an energetic process, but rather the desolvation process effectively cools the gaseous ions. So the analyte ions with low internal energies are allowed to enter into the mass spectrometer from the electrospray probe, and the structure of the analytes generally remain intact (no fragmentation) when appropriate instrumental conditions (e.g., no activation of the ions in gas phase) are used. Nowadays a number of sprayer modifications like pneumatically assisted electrospray [26-28], ultrasonic nebulizer electrospray $[29,30]$, electrosonic spray [31], and nanoelectrospray [23, 32] have been developed to expand the range of ESI applications. Among them the most popular one is nanoelectrospray.

Nanospray ionization is a low flow rate $(20-50 \mathrm{~nL} / \mathrm{min})$ version of electrospray ionization [32]. A very low sample concentration (nanomole/mL) and low volume are required for nanospraying. Such downscaling has been achieved by replacing the spray needle with borosilicate glass capillary of some microliters volume to which a fine tip $(1-4 \mu \mathrm{m}$ inner diameter) is pulled with a micropipette puller. The spray voltage of $0.7-1.1 \mathrm{kV}$ is normally applied via an electrically conducting coating (usually a sputtered gold film) on the outer surface of the spray capillary. When the high voltage is switched on, the analyte solution flow is solely driven by capillary forces refilling the aperture as droplets are leaving the tip. While conventional ESI generates initial charged droplets of $1-2 \mu \mathrm{m}$ in diameter, the nanospray produces the charged droplets of the less than $200 \mathrm{~nm}$ diameter; that is, their volume is about 100-1000 times smaller than the droplets produced by a conventional microemitter. The nanoESI has an increased tolerance to high aqueous solvents and salt contamination $[23,32]$. In this technique not only less analyte sample is consumed than with the standard electrospray ionization, but also a small volume of sample lasts for several minutes, thus enabling multiple experiments to be performed.

3.2. Mass Analyzer. The mass analyzer is the heart of the mass spectrometer. The mass analyzer can be compared with the prism. The component wavelengths of a light are separated by a prism, and then they are detected by an optical receptor. Similarly in the mass analyzer, the different types of ions $(\mathrm{m} / \mathrm{z})$ of an ion beam are separated, and then they are passed to the detector. There are many types of mass analyzers 


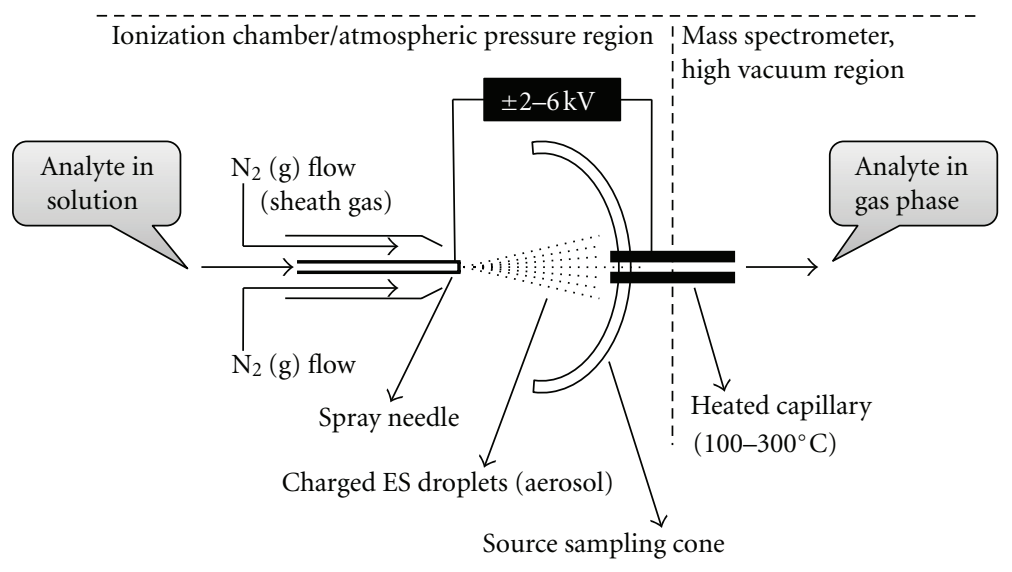

FIgURE 3: A schematic representation of the ESI-ion source.

$[33,34]$, for example, magnetic (B)/electric (E) sector mass analyzer, linear quadrupole ion trap (LIT), three-dimensional quadrupole ion trap (QIT) [35], orbitrap, time-offlight mass analyzer (TOF), and ion cyclotron resonance mass analyzer (ICR), all of these which use the static or dynamic magnetic/electric field, and all operate according to two fundamental laws of physics, for example, Lorentz force law and Newton's second law of motion. Proper selection of the mass analyzer depends on the resolution, mass range, scan rate, and detection limit required for an application. Although the detailed discussion of different types of mass analyzers is beyond the scope of this paper, interested readers can go through any standard mass spectrometry text book for this issue.

3.3. Detector. The simplest way to detect the ion is the use of Faraday cup, where the ion is allowed to be neutralized and the resulting current is measured. This Faraday cup is used when the ion flux is relatively large. But a more modern way to measure the low ion flux is the use of electron multiplier (just like photomultiplier tube to measure the photon flux) $[36,37]$. The energetic ions are allowed to strike a metal or semiconductor plate (e.g., copper/beryllium alloy oxide) called a conversion dynode that emits secondary electrons (SE). This conversion dynode is held at very high voltage (order of $\mathrm{kV}$ ). The secondary electrons emitted are accelerated and focused onto the second and subsequent dynodes (kept in positive potentials), which are set at potentials progressively closer to earth. At each dynode there is an increase in the number of electrons emitted (electron avalanche), such that at the end of the multiplier a gain of approximately $10^{6}$ is achieved. The output current is converted to a voltage signal, which finally can be translated to an intensity value (the ordinate axis of the mass spectrum) by means of an analog-to-digital (ADC) converter. There are several types of multipliers like discrete dynode electron multipliers [36, 37], channel electron multipliers (CEMs) [34], microchannel or multichannel plates (MCPs) [34], and so forth. Unlike other mass spectrometers, ions are not detected by hitting a detector such as an electron multiplier in FT-ICR-MS [38], but ions are detected by the measurement of the image current produced by ions cyclotroning in the presence of a magnetic field. A detector is selected according to its speed, dynamic range, gain, and geometry. Some detectors are sensitive enough to detect a single ion. Although there has been a revolution in the mass spectrometer development in the last twenty years by several researchers and companies, the question regarding the response of the detector haunts the researchers till now. How does the detector respond to the large multiply charged ions produced by ESI? No precise information is available regarding the fact whether the observed peak height corresponding to a multiply charged macroion reflects the number of incident ions, the number of charges they carry, the conformation of the ion, the energy of incidence, its velocity, or an unknown combination of these factors [39]. Though it is assumed that a peak height in a mass spectrum is directly proportional to the number of corresponding incident ions to the detector, this issue still remains suspicious as the detector response has not been characterized appropriately in those aspects mentioned above [39].

Figure 4 shows some hybrid mass spectrometers (commercially available) which are constructed by combining different types of $m / z$ separation devices or mass analyzers. Different types of detectors and spray (ion source) geometries are also noticeable in those instruments (Figures 4(a)-4(c)). These instruments are specially designed for the tandem mass analysis (see later). The trajectory of the ions from ion source to the analyzer is linear (on-axis/line-of-sight) in conventional electrospray sources (Figure 4(a)). But, recently the spray geometries have been modified to orthogonal spray (Figure 4(b)) or Z-spray (Figure 4(c)) where the ion trajectory from source to the analyzer is, respectively, orthogonal and $z$ shaped. These off-axis spray geometries circumvent the problem of the clogging of heated capillaries and skimmers by neutral molecules, nonvolatile materials, and so forth.

\section{The ESI-Mass Spectrum}

Generally the ions derived by ES process are multiply charged, and the analyte remains intact (no fragmentation) when 


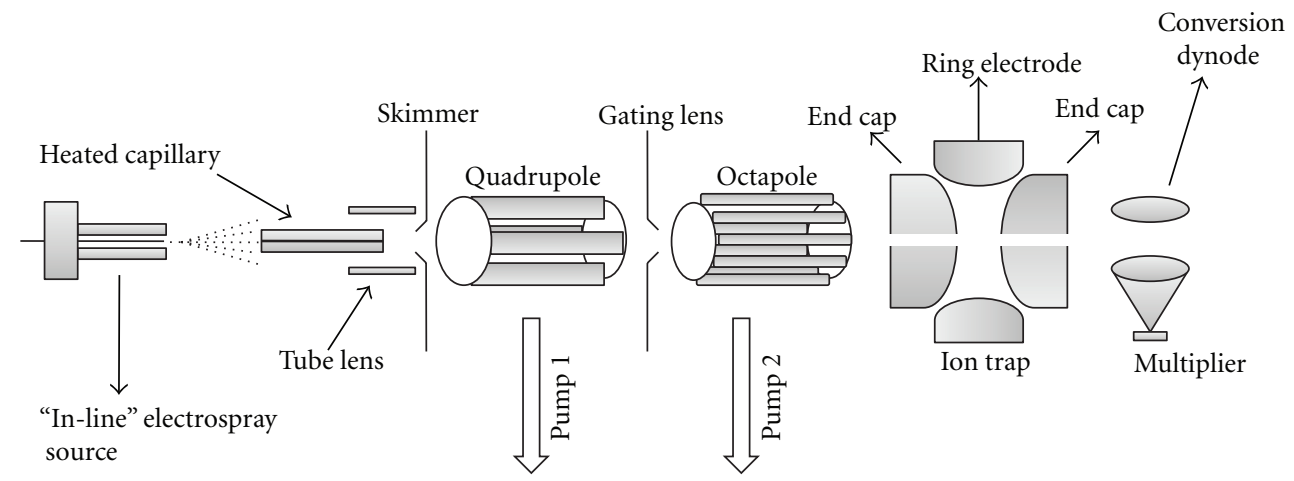

(a)

Orthogonal

electrospray source

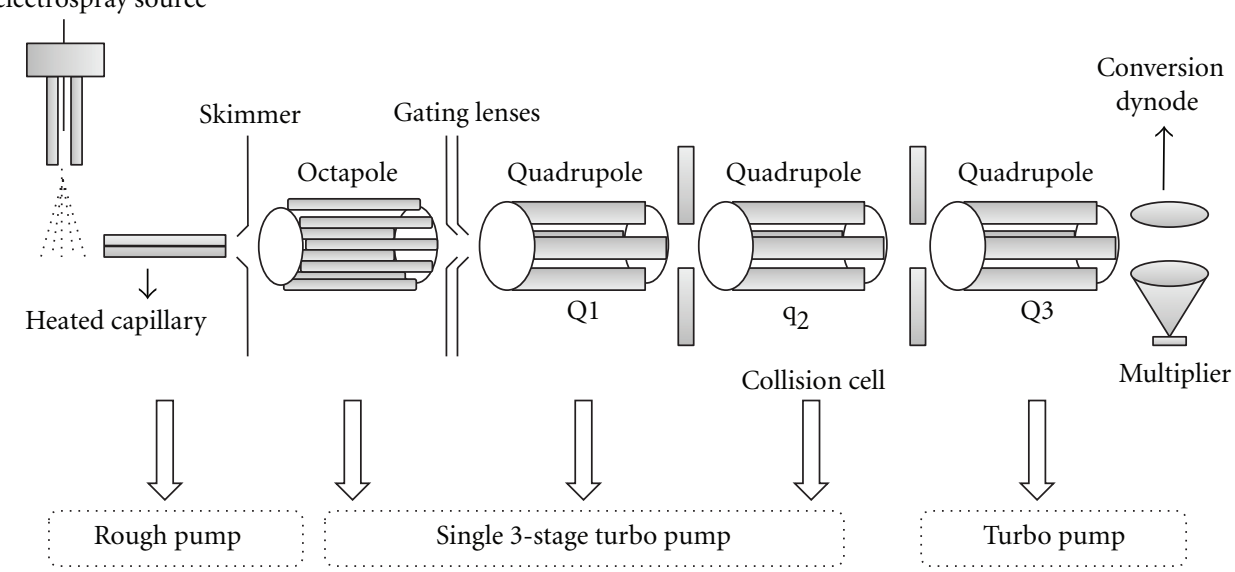

(b)

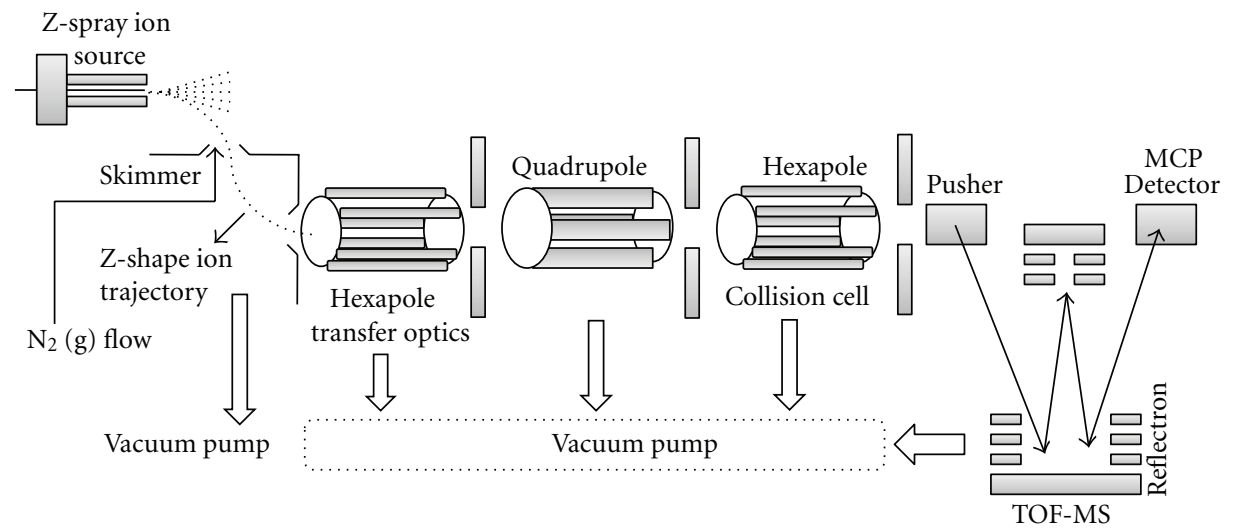

(c)

FIgURE 4: Schematic of the (a) thermo-Finnigan LCQ Deca mass spectrometer (on-axis spray), (b) Agilent 6410 Triple Quad LC/MS system (off-axis/orthogonal spray), and (c) Waters Micromass Q-TOF Ultima ESI-MS (z-spray).

appropriate instrumental conditions are used. In positive ion mode (when the spraying nozzle is kept at positive potential) the charging generally occurs via protonation (sometimes metalation also), but in negative ion mode (when the spraying nozzle is kept at negative potential) charging occurs via deprotonation of the analyte. The mechanism of charging has been discussed later. Since the charging of the analyte occurs by transfer of protons, the ionic species detected are not the true molecular ions (which are formed by the loss or gain of the electron), but they are more preferably protonated or deprotonated molecules [40]. When a pure analyte solution is electrosprayed all the peaks appearing in the corresponding ESI-mass spectrum represent the intact molecular species with variable charging as shown in Figure 5. The ordinate or vertical axis represents the relative abundances of multiply charged species of the same analyte, and the abscissa 


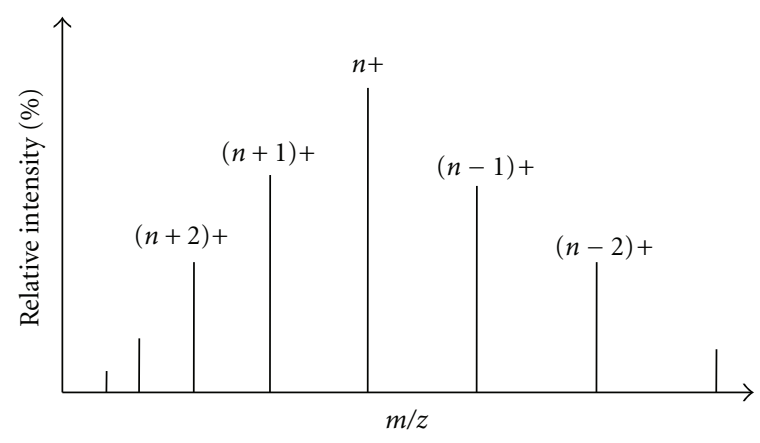

FIGURE 5: A typical cartoon representing the nature of ESI-mass spectrum in positive ion mode.

or horizontal axis represents the mass to charge ratio $(\mathrm{m} / \mathrm{z})$ of the multiply charged analyte. As usual the most intense or the tallest peak (peak of $n+$ charge in Figure 5) with $100 \%$ relative abundance is called the "base peak." The quantity $\mathrm{m} / \mathrm{z}$ is dimensionless since it is the ration of two dimensionless quantities mass number $(m)$ and the elementary charges $(z)$. Sometimes the unit Thomson [Th] is applied to the $m / z$ value to honor Thomson. Very often the symbol "u" (unified atomic mass) or Da (Dalton, in biological mass spectrometry field to honor J. Dalton) is also used as the molecular mass unit.

Now the question is how one can determine the molecular mass of the analyte with the help of the ion signals (different $\mathrm{m} / \mathrm{z}$ values) related to the same molecule? The procedure of finding the charge and mass of the analyte through the ESI-mass spectrum is called "Mathematical Charge Deconvolution" [41-43]. The process is straightforward and based on the assumption that two adjacent peaks in an ESI-mass spectrum of a single analyte have charge state difference one as has been shown in Figure 5. If it is assumed that the molecular mass of the analyte is $M$ and the observed $m / z$ values for two neighboring charge states $n+$ and $(n-1)+$ are $m_{1}$ and $m_{2}$, respectively, then two mathematical equations can easily be drawn as $(M+n) / n=m_{1}$ and $[M+(n-1)] /(n-1)=m_{2}$. Since there are only two unknown parameters $M$ and $n$, a minimum of two equations are required to find out the values of $M$ and $n$. So the above two equations can easily be employed to determine the value of $n$ (charge state) and $M$ (deconvoluted mass). One can think the observed multiple peaks as the multiple mass assessment of the same molecule. A more accurate mass of the analyte can be derived by averaging the calculated mass for each peak. The above algorithm works well for the pure analyte and when the analyte produces the successive charge states of the difference unity. But problems arise when the analyte produces metaliated as well as protonated species in gas phase or skips some charge state in between two observed charge states. Therefore, several refined procedures have been developed to cope with these requirements [44]. Nowadays all the modern ESI-MS instruments are equipped with elaborate software for charge deconvolution.

Proteins, the most popular analytes for ESI-MS study exhibit different charge state distribution profiles in their
ESI-mass spectra. To quantify the charge state distribution of the analyte, the term "average charge state" $\left(Z_{\text {av }}\right)$ was introduced [45] and defined as $\sum z_{i} \cdot I_{i} / \sum I_{i}$, where $I_{i}$ is the mass spectrometrically detected signal intensity of a given charge state $\left(z_{i}\right)$ carried by the $i$ th ion. Latter on several correlations between this average charge state and the protein structures were found (discussed later).

\section{The Mechanism of Electrospray Ionization}

After the development of ESI-MS, many different assumptions and hypotheses were made in the early 1990s to interpret the multiple charging of the analyte by the ES process [46-49]. That time it was thought that the distribution of the charge states in the ESI-MS spectra actually reflects the degree of charging of the analyte (say proteins) in the neutral solution (as determined by solution phase equilibrium) [41, $50,51]$. But later it became evident that there is no correlation between solution charging and electrospray charging after the report of Kelly and coworkers [47]. Their report showed that in positive ion mode ESI produced protonated (positively charged) analyte (myoglobin) though the analyte is overall negatively charged (deprotonated) in basic aspirating solution ( $\mathrm{pH} 10)$, and in negative ion mode it produced deprotonated (negatively charged) analyte (myoglobin) though the analyte is overall positively charged (protonated) in acidic aspirating solution ( $\mathrm{pH} 3$ ). These observations implied that the charging process in ESI might occur in an entirely different manner than that it was thought.

When an analyte is transferred from solution to the gas phase via ESI, the analyte solution undergoes three major processes. These are (a) production of the charged droplets from the high-voltage capillary tip where the analyte solution is injected; (b) repeated solvent evaporation (from the charged droplet) and droplet disintegration, resulting a very small charged droplet, which is able to produce the charged analyte; (c) finally a mechanism by which the gas-phase ion is formed. Since the electrospray process existed long before its application in the mass spectrometry and earlier it was used for the electrostatic dispersion of liquids and the creation of aerosol, the first two processes were mostly studied by the researchers in the aerosol science, and the processes are well understood nowadays $[15,52]$. But the last process, that is, the mechanisms of the ion formation from vary small highly charged droplet is still under controversy, and the exact process happening at this stage is not unambiguously known. Over the last two decades, the issue has hotly been discussed and debated, and several hypotheses based on the theory and experimental evidences were invoked $[22,53,54]$, and here we would discuss the most popular models of the gas-phase ion formation.

5.1. Production of Charged Droplets. When the analyte solution is pumped through the high-voltage capillary (emitter), an electrochemical reaction of the solvent occurs which causes an electron flow to or from the metal capillary depending on its polarity [55]. In absence of any redox active analyte $[56,57]$, the oxidation of the solvent occurs in the positive ion mode and reduction of the solvent occurs in the 


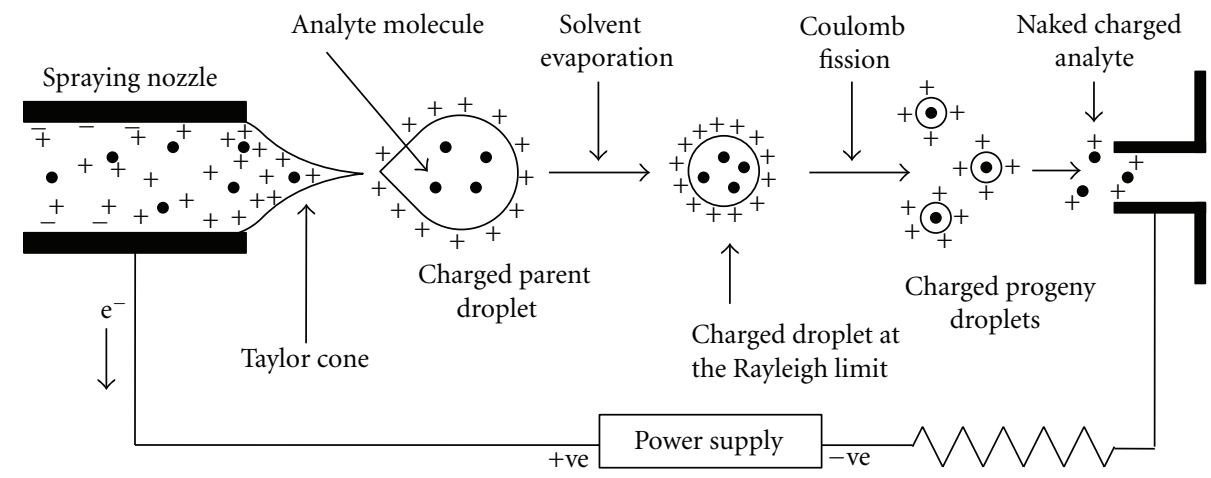

FIGURE 6: Schematic representation of the electrospray ionization process.

negative ion mode as has been shown in Table 1 [58]. So the ES ion source could be "viewed as an electrolytic cell of a special kind" [56]. These redox reactions (Table 1) supply positive or negative ions in the solutions depending on the polarity of the emitter electrode. Generally polar solvents (e.g., water, methanol, acetonitrile, etc.), which easily undergo electrochemical reactions in the spraying nozzle, are used in the ESI-MS experiments [58]. The accumulated charges (positive or negative) would be repelled by the highvoltage capillary (of the same polarity), and then they would drift towards the liquid surface at the capillary outlet (see Figure 6). However, the accumulated like charges at the surface are destabilized, and finally the meniscus would be drawn out and deformed into a cone under the influenced of a very high electric field (typically $\sim 10^{6} \mathrm{~V} / \mathrm{m}$ ) $[22,58]$. This cone is called a Taylor cone [59] after the name of the scientist Taylor who first theoretically described the conditions under which a stable liquid cone can exist with the competing forces of an electric field and the surface tension of the liquid [59]. This Taylor cone is the zone of high turbulence. At high field strength, it immediately starts ejecting a fine jet of liquid from its apex towards the counter electrode (heated capillary) [60]. This charged jet easily breaks up into small droplets. The droplets produced at low flow rate (typically $\sim 5 \mu \mathrm{L} / \mathrm{min}$ ) have a narrow distribution of sizes with a most abundant radius $\sim 1.5 \mu \mathrm{m}$ [22]. Such an electrospray droplet was shown to have a charge of $\sim 10^{-14} \mathrm{C}$, which corresponds to $\sim 60,000$ singly charged ions. All those charged droplets are driven away from each other by Coulombic repulsion and move along the direction of the electric fields (towards the heated capillary) (see Figure 6). Overall, under positive ion mode positively charged aerosol is formed and in negative ion mode negatively charged aerosol is formed. The positive charges are mostly contributed by protons, and negative charges are contributed by some negative ions (e.g., $\mathrm{OH}^{-}$) (see Table 1) [58].

\subsection{Coulomb Explosion and Disintegration of the Charged} Droplets. The charges (say protons in positive ion mode) in the droplets are distributed on its surface with equidistant spacing to minimize the potential energy [39]. There are two forces acting in opposite directions in the charged droplets. One is surface tension of the charged droplet, which tries to retain the spherical shape of the droplet, and the other is Coulomb force of repulsion between the like charges on the surface, which tries to break down the spherical shape of the charged droplet $[22,39,54,58]$. The solvent evaporation occurs when the droplets traverse the space between spraying nozzle and the heated capillary (see Figure 6). As a result the size of the droplet decreases until it reaches the point (Rayleigh limit) [62] where the surface tension can no longer sustain the Coulomb force of repulsion, and at this point "Coulomb explosion" or "Coulomb fission" occurs; that is, the parent droplet disintegrates into much smaller offspring droplets. The emitted stream of the offspring/progeny droplets holds about $2 \%$ mass and $15 \%$ charge of the parent droplet [22]. So the offspring droplets are not only much smaller than their parent but also have much higher charge-to-mass ratio. The process of solvent evaporation and Coulomb fission occurs repeatedly to generate smaller and smaller progeny droplets and finally the charged nanodroplets from which the gas-phase charged analyte molecule is formed [22, 63]. Figure 7 describes the detail evolution of the initial droplets, formed from the Taylor cone, to the droplets that are the precursor of the gasphase ions. Typically the flying microdroplets were observed to vibrate alternately from oblate to prolate shapes, and this elastic vibration causes the parent droplet to emit a tail of much smaller offspring droplets (droplet jet fission) [22, $53,64]$ as has been shown in the inset of Figure 7 . This disruption pattern is quite similar to the disruption at the Taylor cone. Therefore, the charge density on the droplet surface is not homogeneous, but significantly increased in the region of sharper curvature, and it has been shown the charged microdroplets fission somewhat before, at $\sim 80 \%$ of the Rayleigh limit [22]. The concept of this charged droplet jet fission is based on theoretical as well as experimental evidence (flash microphotographs) [64-66]. The life time of an ES droplet largely dependent on several parameters like ion spray voltage, nature of the solvents, sheath gas flow rate, distance between the spraying nozzle and heated capillary and temperature of the heated capillary, and so forth, $[22,28]$ and that would in turn affect the charging of the analyte. However, the average life time of a charged droplet produced by the ES process is around one to a few milliseconds for typical interfaces that one would use in ESI-MS [22,67]. 
TABLE 1: Typical redox reactions of the solvents expected to occur in the electrospray emitter and their corresponding standard potentials.

\begin{tabular}{|c|c|c|c|c|}
\hline \multirow{2}{*}{ Solvent systems } & \multicolumn{2}{|l|}{ Positive-ion mode } & \multicolumn{2}{|l|}{ Negative-ion mode } \\
\hline & Oxidation reactions & $E^{0}(\mathrm{~V})$ & Reduction reactions & $E^{0}(\mathrm{~V})$ \\
\hline \multirow{6}{*}{ Water } & $2 \mathrm{H}_{2} \mathrm{O}=\mathrm{O}_{2}+4 \mathrm{H}^{+}+2 \mathrm{e}^{-}$ & 1.23 & $2 \mathrm{H}_{2} \mathrm{O}+\mathrm{O}_{2}+4 \mathrm{e}^{-}=4 \mathrm{OH}^{-}$ & 0.40 \\
\hline & $2 \mathrm{H}_{2} \mathrm{O}=\mathrm{H}_{2} \mathrm{O}_{2}+2 \mathrm{H}^{+}+2 \mathrm{e}^{-}$ & 1.77 & $\mathrm{H}_{2} \mathrm{O}+\mathrm{O}_{2}^{-}+\mathrm{e}^{-}=\mathrm{HO}_{2}^{-}+\mathrm{OH}^{-}$ & 0.20 \\
\hline & $\mathrm{H}_{2} \mathrm{O}=\mathrm{HO}^{*}+\mathrm{H}^{+}+\mathrm{e}^{-}$ & 2.72 & $\mathrm{H}_{2} \mathrm{O}+\mathrm{HO}_{2}^{-}+\mathrm{e}^{-}=\mathrm{HO}^{*}+2 \mathrm{OH}^{-}$ & 0.18 \\
\hline & & & $2 \mathrm{H}_{2} \mathrm{O}+2 \mathrm{e}^{-}=\mathrm{H}_{2}+2 \mathrm{OH}^{-}$ & 0.07 \\
\hline & & & $2 \mathrm{H}_{2} \mathrm{O}+\mathrm{O}_{2}+2 \mathrm{e}^{-}=\mathrm{H}_{2} \mathrm{O}_{2}+2 \mathrm{OH}^{-}$ & -0.13 \\
\hline & & & $\mathrm{H}_{2} \mathrm{O}+\mathrm{O}_{2}+2 \mathrm{e}^{-}=\mathrm{HO}_{2}^{-}+\mathrm{OH}^{-}$ & -0.83 \\
\hline \multirow{3}{*}{ Methanol } & $\mathrm{CH}_{3} \mathrm{OH}=\mathrm{HCHO}+2 \mathrm{H}^{+}+2 \mathrm{e}^{-}$ & 0.23 & $\mathrm{CH}_{3} \mathrm{OH}+\mathrm{H}_{2} \mathrm{O}+2 \mathrm{e}^{-}=\mathrm{CH}_{4}+2 \mathrm{OH}^{-}$ & -0.25 \\
\hline & $\mathrm{CH}_{3} \mathrm{OH}+\mathrm{H}_{2} \mathrm{O}=\mathrm{HCOOH}+4 \mathrm{H}^{+}+4 \mathrm{e}^{-}$ & 0.10 & $\mathrm{CH}_{3} \mathrm{OH}+2 \mathrm{H}^{+}+2 \mathrm{e}^{-}=\mathrm{CH}_{4}+\mathrm{H}_{2} \mathrm{O}$ & 0.58 \\
\hline & $\mathrm{HCOOH}=\mathrm{CO}_{2}+2 \mathrm{H}^{+}+2 \mathrm{e}^{-}$ & -0.20 & & \\
\hline
\end{tabular}

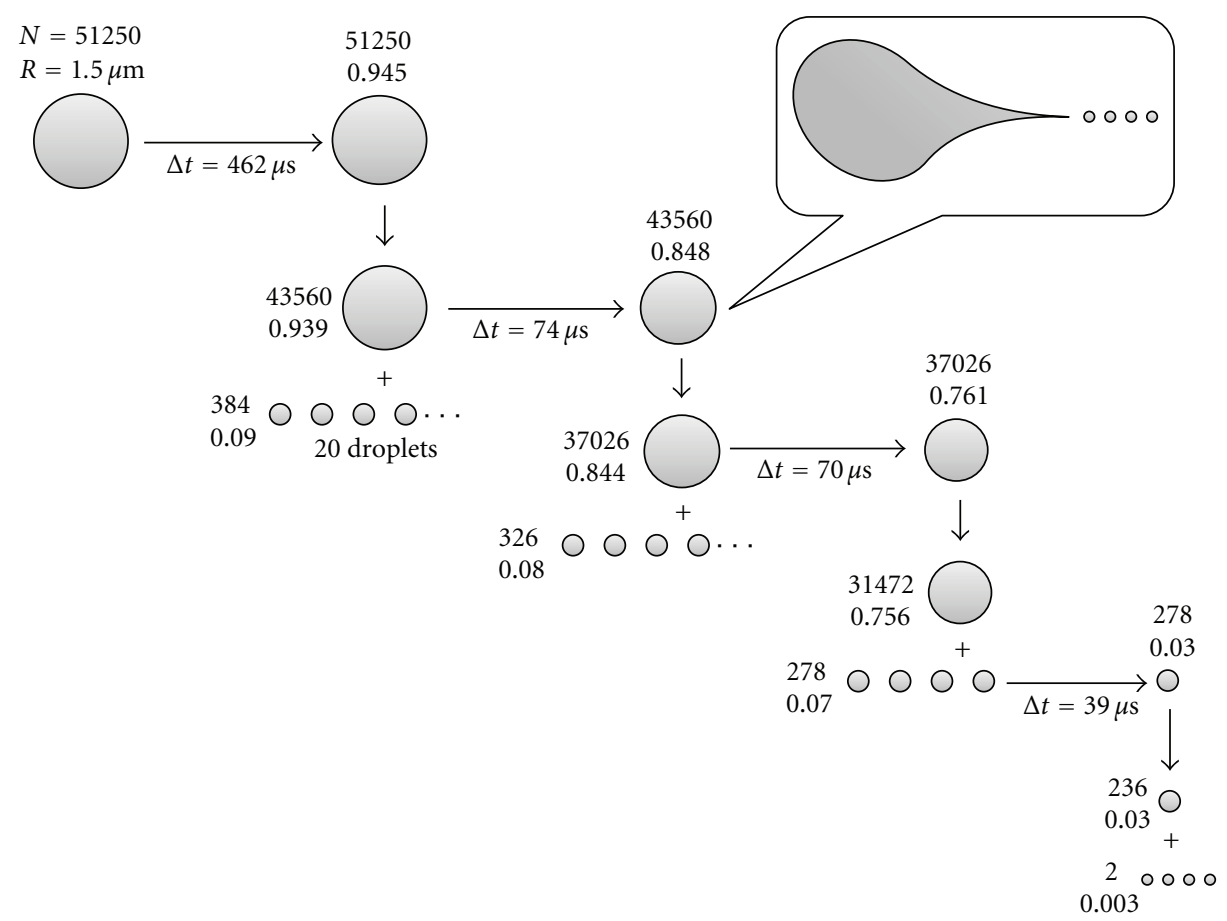

FIGURE 7: Time history of the charged methanol droplet produced by microelectrospray process. The droplet at the top left is a typical parent droplet created at the ES capillary tip. The successive solvent evaporation and Coulomb fission leads to the charged nanodroplets that are the precursors of the gas-phase analyte ions. The numbers beside the droplets give radius $R(\mu \mathrm{m})$ and number of elementary charges $N$ on the ES droplet; $\Delta t$ corresponds to the time required for evaporative droplet shrinkage to size where fission occurs. Only the first three successive fissions of a parent droplet are shown. At the bottom right, the fission of the offspring droplet to produce the charged nanodroplets is shown. The inset shows a drawing of droplet jet fission based on actual flash microphotograph. (Adapted with permission from [22], Copyright 1993, American Chemical Society).

5.3. Formation of Gas-Phase Analyte Ions from the Charged Droplets. Two principle mechanisms have been proposed to account for the formation of gas-phase analyte ions from very small highly charged ES droplets, and those are charge residue model (CRM) [16, 68, 69] and ion evaporation model (IEM) [63].

5.3.1. Charge Residue Model. As a result of a series of solvent evaporation and Coulomb fission, an extremely small charged droplet $(R \approx 1 \mathrm{~nm})$ is formed which contains only one analyte molecule $[16,22]$. Desolvation of this droplet causes its charges (on the surface) to land on the analyte molecules. Since the "residual" droplet charge at the last stage of the solvent evaporation in the ES process is retained by the analyte molecule in the gas phase, this mechanism is called charge residue mechanism/model. Originally this mechanism was hypothesized by Dole et al. [16] and a more detail consideration as well as support of this mechanism was given by Schmelzeisen-Redeker et al. [68].

A Study of Winger and coworkers showed that generally large macromolecules like proteins follow CRM [70]. They determined one interesting empirical correlation (see (1)) between the analyte molecular mass $(M)$ and the observed average charge state $\left(Z_{\mathrm{av}}\right)$ in the ESI-mss spectra of the 


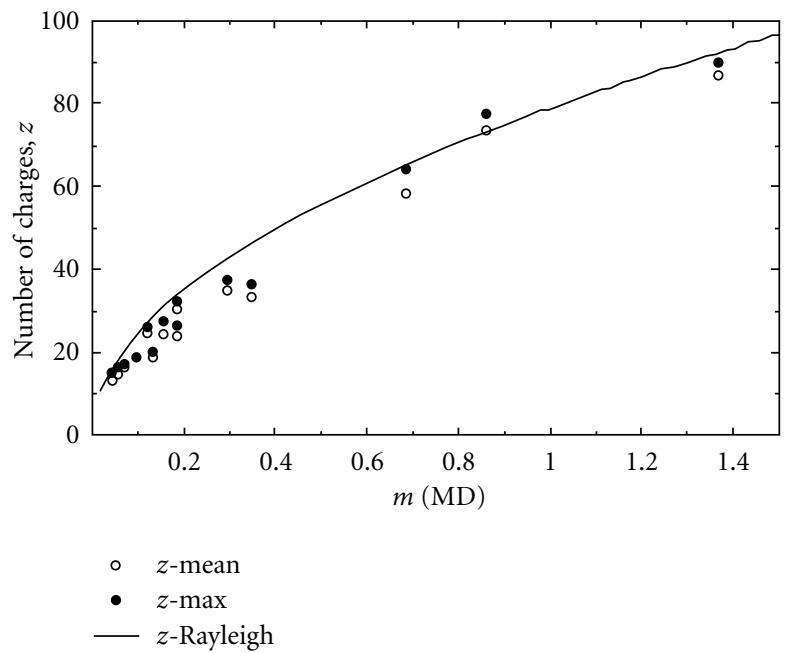

FIGURE 8: Plot of the average charge state $(z)$ against molecular mass $(m)$ for various proteins that follow CRM. [(•) Observed highest charge state; ( $\circ$ ) observed lowest charge state; solid curve corresponds to the average charge state predicted by (4)]. The molecular weights of the proteins given on the $x$-axis are in units of $10^{6} \mathrm{Da}$. (Reprinted with permission from Analytica Chimica Acta [61], Copyright 2000, Elsevier).

corresponding analyte (starburst dendrimers) [71]. The " $a$ " and " $b$ " are constants and $b=0.53$ gave the best result

$$
Z_{\mathrm{av}}=a M^{b}
$$

Later on Fernandez De La Mora [61] showed that the above equation (1) could be theoretically derived for the analytes like proteins that follow CRM. He assumed that after the final Coulomb fission event that produces the ultimate charged water droplet containing one neutral protein molecule would be a little bit larger in size than that of the protein. Then the final solvent evaporation would completely transfer the droplet charges to the protein. He also assumed that the density of the globular protein is the same as that of water $(\rho=1 \mathrm{~g} / \mathrm{c.c})[61,72]$, and then he calculated the radius of the protein as

$$
\left(\frac{4}{3} \pi R^{3}\right) \rho N_{A}=M
$$

The Rayleigh limit charging (which deals with the Rayleigh stability limit for coulomb fission of the charged droplet) of the water droplet having the same radius $(R)$ as of the analyte protein can be given by the Rayleigh equation (3) [62], and then combining (2) and (3) he found the (4) [61] which is similar to (1) empirically obtained by Winger and coworkers. Notably that the exponent for $M$ equals to 0.5 is very much close to the exponent 0.53 of the empirical equation (1)

$$
\begin{gathered}
Z_{R} \cdot e=8 \pi\left(\varepsilon_{0} \gamma R^{3}\right)^{1 / 2}, \\
Z_{R}=4\left(\frac{\pi \gamma \varepsilon_{0}}{\rho e^{2} N_{A}}\right)^{1 / 2} \times M^{1 / 2}=0.078 M^{1 / 2},
\end{gathered}
$$

where $e$ is the elementary charge, $Z$ is the charge number, $\varepsilon_{0}$ is the permittivity of the surrounding medium, $N_{A}$ is the
Avogadro's number, $\rho$ is the density of the water, $M$ is the molecular weight of the protein, and $\gamma$ is the surface tension of the solvent (water). A plot (solid line) shown in Figure 8 is based on the above theoretically derived equation (4), and that fits well with the empirical data (shown by circles) of several proteins investigated by Fernandez De La Mora. So the observed agreement between the charges on the proteins and the charges on water droplets of the same size, at the Rayleigh limit, is not a coincidence but a consequence of the multiply charged proteins being formed by the CRM.

5.3.2. Ion Evaporation Model. After repeated solvent evaporation and Coulomb fission, the radii of the charged droplets decrease to a given size when the electric field due to the charges at the surface of the droplet is strong enough to cause direct emission of the solvated ions [22, 63, 73]. Typically when the droplet reaches the size $R \leq 10 \mathrm{~nm}$, the ion emission dominates over Rayleigh fission. Thus unlike CRM, this mechanism does not require the production of very small droplets $(R \approx 1 \mathrm{~nm})$ that contains only one analyte molecule. This mechanism is called ion evaporation mechanism/model as proposed by Iribarne and Thomson $[22,63,73]$. They proposed that the rate constant $k_{1}$ for ion emission from the highly charged droplet surface can be given by the following equation (5) where $k_{b}$ is the Boltzmann constant, $T$ is the temperature of the droplet, $h$ is the Planck constant, and $\Delta G^{\dagger}$ is the free energy of activation:

$$
k_{1}=\frac{k_{b} T}{h} \exp \left(-\frac{\Delta G^{\dagger}}{R T}\right) .
$$

The activation energy is influenced by several parameters like (a) attraction between the escaping ion and the solvent by which the droplet is composed, (b) Coulomb repulsion of the escaping ion by the remaining charges on the droplet surface, and (c) ion desolvation energy. Although the above Iribarne and Thomson equation (5) can successfully interpret the 


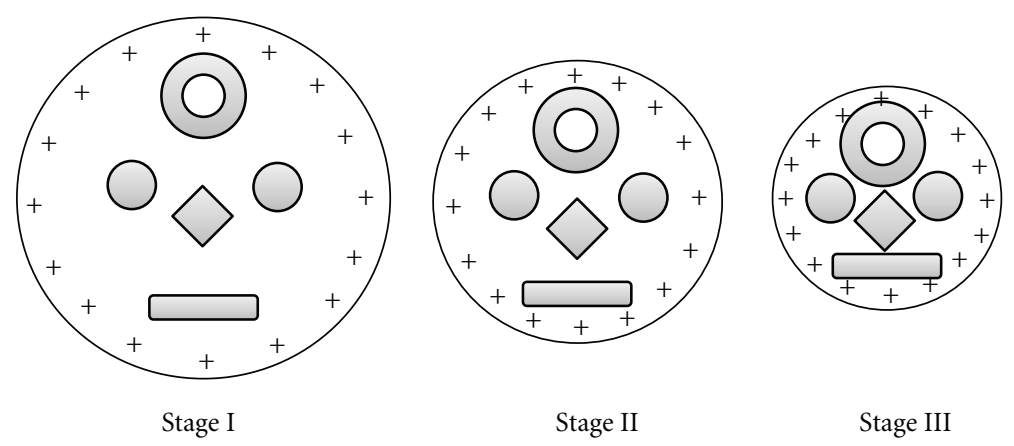

Figure 9: Hypothetical picture of a charge droplet containing five analytes of different shapes and sizes at three different stages of the solvent evaporation before Coulomb fission.

ion evaporation process, it cannot predict the observed relative intensities of ions in the ESI mass spectra, which is mostly influenced by the structural and physicochemical nature of the analyte and the solvent used. However, IEM is experimentally well supported for small inorganic and organic ions $[53,61,74,75]$.

5.3.3. Fenn's Model of Ion Formation: An Extension of IEM. Unlike IEM, the Fenn's model $[39,69]$ states that the analytes remain neutral inside the neutral core of the charge droplet (charges lie on the surface). If the analyte is intrinsically charged (e.g., proteins), this charged neutrality could be maintained either by a nearby counter anion as its "shadow" (i.e., ion pair formation) or by a proton transfer process between analyte and the solvent. The overall neutral analyte would have a rapid Brownian diffusion motion inside the charged droplet. The successive solvent evaporation and Coulomb fission would continuously increase the surface charge density of the droplet. In positive ion mode these charges are basically protons. Protons are pretty small, and they can have a strong attractive interaction with the molecules of polar solvents. When a given part of the analyte encounters the proton-rich surface by Brownian thrashing (energy on the order of $k_{b} T$ ), the basic residues located at that portion of the analyte would be attached to the surface protons. Thus the protons would serve to anchor the analyte molecule nearer to the surface. Thermal activation (Brownian oscillation, internal vibration, and rotation, with amplitudes constrained by $k_{b} T$ ) may provide the energy for the analyte to move some distance outside the droplet. This separation between the protonated analyte residues and the charges on the droplet surface leads to repulsion, which facilitate the escape of a remaining portion of the molecule that carries other charge sites. With increase in the charged residues (outside the droplet surface) of the escaping analyte, the Coulomb repulsion increases and that facilitate the escape of the whole analyte with a varying degree of charging. The degree of charging varies not only for the size, shape, orientation, and fugacity or escaping tendency of the analyte but also for the continuously variable charge spacing and electric field at the droplet surface during the process of repeated solvent evaporation and Coulomb fission. Thus, the number of charges that are attached to the analyte molecule when it desorbs from the surface is the number of charges that it can span on the surface during its emission. The situation is illustrated in Figure 9, which shows three hypothetical snapshots of a charged droplet at different stages during its evaporation before undergoing Coulomb fission. The droplet contains five analytes of different shapes and sizes. The droplet size decreases with solvent evaporation and the distance between equally spaced positive charges decreases since the number of charges remains constant. Clearly, at the evaporation stage III, the desorption of the analytes from the droplet surface would lead more charging than that at the stage I. Again at each stage the charging will vary according to the conformation and size of the analyte. But in practice the ejection of the charged analyte would continuously lower the number of charges and number of analyte species in the host droplet from stage I to stage III. As a result, above and below some critical charge states, the relative ion abundance decreases and that is reflected by a bell-shaped distribution of the ion abundances (see Figure 5). Of course the scenario is much more complicated because of the involvement of the Coulomb fission since it also contributes the charge and analyte concentration in a droplet.

\section{Factors That Influence the Charge State Distribution (CSD) of Proteins}

Multiple charging is an intrinsic feature of electrospray ionization of macromolecules like proteins [41-43]. Several factors affect the charge state distributions (CSDs) of proteins in vacuum generated by ESI [76]. Mostly the physical dimension of the protein molecules in solution are the major determinant of this CSD [76, 77]. As discussed earlier, in positive ion mode the basic sites in the proteins can accommodate protons and in the negative ion mode the acidic sites in the proteins can give up protons (see Figure 10) in the vanishing charged droplet and thus responsible for the gas-phase ion formation mostly via CRM [78]. Here we would discuss some critical factors known to significantly influence the protein CSD.

6.1. Solution $\mathrm{pH}$. The change of $\mathrm{pH}$ of the protein solution can change the protein conformation (tertiary structure), and the degree of the conformational change depends on the 


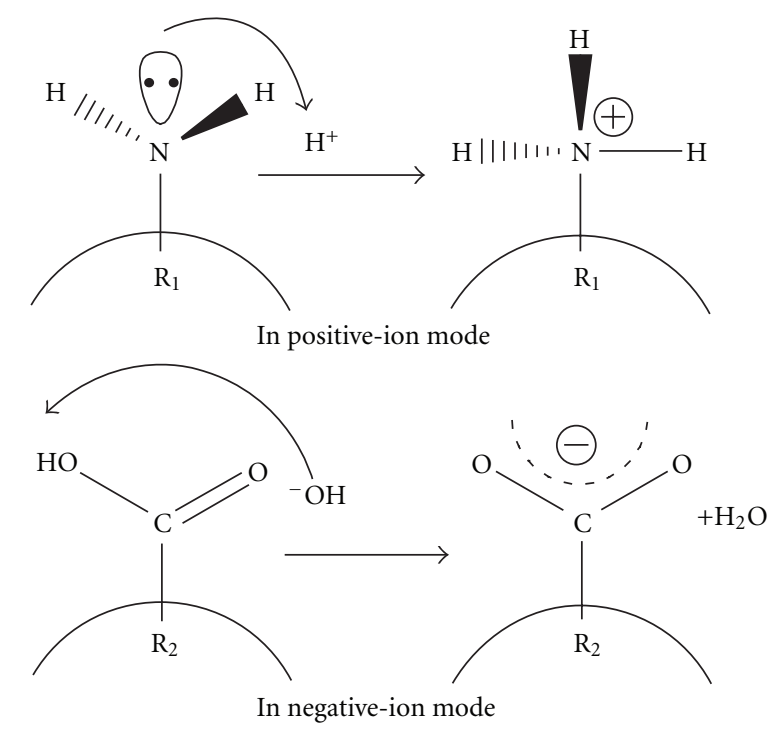

Figure 10: The proton transfer reaction responsible for protein charging in gas phase via ESI.

nature of the protein and the acidity/basicity of the solution. According to the CRM, it is the geometry or size of the protein that actually determines the average charge state (CS) of the electrosprayed protein in vacuum [76]. Relatively small number of charge states (low average CS) is produced when a natively folded protein is transferred to the gas phase upon ESI than that when an unfolded/denatured protein undergoes ESI. This is because the native proteins maintain a compact structure by its tightly folded polypeptide chain, and this compactness is lost upon denaturation. After denaturation, the solvent accessibility as well as the size of the protein increases, which in turn leads to increase the charge state distribution over a broad range $(\mathrm{m} / \mathrm{z})$ with the high average CS $[45,48,76,79]$.

Figure 11 shows a typical example of ESI-CSD of cytochrome $\mathrm{c}$ at different $\mathrm{pH}$ in positive ion mode [80]. At $\mathrm{pH}$ 6.4 , where cyt $\mathrm{c}$ is known to adopt native, tightly folded conformation, the positive ion ESI-MS (Figure 11(a)) shows relatively narrow CSD with +8 as the most intense CS (base peak). But at $\mathrm{pH} 2.3$, where a substantial unfolding of cyt $\mathrm{c}$ occurs, the positive ion ESI-MS (Figure 11(d)) shows a broad CSD with +17 as the most intense CS (base peak). Native and nonnative protein states often coexist at equilibrium under mildly denaturing conditions. In such conditions, the CSD becomes bimodal, reflecting the presence of both native and denatured states. At pH 2.6 cyt c exists in both native and unfolded states as is evidenced by the bimodal CSD in the ESI-mass spectrum (Figure 11(c)).

In certain cases proteins, for example, ubiquitin unfolds in both acidic ( $\mathrm{pH} 2)$ and basic solution $(\mathrm{pH} 11.7)$ and when the protein was electrosprayed from both acidic and basic solution, the corresponding positive ion mass spectra showed characteristic broad CSD with maxima at +11 and +8 , respectively, [81]. But the ESI-mass spectrum of ubiquitin in neutral solution ( $\mathrm{pH}$ 7.2) [81] showed narrow CSD with most intense charge at +6 .
The native environment of pepsin (in gastric juice) is extremely acidic, and at native $\mathrm{pH}(\mathrm{pH} \leq 2)$ it remains in folded active form. So when it is electrosprayed from the acidic solution ( $\mathrm{pH}$ 1.6), it shows remarkably narrow CSD [82], and the CSD does not change until the solution $\mathrm{pH}$ is raised above 2.5 , a threshold $\mathrm{pH}$ of pepsin deactivation [77]. The large scale unfolding of pepsin occurs in neutral and basic solutions. Therefore, a dramatic change of pepsin CSD in ESI-mass spectra acquired under these conditions [76, 77] is observed, and the corresponding most intense CS increased to above +30 .

So the analysis of the CSD of proteins in ESI-MS provides reliable information on the protein structure and stability at different solution $\mathrm{pH}$.

6.2. Number of Acidic and Basic Functional Groups in the Proteins. Conformation-dependent neutralization theory (CDNT) was proposed to interpret the appearance of main CS in ESI of proteins $[83,84]$. The difference between acidic (aspartic acid, glutamic acid, etc.) and basic (arginine, lysine, histidine, etc.) residues in the protein sequence was used to determine the predominant charge state in the ESI-mass spectrum. However, the CDNT could not explain the appearance of the positive ion mass spectra of several proteins although they contain overall negative charge and vice versa. Later it was proposed that only the surface-exposed basic or acidic groups of a protein could hold charge in the gas phase [85]. However, some surface-exposed residues may form salt bridges, ion pair, or hydrogen bonding within the protein, reducing the effective charge density on these residues [86] and thereby decreasing the charge on the protein. Hence, we reported a more refined model to interpret the CS based on the three-dimensional structure (crystal structure) of the protein [78]. In view of this, we have identified the free basic and acidic groups (which do not form any ion pair or salt bridge) on the protein surface from the crystal structure analysis of a series of the proteins. Then we investigated the ESI-mass spectra of those native folded proteins in both positive and negative ion mode [78]. Interestingly it was observed that the maximum charge state of the gaseous protein ion actually corresponds to the number of surface-exposed free basic (in positive ion mode) or free acidic residues (in negative ion mode). This model was further supported by the ESImass spectra of the denatured proteins [78]. Upon denaturation all the acidic and basic residues become surface exposed, and the number of the basic and acidic residues in the protein sequence corresponded to the maximum CS in positive and negative ion mode, respectively.

Some exceptional examples of the above model were reported later. One particularly interesting example is the ESImass spectra of native folded pepsin $(33 \mathrm{kDa})$ which contains total 41 acidic and only four basic residues [82]. Despite the small number of basic sites, the native pepsin $(\mathrm{pH} \leq 2)$ can accommodate maximum 11 positive charges (most intense CS is +10) in gas phase upon positive ion ESI [76, 77]. This maximum charge state $(+11)$ is higher than that predicted by our model and lower than that predicted by CRM ((4), which predicts +14 as the average CS). Since most proteins possess a high number of basic sites, the requisite number of 


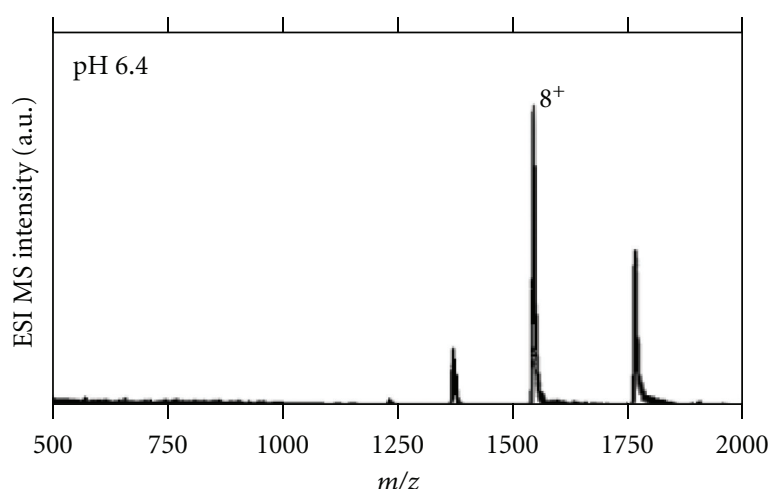

(a)

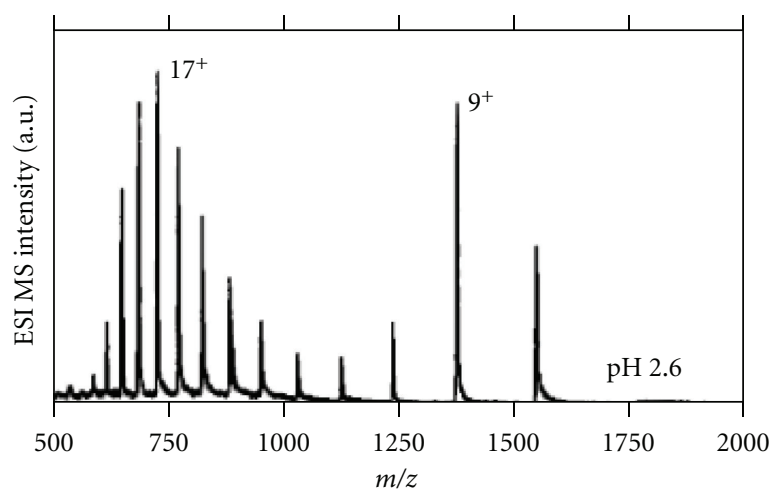

(c)

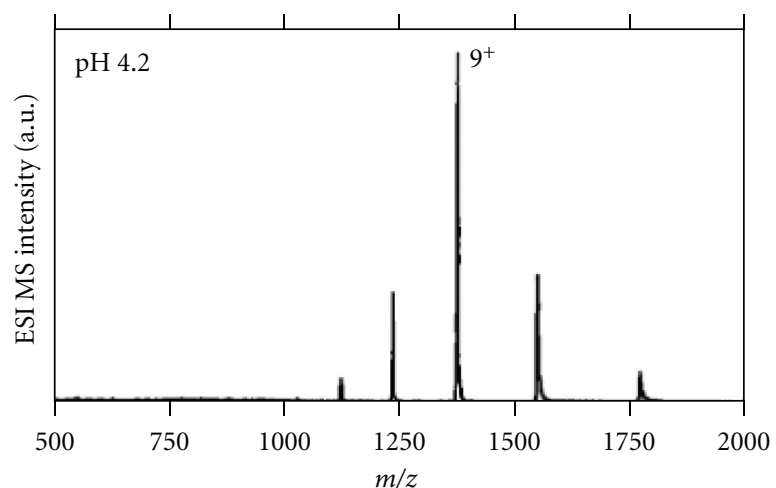

(b)

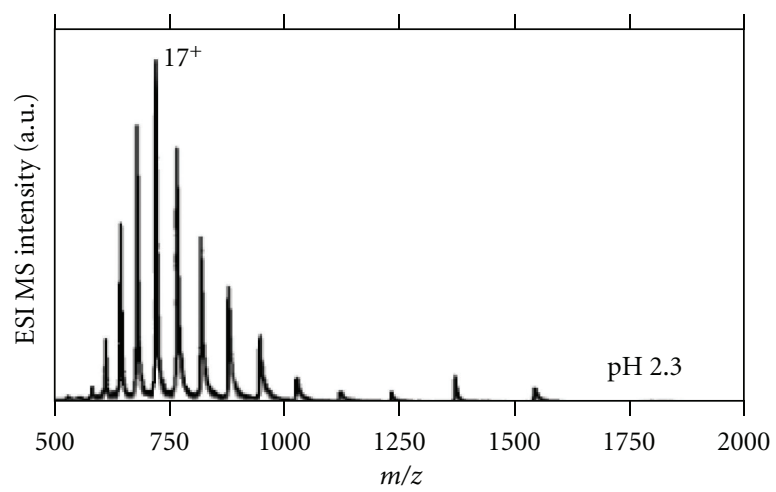

(d)

FIGURE 11: ESI-mass spectra of cyt $\mathrm{c}$ in water containing 3\% methanol and $0.5 \mathrm{mM}$ ammonium acetate at (a) pH 6.4, (b) pH 4.2, (c) pH 2.6, and (d) $\mathrm{pH}$ 2.3. The $\mathrm{pH}$ was adjusted by the addition of hydrochloric acid. (Reprinted with permission from Biochemistry [80], Copyright 1997, American Chemical Society).

positive charges as predicted by CRM can almost always be distributed among the available free basic sites on the surface of the native proteins. But, the ability of gaseous pepsin to accommodate a number of protons far exceeding the number of available basic sites might be due to the participation of the other mild basic functional groups (e.g., amide moiety, etc.) or collectively a number of polar functional groups over the large flexible surface of the protein to hold (solvate) protons in gas phase [87]. The lack of the required number of strong basic functional groups in pepsin possibly inhibits the extensive protonation as predicted by CRM. Moreover, it has been proposed that the proton affinity of the solvent molecules provides a "cut-off" level for the amino acid residues that are protonated in gas phase by ESI [87].

6.3. Protein Surface Area in Solution. Despite the fact that the extent of multiple charging in ESI is influenced by the number of surface-exposed free acidic/basic functional groups in the proteins (i.e., the gas-phase ion chemistry), the physical dimension or the structural integrity of the protein also largely influence the CSD. Kaltashov and Mohimen [77] demonstrated that the CSD of protein ions in ESI can be correlated to the solvent-exposed surface area in solution. In their study on 22 proteins ranging from the small protein insulin $(5 \mathrm{kDa})$ to the large protein ferritin $(500 \mathrm{kDa})$, they showed that the observed average charge states $\left(Z_{\mathrm{av}}\right)$ in the ESI-mass spectra could be correlated more precisely to the solvent exposed surface area rather than the radius or molecular weight of the proteins as suggested by CRM ((3) and (4)). The spherical approximation of the proteins which was used by Fernandez De La Mora [61] could provide erroneous results in CRM ((3) and (4)) since in practice the protein shape can deviate from spherical. Therefore, they extended (3) to (6) as given below to correlate the $Z_{\mathrm{av}}$ with the protein surface area $S$ (Since, $S=4 \pi R^{2}$ ) [77].

$$
Z_{\mathrm{av}} \cdot e=4\left(4 \pi \varepsilon_{0}^{2} \gamma^{2} S^{3}\right)^{1 / 4}
$$

Their empirical data is shown in Figure 12, which clearly indicates that the surface area $(S)$ evaluated from the known crystal structure and the charge state $Z_{\mathrm{av}}$, obtained from the ESI-mass spectra of the proteins, are correlated and fitted well by (7) or (8) with the value $a=0.69$. The fit of the data points (Figure 12) is much better than the fit in the Fernandez De La Mora plot (Figure 8)

$$
\begin{aligned}
Z_{\mathrm{av}} & =A S^{a}, \\
\ln Z_{\mathrm{av}} & =\ln A+a \ln S .
\end{aligned}
$$

Thus, they showed that the average CS-molecular mass correlation holds only for the tightly packed globular protein. 


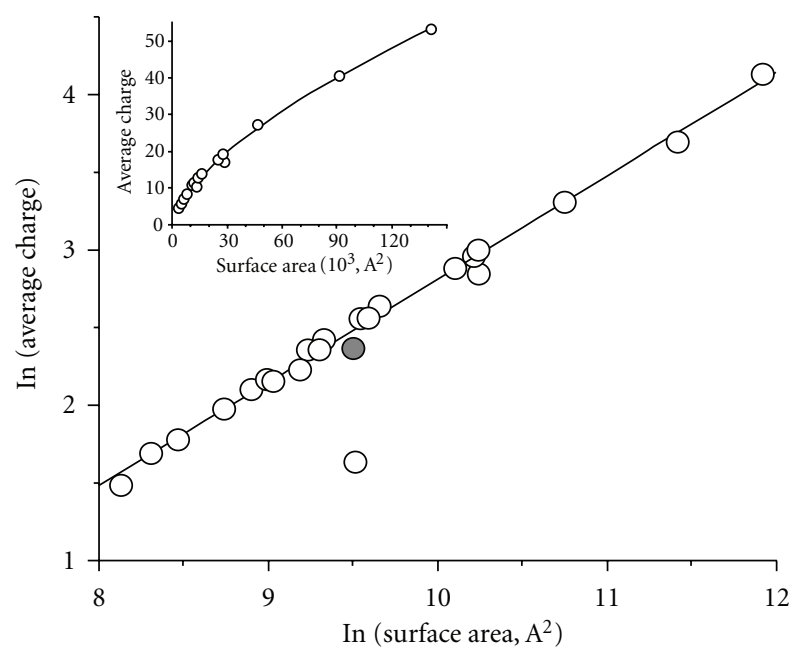

FIGURE 12: Correlation between the average charge state of protein ions generated by ESI under near-native conditions ( $10 \mathrm{mM}$ ammonium acetate, $\mathrm{pH}$ adjusted to 7) and their surface areas in solution, whose calculation was based upon their crystal structures. The data are plotted in the logarithmic scale (a graph plotted in the normal scale is shown in the inset). A gray-shaded dot represents a pepsin data point. An open circle underneath represents the highest charge of pepsin if the extent of multiple charging was limited by the number of basic residues within the protein molecule. (Reprinted with permission from Analytical Chemistry [77], Copyright 2005, American Chemical Society).

But, there are some proteins (e.g., ferritin) that are not tightly packed in their native conformations and it is actually the solvent exposed surface area of the proteins that is the major determinant of the average CS of the gaseous proteins produced by ESI process [77].

6.4. Presence of Nonvolatile Salts in Protein Solution. It is often the case that the proteins are purified and stored in some buffer solution containing nonvolatile salts (e.g., sodium chloride, potassium chloride, sodium phosphate, potassium phosphate, etc.). So if the protein solution is not properly desalted before injecting it in the ESI probe, the ions such as $\mathrm{Na}^{+}, \mathrm{K}^{+}$, and so forth, make strong ion pairing with the ionized acidic residues of the protein in the gas phase [88]. The nonvolatile metal ion impurities not only form strong bonds with carboxylate functional groups but also with other polar functional groups including the amide groups in the peptide backbone $[89,90]$. This ion pairing would be driven by large loss of the solvent from the droplet and thus concentrating the nonvolatile salt component along with the proteins in the vanishing charged droplet. The binding of those metal ions $\left(\mathrm{Na}^{+}\right.$and $\left.\mathrm{K}^{+}\right)$with the protein in the gas phase is so strong that they even survive in the cleanup stages (heated capillary, nozzle-skimmer dissociation potential) of the ESI mass spectrometer [91]. But the adduct formation of the metal ions $\left(\mathrm{M}^{+}\right)$and/or their salts (MA) with the proteins is highly undesirable because of the mass shifting in variable extent that generates multiple peaks corresponding to each charge state (see Figure 13) [91]. The observed multiple peaks corresponding to each charge state

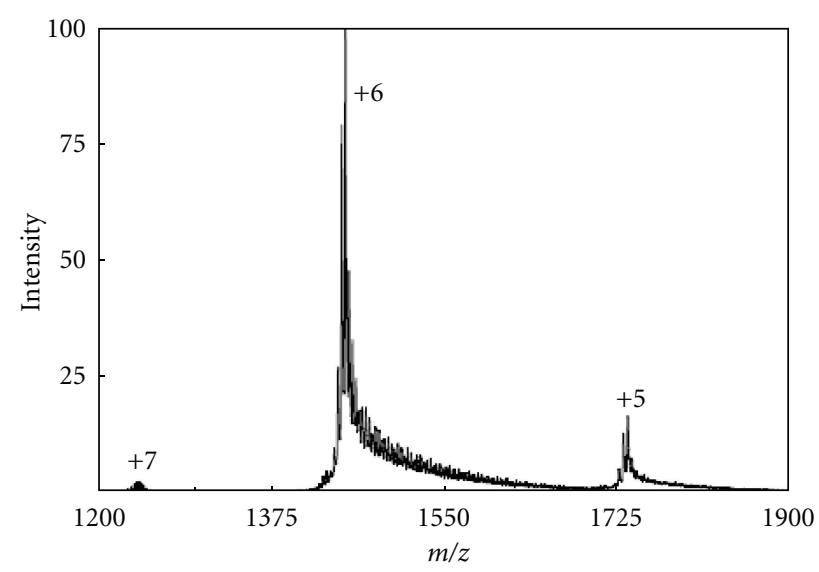

Figure 13: Nano-ESI-mass spectrum of $25 \mu \mathrm{M}$ ubiquitin in $1 \mathrm{mM}$ $\mathrm{NaCl}$ solution. The spectrum was obtained at low nozzle-skimmer potential, so that there was little collisional activation of the protein. It is obvious that each charge state is not a single peak but consists of multiple peaks due to the adduct formation of the salt ions (e.g., $\mathrm{Na}^{+} \& \mathrm{Cl}^{-}$) with ubiquitin. (Reprinted with permission from Journal of the American Society for Mass Spectrometry [91], Copyright 2005, Elsevier).

can be rationalized by (a) replacement of $\mathrm{H}^{+}$with $\mathrm{M}^{+}$and (b) ion pairing of $\mathrm{M}^{+}$with the ionized acidic residues (aspartic acid/glutamic acid/C-terminal carboxylic acid, etc.) and/or ion pairing of $\mathrm{A}^{-}$(counter anion of the non volatile salt) with the ionized basic residues (Arginine, Lysine, Histidine, $\mathrm{N}$-terminal amine, etc.) [91]. If the mass spectrometer is not of sufficiently high resolution, then a complicated and "messy" spectrum is produced for the adduct formation of the component ions of the salt impurities with the protein in the gas phase.

In our recent study we have showen that the relative volatility of the charged particles (from salts) and the surface accessibility of the polar residues of the protein towards the charged particles are important factors in the CSD of the protein in gas phase [92]. The surface accessibility of surfaceexposed free basic residues (SEFBRs) and surface-exposed free acidic residues (SEFARs) were determined from the crystal structure and compared with the most probable chargestate (most-intense peak obtained in the positive ion and the negative ion mode ESI-MS spectra of the proteins). The results indicated that the number of the SEFBRs that have surface accessibility above the mean surface accessibility of all the SEFBRs in the protein corresponds to the most-intense charge state of the protein in the positive ion mode. Analogously, the number of the SEFARs that have surface accessibility above the mean surface accessibility of all SEFARs in the protein would give the most-intense negative ion charge state of the protein. Hence, the most-intense charge states both in the positive ion as well as in the negative ion modes for a large number of proteins could be predicted based on this simple model from surface accessibility of the protein.

6.5. Use of Ammonium Acetate Salt Additive. Ammonium acetate buffer solution is very often used in the mass spectrometric analysis of proteins (see Figure 11) since unlike 
other buffer of nonvolatile salts it produces very clean mass spectra solely due to the protonated proteins in the gas phase $[88,91]$. Even the use of ammonium acetate prevents the formation of sodium/potassium (if present as impurities) adduct with the gaseous protein. When ammonium acetate is added to the protein solution, following ion pairing reaction (8) occurs on the solvent accessed surface of the protein [91]. Ammonium cations pair with acidic functional groups, and acetate anions pair with basic functional groups in the protein in the gas phase upon ESI. The larger concentration of ammonium acetate relative to sodium/potassium ion impurities reduces the possibility of ion pairing involving sodium/ potassium because of the predominance of ammonium acetate interaction with proteins (8). When the resulting protein ions containing the ion pairs (8) fly through the heated capillary and nozzle skimmer in the intermediate pressure region of the ESI interface, they encounter collision with the background gas and solvent vapor, which causes loss of volatile acetic acid and ammonia by the proton transfer reaction (9). The process is entropically favorable, and the dissociation is also facile because of the low bond (proton transfer) energy for the dissociation $(15 \mathrm{kcal} / \mathrm{mol}$ for acetic acid and $11 \mathrm{kcal} / \mathrm{mol}$ for ammonia) [91]. The net effect of the complete process is nothing but the proton transfer from the protonated basic residues to deprotonated acidic residues. Though the positive and negative groups are neutralized, the molecular weight of the protein does not change. Thus, a clean mass spectrum of the protein is obtained without the mass change

$$
\begin{aligned}
& { }^{+} \mathrm{H}_{3} \mathrm{~N} \text {-(protein)-COO}{ }^{-}+\mathrm{CH}_{3} \mathrm{COONH}_{4} \\
& \quad=\mathrm{CH}_{3} \mathrm{COO}^{-+} \mathrm{H}_{3} \mathrm{~N} \text {-(protein)- } \mathrm{COO}^{-} \mathrm{NH}_{4}^{+}, \\
& \mathrm{CH}_{3} \mathrm{COO}^{-+} \mathrm{H}_{3} \mathrm{~N} \text {-(protein)-COO}{ }^{-} \mathrm{NH}_{4}^{+} \\
& \quad=\mathrm{CH}_{3} \mathrm{COOH}+\mathrm{H}_{2} \mathrm{~N} \text {-(protein)-COOH }+\mathrm{NH}_{3} .
\end{aligned}
$$

Felitsyn et al. [93] and Peschke et al. [94] also suggested that, in presence of the volatile salt like ammonium acetate, the ammonium cations can also bind to the basic residues of the protein, and there is proton transfer reaction from the ammonium ion to the basic residues of the protein with formation of volatile ammonia (base) and the protonated protein in the gas phase. Thus, ammonium acetate can also enhance the propensity of protonation of the protein in the gas phase.

The above equations ((8) and (9)) suggest that the use of ammonium acetate not only suppresses the metal ion adduct formation but also prevents the adduct formation involving the anion of strong acids (e.g., phosphate, trifluoroacetate anions, etc.) and ionized basic residues. Though (trifluoroacetic acid) TFA is frequently used in the mobile phase of the liquid chromatography mass spectrometry (LC-MS), the presence of the TFA anion in the effluent causes the loss of sensitivity, and the use of ammonium acetate prevents that sensitivity loss [95].

6.6. The Nature of Solvent. Several physical properties of the solvent like polarity (dielectric constant) [96], gas-phase basicity [97-99], and the surface tension $[61,100,101]$ are also known to be responsible for the CSD of the protein. It is expected that the solvent with higher dielectric constants will tolerate high charge densities in the evaporating droplets produced by the electrospray process. The excess charges can also be confined to a thin layer at the surface because of the increased conductivity of the polar solvent with higher dielectric constant. At the last stage of solvent evaporation or gaseous ion emission from the charged droplet, high polarity solvents are more effective in stabilizing the multiply charged species, whereas the low polarity solvent may disfavor that. So the solvent with higher dielectric constant would boost higher charge states in the gaseous analyte ions generated from those ES solvent droplets. Loo et al. also showed that the denaturing capacities of different solvents also affect the protein CSD, which in turn reflect the conformation (solvent accessibility) of the protein in that solution [102].

Apart from the apparent gas-phase basicities (calculated based on the intrinsic gas-phase basicities and Coulomb energy of the interacting charges) of the basic sites in the protein, the gas-phase basicity of the solvent is also an important factor to significantly affect the CSD of the protein $[87,103]$. The effect of the solvent composition on both maximum CS and the CSD of the proteins were investigated by Iavarone and coworkers [96]. They showed that CSD of cytochrome c and myoglobin (see Figure 14), formed from 47\%/50\%/3\% water/solvent/acetic acid solutions, shifts to lower charge (higher $\mathrm{m} / \mathrm{z}$ ) when the $50 \%$ solvent fraction is changed from water to methanol, to acetonitrile, to isopropanol. This is also the order of increasing gas-phase basicities of these solvents. However, the effect is relatively small for these solvents, possibly due to their limited concentration (in gas phase) inside the electrospray interface. But the addition of small amounts of diethylamine $(0.4 \%)$ in the aspirating solution results in dramatic shifts to lower charge, presumably due to preferential proton transfer from the higher charge state ions to diethylamine. These results clearly show that the maximum charge states and charge state distributions of ions formed by electrospray ionization are influenced by solvents that are more volatile than water and the gas-phase basicity of the solvent too [96].

It is also not surprising that along with different physical properties of the solvent the surface tension plays an important role to the CSD of the protein, since the surface tension parameter $(\gamma)$ is involved in the Rayleigh equation (3) [62], based on which the CRM is proposed [61]. The increase in surface tension of the solvent should increase the average charge state of the analyte. Iavarone and Williams showed that, in absence of other factors, the surface tension of the ultimate electrospray droplet (formed after repeated solvent evaporation and Coulomb fission), from which the charged gaseous analyte is formed, is a significant factor in determining the overall analyte charge [100].

6.7. The Supercharging Effect. Iavarone and coworkers reported interesting additives, for example, m-nitrobenzyl alcohol (m-NBA) and glycerol to the aqueous solution of the protein and peptide, which can dramatically increase both the maximum charge state and the most intense charge state 


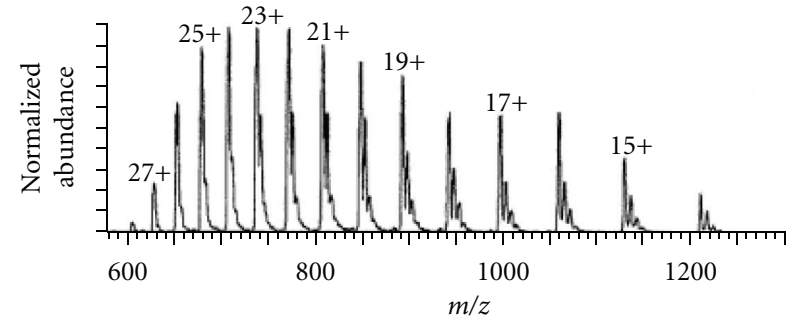

(a)

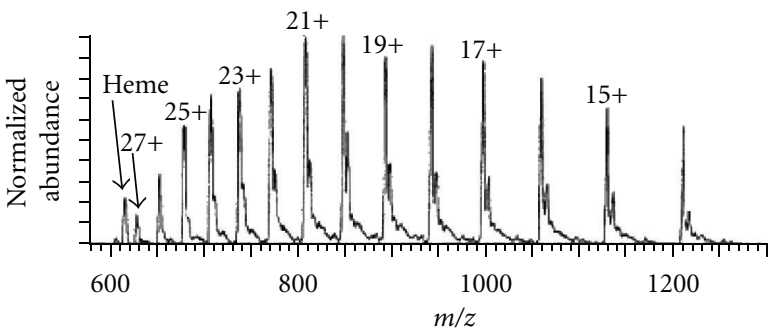

(b)

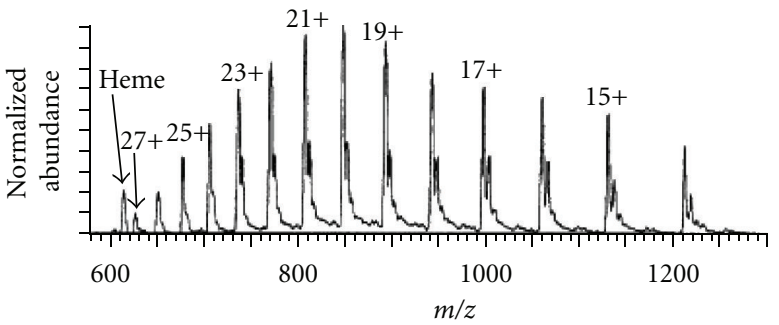

(c)

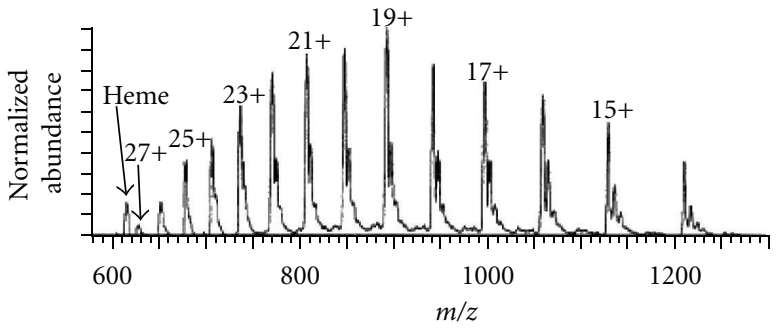

(d)

Figure 14: Myoglobin $\left(10^{-5} \mathrm{M}\right)$ electrosprayed from 47\%/50\%/3\% water/solvent/acetic acid solutions, where the "solvent" was (a) water, (b) methanol, (c) acetonitrile, or (d) isopropanol. (Reprinted with permission from Journal of the American Society for Mass Spectrometry [96], Copyright 2000, Elsevier).

[101]. They termed this phenomenon "supercharging effect." Figure 15 shows that the addition of just $<1 \% \mathrm{~m}-\mathrm{NBA}$ to the electrospray solution, the maximum charge state as well as average charge state increases significantly [101]. Similarly the addition of small amount of $\mathrm{m}$-NBA in the peptide (KKKK) solution substantially increased the most intense and average CS [101]. The exact mechanism of this enhanced charging is still not clear. Recently they have suggested that these supercharging reagents have low vapor pressures (less volatile), and aqueous droplets are preferentially enriched in these reagents as evaporation occurs [100]. Less evaporative cooling will occur after the droplets are substantially

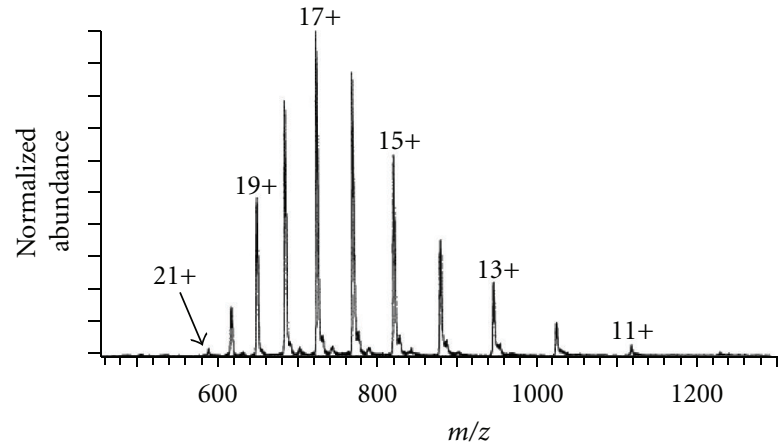

(a)

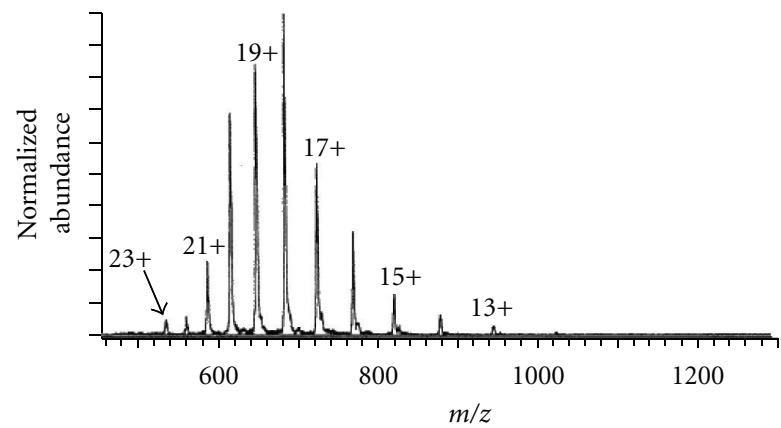

(b)

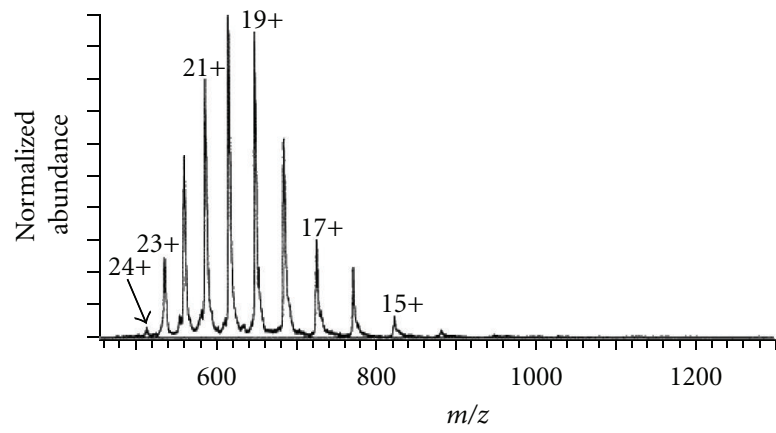

(c)

FIGURE 15: Electrospray ionization mass spectra of cytochrome c $\left(10^{-5} \mathrm{M}\right)$ from solutions containing (a) 0 , (b) 0.3 , and (c) $0.7 \% \mathrm{~m}$ NBA. The base solution is $47 / 50 / 3 \%$ water/methanol/acetic acid. (Reprinted with permission from Analytical Chemistry [101], Copyright 2001, American Chemical Society).

enriched in the low volatility supercharging reagent, and the droplet temperature should be higher compared with when these reagents are not present. Protein unfolding induced by chemical and/or thermal denaturation in the final electrospray droplet, from which the charged gaseous protein is produced, appears to be the primary origin of the enhanced charging $[104,105]$. The fact is further supported by the arrival time distributions obtained from traveling wave ion mobility spectrometry [105], which showed that the higher charge state ions that are formed with the supercharging reagents are significantly more unfolded than lower charge state ions. Though this model successfully explained the supercharging of proteins and their noncovalent complexes, it fails 
to explain the supercharging of small molecules like small peptides [101], which do not have any tertiary structure. A detail investigation of the physical parameters of the evaporating and disintegrating droplet containing this supercharging reagent is required in the future to understand the exact mechanism of supercharging.

Recently Lomeli group has reported other supercharging agents, for example, benzyl alcohol, m-nitroacetophenone, m-nitrobenzonitrile, o-NBA, m-NBA, p-NBA, m-nitrophenyl ethanol, sulfolane (tetramethylene sulfone), and m-(trifluoromethyl)-benzyl alcohol [106]. Among these sulfolane displayed a greater charge increase $(61 \%)$ than m-NBA (21\%) for myoglobin in aqueous solutions based on average charge state. All these reagents that promote higher ESI charging appear to have low solution-phase basicities and relatively low gas-phase basicities and are less volatile than water [106].

Thus the increased multiple charging by the supercharging reagents promises its implication in the accurate mass measurement of the large macromolecules and the structural characterization of the proteins by tandem mass spectrometry and $\mathrm{MS}^{n}$ experiments, where the multiple charging is important for efficient fragmentation (discussed later) [107$110]$.

6.8. Modification of the Protein Charge State Distribution. Several approaches like acid/alcohol-induced proteins denaturation [102], protein disulphide bond reduction using chemical reducing agent dithiothreitol, and so forth, [50] were undertaken to modify the protein CSD in last two decades. When the disulfide bonds are reduced, much higher charge states can be obtained because the reduction of the disulfide bonds allows the protein to unfold further and expose additional acidic/basic sites for protonation/deprotonation [50].

Though the protein CSD can be altered by manipulating the solution conditions ( $\mathrm{pH}$, reduction of disulphide bonds, use of different solvents, denaturing agent and supercharging agent, etc.), it can also lead to deleterious effects such as poor ESI response, dissociation of noncovalent complexes, and so forth. But, sometimes it is desirable to alter CSDs independent of initial solution conditions. The CS alteration by gas-phase proton transfer reaction (post-ESI process) has been demonstrated via ion/ion $[111,112]$ or ion/molecule [113] reaction. But that resulted in significant reduction of the absolute charge of the gaseous analytes. Recently Kharlamova and coworkers have established a method for the manipulation of the CSD of the electrosprayed proteins by exposing the nano ES droplets to the volatile acid/base vapors in the atmospheric pressure region of the mass spectrometer $[114,115]$. Exposure of the positive ES droplets to the acid vapors [115] and the negative ES droplets to the base vapors [114] increases the propensity of high CS formation of the analyte (protein). On the basis of changes in protein CSDs, protein folding and unfolding phenomena are implicated in their studies. Since no change in the CS distributions of buffered proteins exposed to reagent acid/base vapors was observed, the charge state changes are attributed largely to a $\mathrm{pH}$ effect. They suggested that, when the acid/base vapor interacts with the nanoelectrospray generated protein droplets, it changes the $\mathrm{pH}$ of the droplets and thereby affects the structure of the protein present in the ES droplets during the very short nanodroplet lifetime (few tens of microseconds). This change of the protein structure is attributed by the change of the CSD. They also showed that the species bound by relatively weak interactions can be preserved, at least to some extent, allowing for the observation of high charge states of protein-ligand complexes [114, 115].

Recently Krusemark et al. used chemical derivatization method to control the CSD, which eventually gave the answer about the role of protein functional groups in the CSD [116]. When the free carboxylic acid function groups of the denatured proteins were modified by amidation (neutral functional group), minimal change in the CSD in positive ion mode was observed compared to the unmodified proteins, indicating that the carboxylic acid functional groups do not play significant role in charging in the positive ion mode. The modification of proteins with additional basic sites or fixed positive charges generated substantially higher charge states in positive ion mode, providing evidence that the number of ionizable (basic) sites determines ESI charging for denatured proteins irrespective of their shape and sizes. Combining this chemical modification and the ion/molecule or ion/ion reactions in gas phase, the authors also illustrated some unique approaches to alter/control the CSD [117].

\subsection{Analyte Concentration and the Presence of Electrolyte} Impurities. Apart from the analyte structure and conformation, the analyte concentration in the initial spray solution is also an important factor that significantly affects the ESI-MS signal intensity $[22,39,118]$. For multiply charged analyte, ions of discrete charge state exhibit a linear response of the ion signal with the analyte concentration in solution until a certain concentration limit is exceeded. This concentration limit is dependent on the nature of the analyte. Beyond that concentration the signal intensity loses that linear response and may even decrease at extremely high concentration. This departure from the linearity as the aspirating solution concentration increases can be attributed to the analyte concentration having reached its saturation value during the droplet evaporation so that further loss of solvent results in precipitation, rather than any further increase in its concentration in solution [39]. At elevated concentration the relative abundances of the gaseous analyte ions of higher charge state also decrease due to the increase in competition between the analyte molecules inside the ES droplet for the limited number of available charges on the droplet surfaces [119].

The presence of any ionic species (i.e., electrolytes) other than analyte in the solution (except for small amounts of electrospray friendly acids, bases, or buffers as discussed before) is usually avoided when possible, because their presence in the ES solution has been found to suppress the formation of gas-phase ions of the analyte of interest [118, 120122].

6.10. Instrumental Parameters. Very often it is observed that the CSD in the ESI-mass spectra of a particular analyte acquired from different instruments is significantly different though a specific protocol for the sample preparation has 
been followed. Moreover, ES-mass spectra acquired from the same instrument at different points in time can show some degree of variability. This is because there are several instrumental parameters which are responsible for the ion production, filtration, and detection. The instrumental parameters like spray tip orifice diameter (e.g., microspray and nanospray $[32,123]$ ), ion spray voltage (different onset voltages for different solvents [22]), source geometry [98, 124] (e.g., on-axis, off-axis, etc., [125]), source gas pressure [39, 126], source temperature [58], heated capillary temperature (thermal dissociation may occur here) [58, 126-128], sheath/ auxiliary gas flow rate [39] that (affects the evaporation and cooling rate of the ES droplets), nozzle-skimmer voltage (declustering potential) [129-132], different ion-optics voltages $[34,58]$ (that guide the ion filtration and trapping) $[34,58]$ and nature of the detectors (detector response) [34, 58] are all known to influence the ESI-MS response of the analyte.

\section{Is Substantial Conformational Change of the Protein Possible inside the ES Droplet?}

There are still several aspects of ESI not fully understood though it is almost two and half decades elapsed after the discovery of ESI-MS. One such major issue is the conformational and other subtle chemical properties of the analyte during the transfer from solution to gas phase. The issue becomes further complicated due to the complexity of the processes affecting the ES droplets including the charge separation [22], solvent electrolysis at the emitter tip [133, 134], droplet evaporation then subdivision [22] the increase of the droplet acidity/basicity, and so forth. As discussed earlier the droplets produced at low flow rate (typically $\sim 5 \mu \mathrm{L} / \mathrm{min}$ ) have a narrow distribution of sizes with a most abundant radius $\sim 1.5 \mu \mathrm{m}$ [22]. Such an electrospray droplet was earlier shown to have a charge of $\sim 10^{-14} \mathrm{C}$, which corresponds to $\sim 60,000$ singly charged ions [16]. If we assume that all these singly charged ions are protons (in positive ion mode) and they are homogeneously distributed in the droplet, then the estimated $\mathrm{pH}$ of the initially produced droplet would be $\sim 5.2$. The repeated solvent evaporation and Coulomb fission of the droplets would increase the proton density and thereby continuously lower the $\mathrm{pH}$ of the droplets. According to the IEM, the gas-phase ions are supposed to be formed when the droplet reaches the radius $\leq 10 \mathrm{~nm}$ [63]. The Rayleigh charging [62] at this limit $(r=10 \mathrm{~nm})$ corresponds to 125 elementary charges (protons) in the droplet. So the corresponding $\mathrm{pH}$ of the droplet at this limit is $\sim 1.3$. The acidity of the ES droplets was also experimentally measured [135]. Overall the chemical composition in the final small droplets from which the naked analyte ions are formed may be significantly different from that of the original sample solution [22]. For example, the acid/base equilibrium, the conformational states, and/or noncovalent bonding in the analyte may all be affected by the subtle changes in the composition and properties of the droplets during the electrospray. There have been no reports addressing the possible effects of the microenvironment of the solvent droplets on the analyte during the ES process. Generally it has been assumed that the solute molecules residing at the neutral core of the charged droplet remain "oblivious" to the harsh conditions on the droplet surface and the environment beyond it until the last of the solvent molecules is gone. As a consequence it is presumed that the protein charge state distribution in the gas phase actually represents the protein conformation in the initial solution. In some reports it has been also assumed that the violent nature of charged jet breakup and subsequent Coulombic explosion of the ES droplets encapsulating the proteins can cause repacking of the supramolecular assemblies, forcing them to hold a minimal volume $[77,136]$. But no direct experimental evidence is still available to support this assumption on the molecular rearrangement inside the charged ES droplets. So the molecular behavior inside the charged ES droplets still remains like a "black box" and the exact processes that happen to a molecule residing inside the charged droplets are far from being understood.

If the physical and chemical properties of the ES droplet continuously change during the lifetime of the droplet then what happens to the conformation of the proteins residing inside the charged droplet? Does a protein change its tertiary structure or conformation inside the violently behaved (charged jet breakup) charged ES droplet? The preservation of the overall protein integrity via ES process does not necessarily mean the retention of the initial solution structure intact inside the charged droplets. Some recent works [137, 138] suggested that after the ES process the new gaseous environment can ultimately cause dramatic structural alteration of the protein (post-ESI process) and the existence of gaseous macromolecules (proteins) with a number of different conformations [138]. Though in the solvent-free environment the protein conformational change is not surprising, but the issue regarding the conformational change inside the ES droplet relative to the initial solvent is still far from being understood. If the protein molecule is susceptible to change their three-dimensional conformation inside the ES droplet, then the CSD in the corresponding ESI-mass spectrum should obviously reflect the three-dimensional structure of the protein inside the droplet not in the initial solution.

In view of this we have recently conducted some experiments [139] on some model analytes (small molecules) that are labile to be transformed inside the charge droplet. It is often argued that the charges on an ES droplet are distributed over its surface with equidistant spacing and that they are locked into this pattern by the forces of Coulomb repulsion [39], and the bulk or core of the ES droplet essentially remains free of charge to minimize the potential energy of the droplet [140]. But when we put a highly stable intrinsically charged molecule inside the charged ES droplets, we observed a drastic transformation of their structure due to huge Coulomb force of repulsion on the positively charged analyte imparted by the surface protons of the ES droplet (see Scheme 1). This result unambiguously suggests that the violent nature of the charged ES droplets can affect the analyte residing inside it depending on the nature of the analyte [139].

Recently we have also induced the protein conformational change inside the charge droplet by perturbing the droplet solvent composition during the lifetime of the 


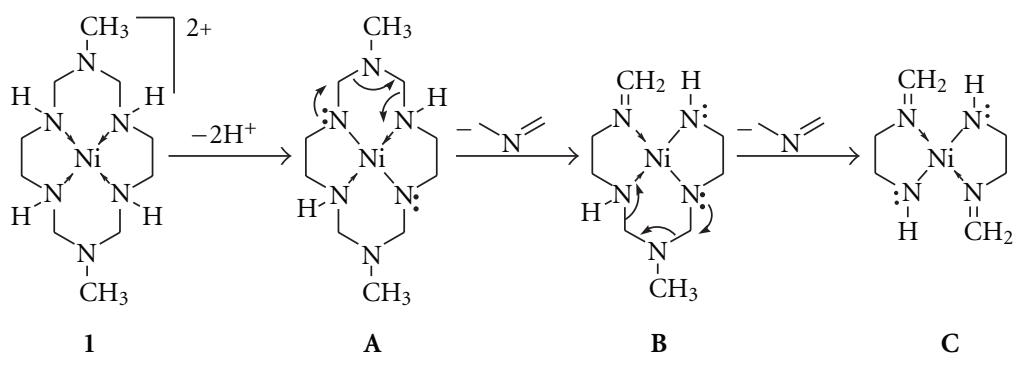

Scheme 1: The fragmentation pathway of the cationic complex 1 inside the charged droplet.

droplet (unpublished work). But it is not clear to us whether without perturbing the solvent composition of the charge droplet the protein conformational change is possible or not in the natural way of ES process.

\section{Tandem Mass Spectrometry: Collision-Induced Dissociation}

The word "tandem" means arrangement of two or more objects/persons one behind another, [141]. Similarly tandem mass spectrometry (MS/MS) is a method where the gaseous ions are subjected to two or more sequential stages of mass analysis (which may be separated spatially or temporally) according to quotient mass/charge $[40,142]$. For example, in a tandem mass spectrometric experiment, a precursor ion is mass selected by a mass analyzer $Q_{1}$ (see Figure 4(b)) and then focused into a reaction cell $\mathrm{q}_{2}$ (collision cell) where it undergoes a gas-phase chemical reaction. The reaction gives different product ions with different masses, which are then passed to another mass analyzer $\mathrm{Q}_{3}$ (see Figure 4(b)). This last mass analyzer scans the masses of the product ions and generates the product ion spectrum. The mass analyzers are set up in series either in space (sector, triple quadrupole, and hybrid instruments) or in time (trapping instruments).

ESI transforms the analyte in gas phase without rupturing any covalent bonds and provides the information about the molecular weight (MW). This MW alone can not determine the structure of an unknown analyte. So, the fragmentation of the gaseous analyte is deliberately required for the structural elucidation. The fragment ion spectrum is basically the fingerprint of the presence of a particular analyte (precursor ion). By investigating the fragmentation reaction (fragment-ion spectrum), one can actually determine the correct chemical structure of the unknown analyte sample. The task is like a jigsaw puzzle, where the players have been given a broken plate and asked to join them together in a sensible way to find the actual shape of the plate. Now the question is how one can fragment a charged molecule in gas phase? The mass-selected ion (precursor analyte) is activated in the collision cell (e.g., $\mathrm{q}_{2}$ in Figure $4(\mathrm{~b})$ ) by increasing its internal energy. This activation causes the homolytic or heterolytic cleavage of the chemical bonds. As a result different fragment ions (product ions) are produced. There are different methods of precursor ion activation, which include collisional activation (collision-induced dissociation or CID [143], surface-induced dissociation or SID
$[144,145]$, etc.), photon-induced activation (infrared multiphoton dissociation or IRMPD [146], blackbody infrared radiative dissociation or BIRD $[147,148]$, ultraviolet photodissociation or UVPD $[149,150]$, etc.) and electron-mediated activation (electron capture dissociation or ECD [151], electron transfer dissociation or ETD [152], electron detachment dissociation or EDD [153], electron-induced dissociation or EID [154]), and so forth. Here we would discuss about the most popular and most common ion activation method in the ESI-MS system, which is collision-induced dissociation (CID).

In collision-induced dissociation, the gaseous precursor ion is allowed to collide with a gaseous target in the collision cell. The gaseous target is inert and neutral, generally inert gases such as nitrogen, helium, or argon [155]. As a result of collision, the energy is gained and redistributed among different vibrational degrees of freedom (internal energy) within the precursor ion. Thus, an unstable excited state of the precursor ion is populated, which causes the precursor ion to decompose into the product ions in a process termed "collision-induced dissociation" (CID) [143]. So the CID is basically a unimolecular fragmentation reaction of the massselected precursor ion.

8.1. Multistage CID/Tandem Mass Spectrometry. But it is often the case that the single-stage collision-induced dissociation provides a lot of confusing fragmentation information or does not provide enough information for the structural elucidation. In both of these cases multistage tandem mass spectrometry $\left(\mathrm{MS}^{n}\right) /$ multistage CID is performed. Generally $\mathrm{MS}^{n}$ experiments are performed in ion-trap or in FT-ICR instrument, where each MS step is separated in time [58]. Those trapping instruments allow the refragmentation of the product ions and thus produce next generation of product ions and so on. For example, in the first stage, the normal ESI-mass spectrum $\left(\mathrm{MS}^{1}\right)$ is produced without fragmentation. Then one precursor ion is isolated in the trap and fragmented to produce the first generation product/fragment ions, and the corresponding spectrum is called MS/MS or $\mathrm{MS}^{2}$ spectrum. Again one precursor is isolated from the first generation fragment ion (from $\mathrm{MS}^{2}$ spectrum) and then fragmented to produce the second generation product ions, which are scanned to record the $\mathrm{MS}^{3}$ spectrum (MS/MS/ MS). Thus process of isolation and fragmentation can be repeated a number of times, resulting in a series of $\mathrm{MS}^{n}$ spectra where " $n$ " represents the number of times, that is, 
$(n-1)$ times, the isolation-fragmentation cycle has been carried out.

8.2. High- and Low-Energy CID. The appearance of the CID spectrum is dependent on several parameters like nature of the projectile ion and target gas, target gas number density, ion activation time, nature of the collision cell, and above all on the collision energy between gaseous projectile ion and the target atom/molecule [58]. This collision is controlled by the kinetic/translational energy of the projectile. The fraction of the kinetic energy that can be converted to the internal energy of the precursor ion in a collision is determined by the centre of mass collision energy $\left(E_{\mathrm{cm}}\right)$ [143]

$$
E_{\mathrm{cm}}=\frac{m}{m+M} E_{K}
$$

where " $m$ " is the atomic/molecular weight of the target gas " $M$ " is the molecular weight of the precursor ion, and " $E_{K}$ " is the precursor ion kinetic energy. $E_{\mathrm{cm}}$ is the maximum amount of the precursor ion's kinetic energy, which can be converted into the internal energy for fragmentation. The $E_{\mathrm{cm}}$ above $25 \mathrm{eV}$ is defined as high collision energy and that below $20 \mathrm{eV}$ as low collision energy [58, 158, 159]. Since a very high kinetic energy $(\mathrm{KeV})$ is gained by the projectile ion in the traditional sector instruments, the high energy CID spectrum is produced in those instruments [58]. But the projectile translational energy is in the range tens to hundreds of electronvolts in the triple-quadrupole instruments and thus those instruments provide low energy CID spectrum [58]. In the ion-trapping instruments (e.g., QIT), the ions are trapped within a three-dimensional electric field inside the ion trap, and a stable ion trajectory is guided by Mathieu equation. So in QIT the precursor ion kinetic energy can only be raised to a level where stable ion motion still occurs. Consequently the achievable kinetic energy of the precursor ion falls in the range of low energy CID regime [58].

In low energy CID, the internal energy increase is sufficient to vibrationally (not electronically) excite the precursor ion, which results in the cleavage of the most labile bonds when a certain threshold energy is reached. But in high energy CID, electronic excitation of the precursor ion becomes possible if the ion-neutral interaction time is very short $\left(<10^{-14} \mathrm{~s}\right)$. But this generally does not occur for medium-to-large size molecules undergoing high-energy CID [58]. In those cases a curve-crossing mechanism more likely occurs [58]. For example, a crossover from the first electronically excited state to the higher vibrational level of the ground state occurs. But both direct electronic excitation and curve-crossing are likely to result, a different fragmentation pattern compared to that in the low-energy CID. Although the high-energy CID spectrum is typically much more complex than low-energy spectrum, it contains maximum structural information. For example, generally backbone cleavage of the peptide is observed upon low-energy CID but sidechain cleavage including, backbone cleavage of the peptide is observed upon high-energy CID [159-161]. High-energy CID is known to promote charge-remote fragmentation
$[162,163]$, while low-energy CID is often guided by chargedirected fragmentation mechanism (see later) [161].

Here we would discuss the low- and/or high-energy fragmentation of some biologically important molecules like peptides, oligosaccharides, oligonucleotides, and lipids, which are very often analyzed by ESI-CID-MS/MS experiments.

8.3. CID of Peptides. When a peptide is electrosprayed in positive ion mode, gaseous protonated peptide is produced. The protons are mostly localized on the most basic sites (e.g., Arg, Lys, and his side-chain or N-terminal $\alpha-\mathrm{NH}_{2}$ group) in the peptides prior to activation [164, 165]. Upon collisional activation, the ionizing protons are transferred from the unreactive sites of higher gas-phase basicity (e.g., Arg, Lys, and his side-chain or $\mathrm{N}$-terminal $\alpha-\mathrm{NH}_{2}$ group) to several backbone amides to form energetically less favored but reactive backbone-amide-protonated species [161]. The amount of activation energy that has to supply to the precursorprotonated peptide to make the proton sufficiently mobile is dependent on the gas-phase proton affinities of the different amino acids (Arg $>$ Lys $>$ His $>$ Try $>$ Glu $>$ Pro $>$ Gln $>$ Met $>$ Tyr $>$ Asn $>$ Phe $>$ Thr $>$ Ile $>$ Leu $>$ Val $>$ Asp $>$ Ser $>$ Ala $>$ Cys $>$ Gly) $[166,167]$ present in the sequence. For example, when a doubly protonated peptide, which contains a strongly basic amino acid residue (e.g., Arg/Lys/His), is collisionally activated one proton would mostly be anchored on the basic residue, and the second one would be mobile in the backbone leading to the heterogeneous population of the ions varying the location of the second proton. This fast proton "dancing"/migration process to various backbone amide bonds is called "mobile proton model" as proposed by Wysocki (see Figure 16) $[156,168,169]$. This mobile proton model has been verified by hydrogen/deuterium scrambling studies [170] and theoretically also [171, 172]. Since amide nitrogen protonation removes the resonance stabilization of the amide bond, the protonated amide bonds become weak and labile to fragment in low-energy CID. As a result of heterogeneous population of the activated precursor ions, a series of peptide bonds are cleaved [161, 173]. Apart from the amide bond fragmentation, other backbone bond fragmentation is also possible via mobile proton model. A notation has been developed to indicate the peptide fragments that arise from the CID of the protonated peptides. The N-terminal fragment ions (charge is retained on the $\mathrm{N}$-terminus) are indicated by $\mathrm{a}_{n}, \mathrm{~b}_{n}$, and $\mathrm{c}_{n}$, and C-terminal fragment ions (charge is retained on the C-terminus) are indicated by $\mathrm{x}_{n}, \mathrm{y}_{n}$, and $\mathrm{z}_{n}[174,175]$ (see Figure 17). The subscript " $n$ " indicates the number of amino acid residues in the fragment. As shown in Figure 17, the N-terminal $\mathrm{a}_{n}, \mathrm{~b}_{n}$, and $\mathrm{c}_{n}$ ions are complimentary to the C-terminal $\mathrm{x}_{(n-m)}, \mathrm{y}_{(n-m)}$, and $\mathrm{Z}_{(n-m)}$ ions, respectively, where " $m$ " is the total number of constituent amino acids in the precursor peptide. Under lowenergy collision condition, the peptide dissociation mainly leads to the formation of $\mathrm{N}$-terminal $\mathrm{a}, \mathrm{b}$-fragments, and C-terminal y-fragment $[58,161]$. As a qualitative basis, the fragment with higher gas-phase basicity (GB) will remain protonated with higher probability than the fragment with lower GB [161]. New fragment can further be created, under 


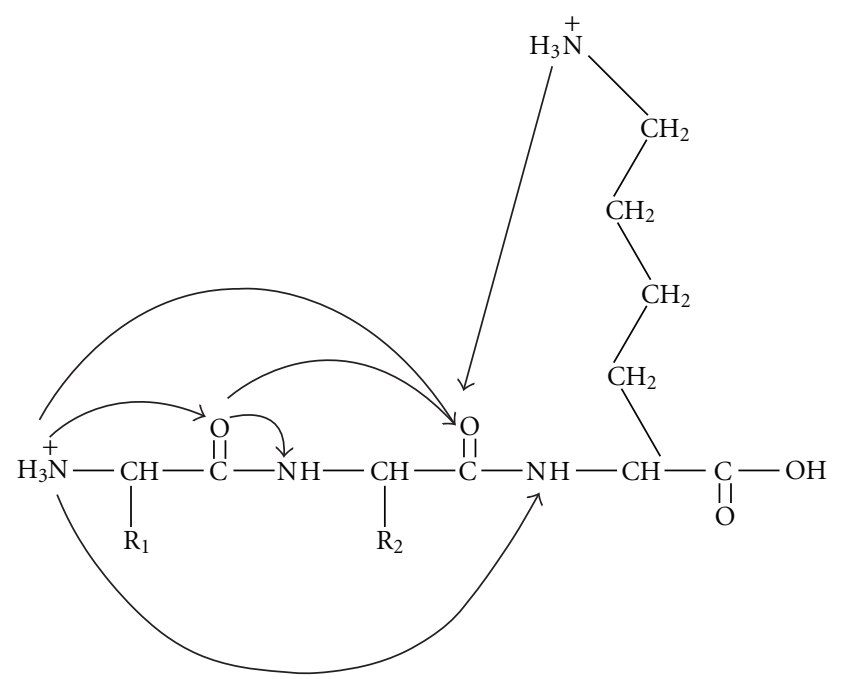

FIGURe 16: Mobile proton model. (Reprinted with permission from Journal of the American Society for Mass Spectrometry [156], Copyright 2010, Elsevier).

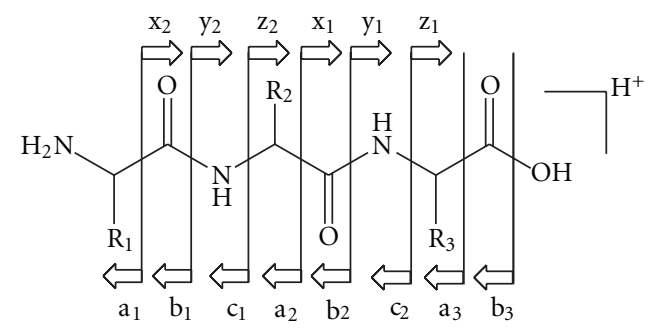<smiles>[R]CNC(=O)C([R])N</smiles>

$\mathrm{a}_{2}$<smiles>[R1]C(C=O)NC(=O)C([R])N</smiles>

$\mathrm{b}_{2}$<smiles>[R]C(N)C(=O)NC([R2])C([NH3+])=O</smiles>

$c_{2}$<smiles>[R3]C(NC=O)C(=O)O</smiles>

$\mathrm{x}_{1}$<smiles>[R3]C([NH3+])C(=O)O</smiles>

$\mathrm{y}_{1}$<smiles>[R3]C(=O)O</smiles>

FIGURE 17: Nomenclature of the peptide fragments showing some typical qualitative structure of the fragments.

multiple collision condition, by the primary fragment dissociation leading to the secondary ion products (satellites) such as internal fragments [176], amino acid-specific immonium ions [177], neutral-loss a/b/y-ions (e.g., $\mathrm{b}_{n}-\mathrm{NH}_{3}, \mathrm{~b}_{n}-\mathrm{H}_{2} \mathrm{O}$, etc.) $[178,179]$, and smaller member of $b$, a, and y-ion series. All these ions provide peptide sequence information directly and that is why they are called "direct sequence ion" [180]. Figure 18 shows a typical example of the CID-MS/MS 


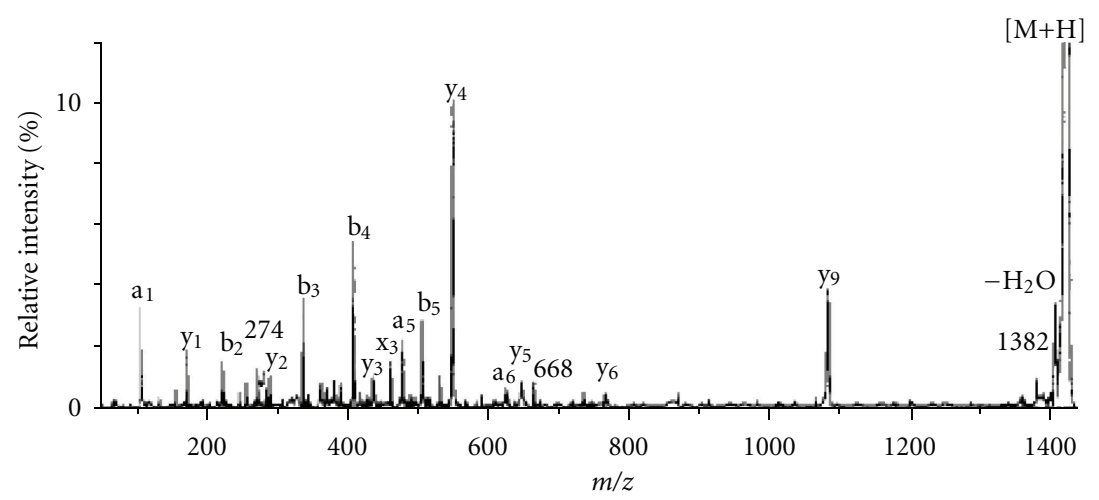

(a)

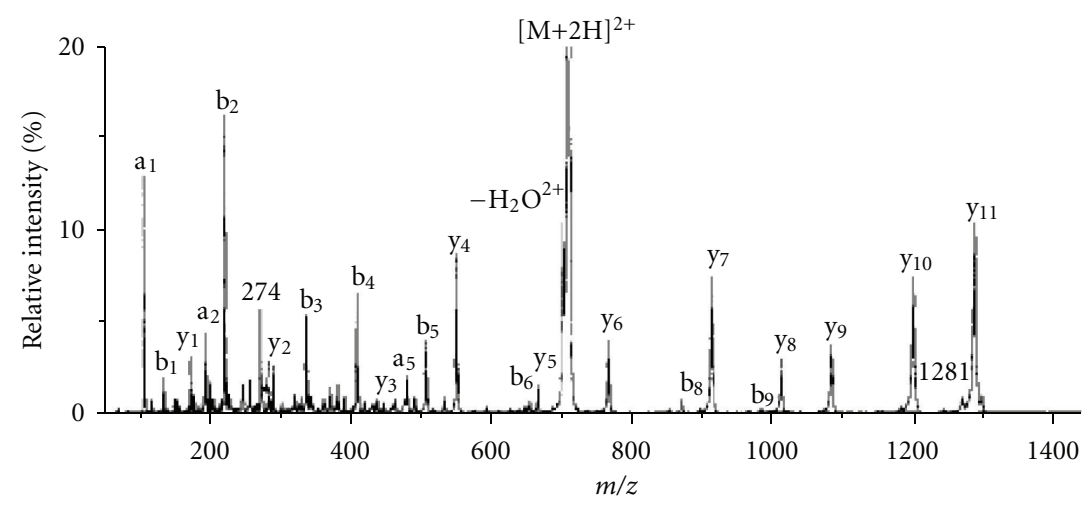

(b)

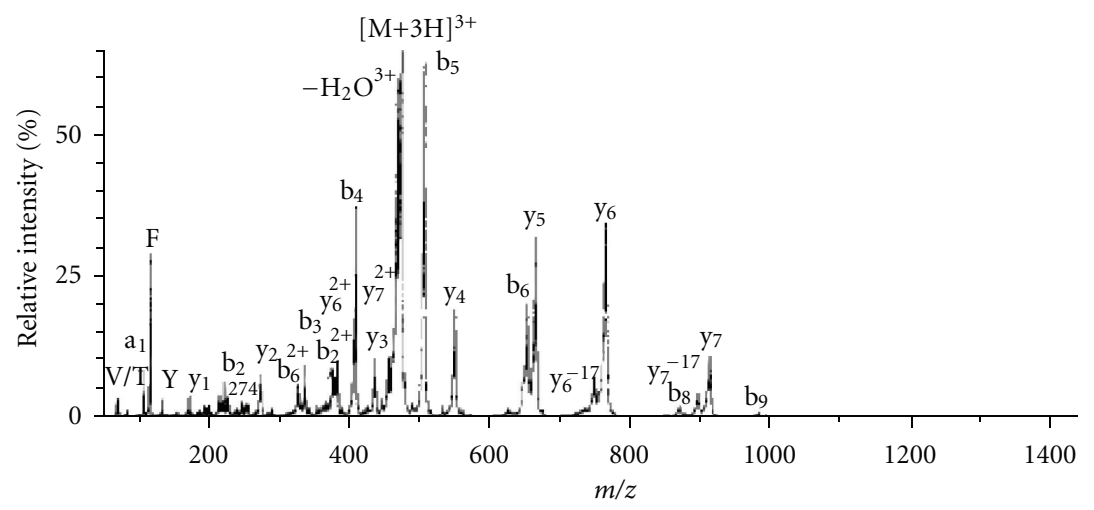

(c)

FIGURE 18: CID-MS/MS spectra of different protonated forms of the peptide HSDAVFTDNYTR: (a) CID of singly protonated peptide [M + $\mathrm{H}]^{+}$, (b) CID of doubly protonated peptide $[\mathrm{M}+2 \mathrm{H}]^{2+}$, and (c) CID of triply protonated peptide $[\mathrm{M}+3 \mathrm{H}]^{3+}$. (Reprinted with permission from Analytical Chemistry [157], Copyright 1993, American Chemical Society).

spectra of the different protonated forms of the peptide HSDAVFTDNYTR representing different "direct sequence ions" [157].

The actual mechanism by which the peptide backbone is cleaved follows complicated pathways. Although the peptide fragment ions (product ions) were identified long ago [107, 174], it is the recent trend to understand the mechanism of the fragmentation of gaseous protonated peptides. For example, recently it has been understood how a singly protonated peptide can fragment to produce the C-terminal/Nterminal fragment ions [181]. The $\mathrm{b}_{n}$-ion does not exist as acylium cation as shown in Figure 17, rather they form a cyclic oxazolone structure in the gas phase. Scheme 2 shows the proposed mechanism of the amide bond cleavage of a singly protonated peptide [181]. Before the cleavage of a protonated amide bond, the corresponding amide carbonyl is attacked by the nucleophilic oxygen of the previous amide carbonyl group and thus makes an oxazolone ring followed by a proton-bound complex between the oxazolone (N-terminal) and a truncated peptide or amino acid (C-terminal). Then the fragmentation of the proton-bound complex can occur by the proton transfer process leading to either $\mathrm{b}_{n}$-ion 

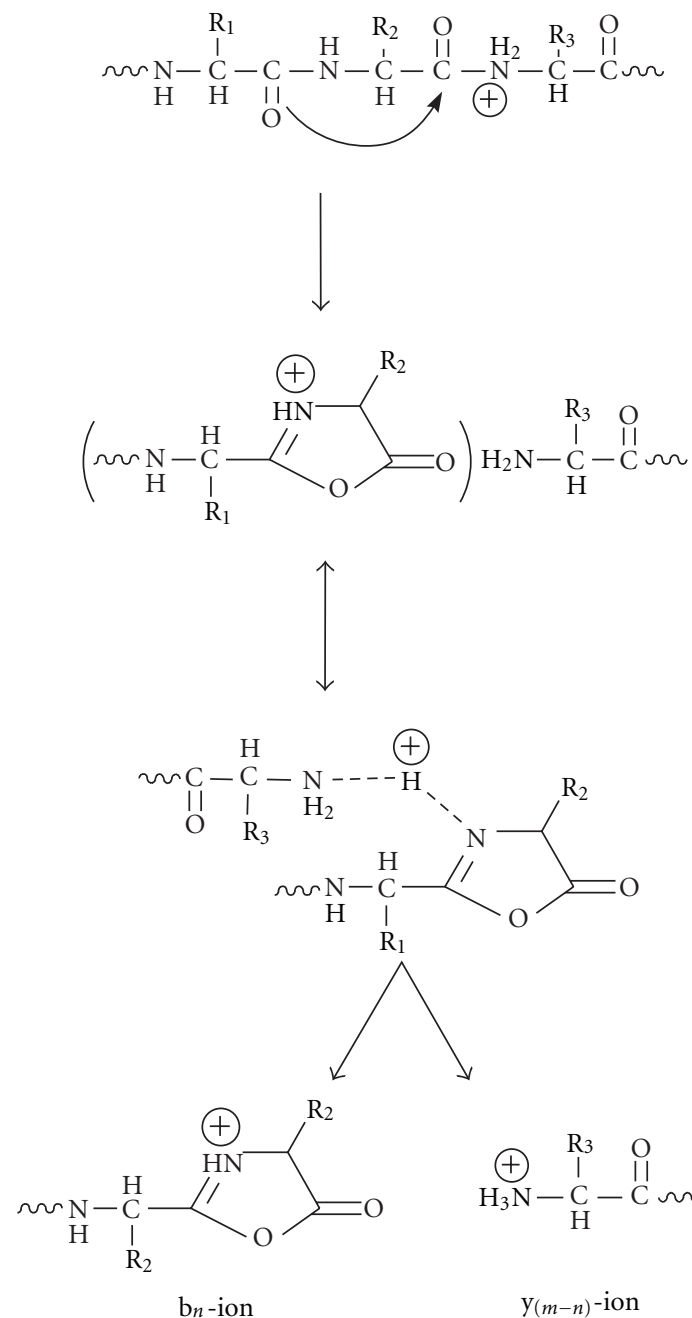

Scheme 2: A mechanism for the production of $\mathrm{b}_{n}$ and $\mathrm{y}_{n}$ ions.

or $\mathrm{y}_{n}$-ion. Thus, the propensity of the formation of $\mathrm{b}_{n}$ or $\mathrm{y}_{n}$ ion is dependent on the relative proton affinities of the N-terminal oxazolone and the C-terminal truncated peptide/amino acid. The $\mathrm{N}$-terminal oxazolone $\left(\mathrm{b}_{n}\right.$-ion) can undergo a neutral loss of carbon monoxide (CO) to form $\mathrm{a}_{n}$-ion. It has also been proposed that the N-terminal a, bfragments are terminated with five membered [182] (oxazolone) ring, via rearrangement type reaction. Generally the amide bonds $\mathrm{N}$-terminal to proline and C-terminal to Asp/Glu are more prone to fragmentation [183]. This is because the tertiary amide nitrogen of the proline residue is more basic and thus more likely to be protonated than other backbone amide bonds due to the mobile proton mechanism and thereby leading to enhanced peptide bond cleavage. The acidic residues Asp/Glu provide "local" mobile proton, which catalyzes the cleavage at the peptide bonds C-terminal to these residues [183]. It should be noted that the dissociation of the doubly or multiply charged peptide is more advantageous compared to that of a singly protonated peptide [58]. The population of more than one charge on the peptide backbone results in more dissociation pathways by mobile proton mechanism and thus produces more fragment ions to provide much more sequence information compared to that derived from the singly protonated peptide. Furthermore, the presence of more than one charge of similar polarity can impart Coulomb repulsion in gas phase rendering the precursor ion less stable and thereby further contributes to more facile dissociation. In general the peptide fragmentation is mostly influenced by the charge (e.g., protons), and thereby the fragmentation is called "charge directed fragmentation" $[159,161]$.

However, this conventional knowledge of fragmentation pathways and rules cannot reasonably explain many anomalous fragmentations because it is often the case $[157,184-$ 187] that abundant fragment ions appear in the MS/MS spectra of peptides that do not belong to the above-discussed direct sequence ion series. These fragments are formed in complex rearrangements and are termed as "nondirect sequence ions" [180]. The nondirect sequence ions discovered so far include scrambled fragments of the b/a type ions, which is equivalent to the loss of amino acid residue from the interior 


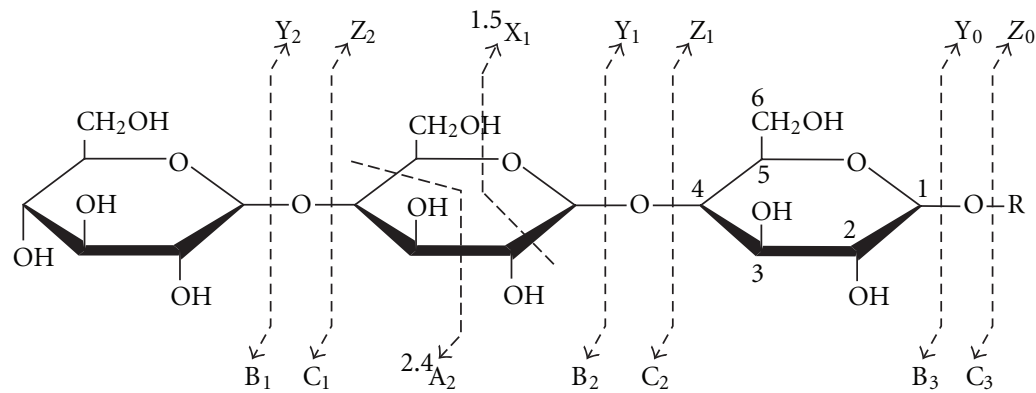

FIGURE 19: Nomenclature of the product ions formed from the precursor oligosaccharide.

of the peptide chain [180]. As reported in the recent literatures [180, 187-192], the first step of the mechanism concerned to the internal amino acid loss (sequence-scrambling fragmentation pathway) is a nucleophilic attack by N-terminal $\alpha-\mathrm{NH}_{2}$ group on the acylium carbocation of the b-ion (a primary fragment) forming a protonated cyclic-peptide intermediate (CPI). This CPI reopens at other sites, producing linear fragment ions where residues are relocated at the $\mathrm{C} / \mathrm{N}$-termini. These linear fragment ions further dissociate via conventional fragmentation pathways, forming daughter ions with neutral losses of internal residues from the parent ions. These types of ions are called the nondirect sequence ions of the protonated parent peptides. At the first stage of CID, this unique fragmentation of singly charged bions is difficult to be observed. However, under multi-stage CID, almost all of the investigated b-ions (containing three to seven residues) notably displayed the above unique fragmentation patterns. The propensity of the sequence scrambling increases with the increase in the chain length and the charge states of the peptides [193]. A recent report [194], on the basis of the analysis of 15,897 low-energy and 10,878 highenergy CID mass spectra of doubly protonated tryptic peptides, is suggesting that the rate of sequence scrambling due to b-ion cyclization is negligible $(<1 \%)$ and can be safely ignored as a possible source of erroneous sequence assignment in shotgun proteomics. Recently we have also found the loss of a specific amino acid residue from the interior of the protonated peptide in gas phase, which follows a degradation mechanism other than the above sequence scrambling pathway (unpublished work).

Although historically the peptide fragmentation is performed on the gaseous protonated peptides to derive the sequence information [173], fewer efforts have been invested on the dissociation of the gaseous deprotonated peptides. Hence the dissociation pathways of the deprotonated peptides are not well established [173]. It should be noted that in negative ion mode the $-\mathrm{OH}$ functional groups in serine, threonine, and tyrosine side-chains and -COOH functional groups in glutamic and aspartic acid side-chains are the potential deprotonation sites [195, 196]. Fragmentation of deprotonated peptides has been shown to provide complementary structural information to their positive counterparts [196-198]. Therefore, sequencing unknown peptides can benefit from the interpretation of both positive and negative mass spectra.
Several aspects of CID of the protonated peptides are still under controversy. It is continuously being debated where exactly the proton is located before the amide bond cleavage, whether the location is carbonyl oxygen or amide nitrogen $[107,164,168,171,199,200]$. How exactly the fragmentation pattern is dependent on the amino acid sequence of the precursor peptides and how different fragments get stabilized? Apart from sequence informative ions, there are lots of anomalous fragments, which are observed in the MS/MS spectra of the peptides. As a future outlook the detail understanding of the formation of those anomalous fragment ions is required and that continuously drawing the attention of the mass spectroscopists.

8.4. CID of Oligosaccharides. The analytical and structural characterization of carbohydrates or saccharides (highly abundant biological compounds) is quite a challenging problem because of the diversity of the linkage types, linkage position, and anomeric configuration [201]. Analogous to the peptide cleavage in the gas phase, the gaseous protonated/ metallated oligosaccharides also undergo facile cleavages in certain specific positions upon CID. A systematic nomenclature (see Figure 19) of the different product ions produced from a precursor oligosaccharide was introduced [202] by Domon and Costello in 1988. Under low-energy collision conditions, the abundant product ions (B, C, Y, and Z) are generated by the glycosidic bond cleavages. But the highenergy collision conditions tend to favor cross ring cleavages, which produces "A" or " $\mathrm{X}$ " type fragments (see Figure 19) [203]. These cross-ring cleavage preferably produced by charge remote fragmentation from the sodium adduct of the precursor analyte [203]. The dominant pathway for the ion decomposition is highly dependent on the nature of the precursor ion, that is, protonated or metallated, or the cationic or anionic adduct species [203-207]. Generally for protonated oligosaccharides, the protons are mainly located on the glycosidic oxygen and thereby induce the cleavage of either $\mathrm{C}_{1}-\mathrm{O}$ bond or $\mathrm{C}_{4}-\mathrm{O}$ bond (see Figure 19) $[202,204]$. The $\mathrm{C}_{1}-\mathrm{O}$ and $\mathrm{C}_{4}-\mathrm{O}$ bond cleavages give rise to the formation of $\mathrm{B}_{n} / \mathrm{Y}_{m}$ and $\mathrm{C}_{i} / \mathrm{Z}_{j}$ complementary ions, respectively, via "ion-dipole complex" mechanism involving an oxonium ion [58] (see Schemes 3 and 4).

8.5. CID of Oligonucleotides. Low energy CID is also useful for the structural elucidation of nucleic acids like DNA, RNA, 


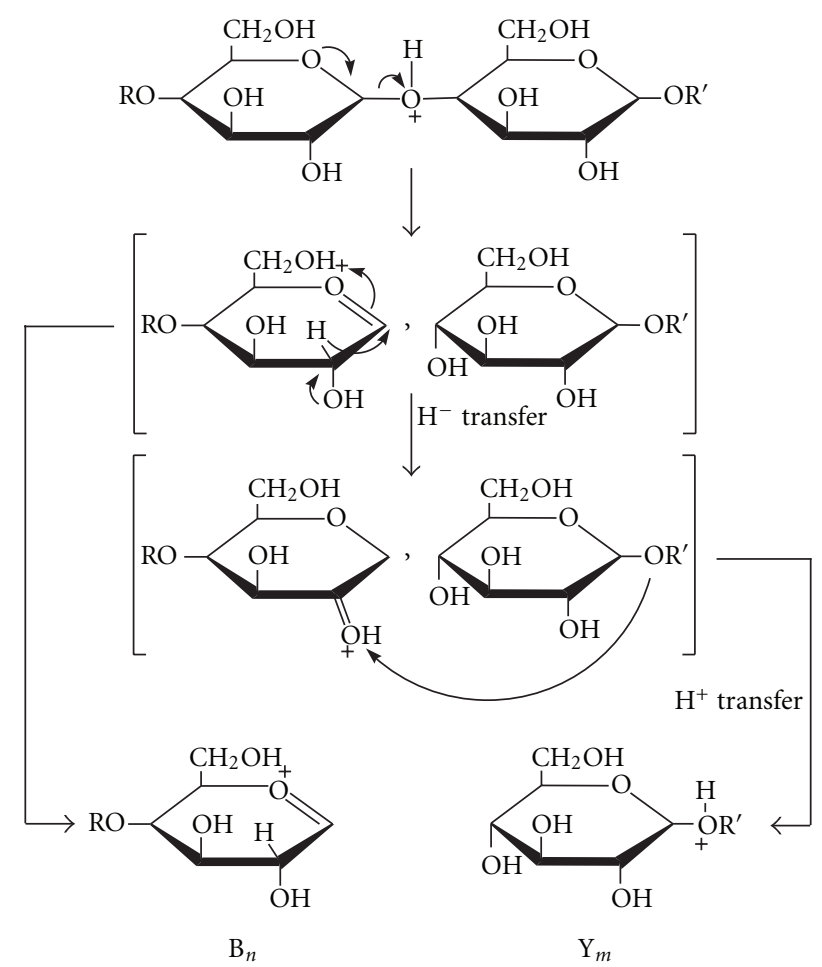

Scheme 3: The proposed mechanism of the formation of $\mathrm{B}_{n}$ and $\mathrm{Y}_{m}$ product ions via ion-dipole complex.

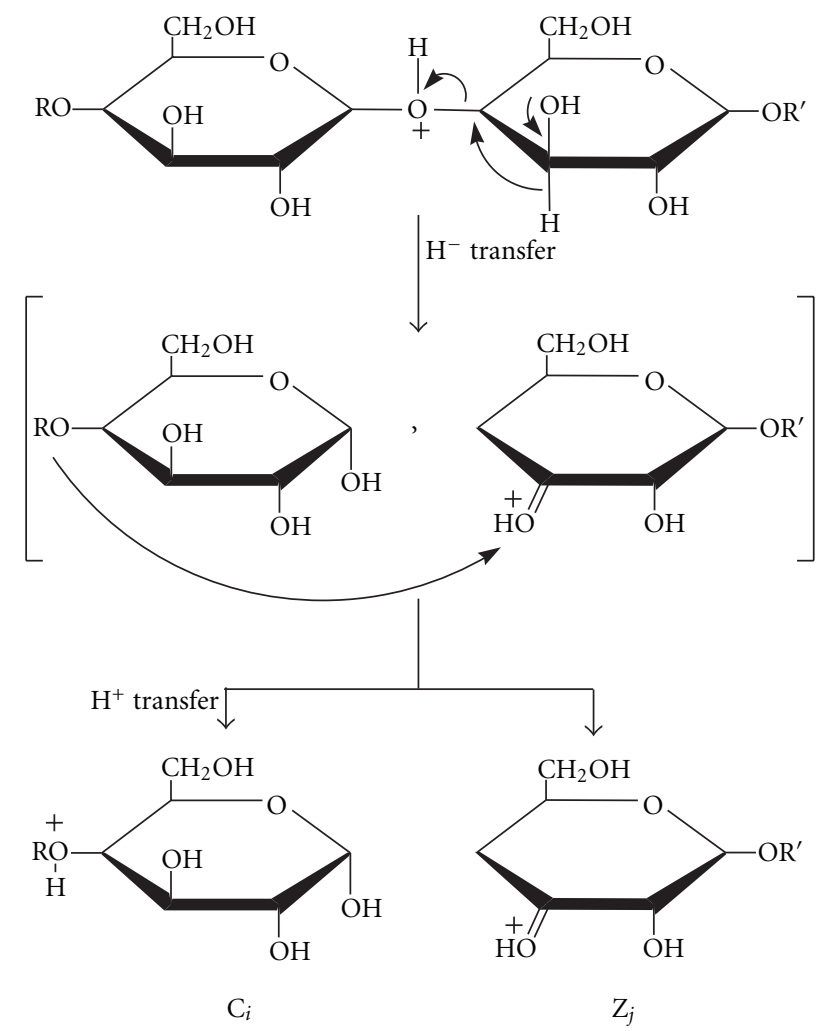

Scheme 4: Proposed mechanism of the formation of $\mathrm{C}_{i} \& \mathrm{Z}_{j}$ product ions via ion-dipole complex. 


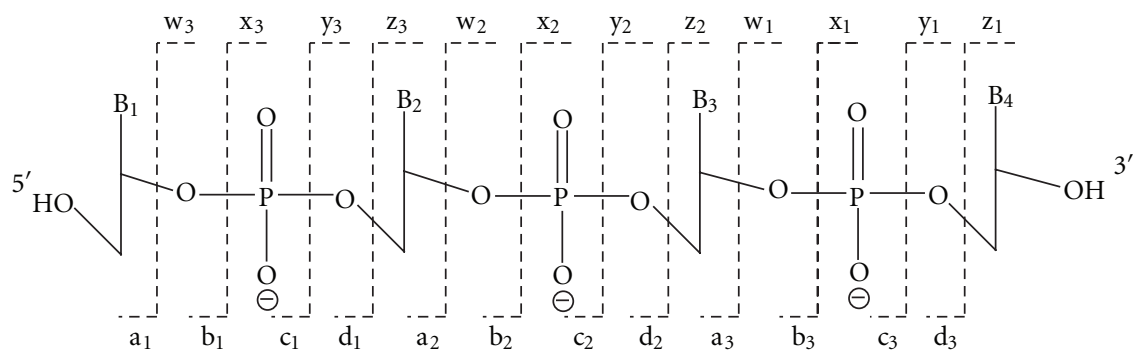

FIGURE 20: Nomenclature of the fragment ions produced by the CID of oligonucleotides.

and so forth, [208]. Polyanionic oligonucleotides derived from DNA/RNA can be efficiently transferred to the gasphase by ESI. Those oligonucleotides undergo selective fragmentation in CID producing ladder-like product ion spectra similar to that produced by peptides. A systematic nomenclature was proposed by McLuckey et al. [208] to describe the product/fragment ions generated by CID of the oligonucleotide (see Figure 20). Cleavage of the four types of phosphodiester bond yields eight types of fragments for example, $\mathrm{a}_{n}, \mathrm{~b}_{n}, \mathrm{c}_{n}$, and $\mathrm{d}_{n}$, which contain the $5^{\prime}-\mathrm{OH}$ group, and $\mathrm{w}_{n}, \mathrm{x}_{n}, \mathrm{y}_{n}$, and $\mathrm{z}_{n}$, which contain $3^{\prime}-\mathrm{OH}$ group. The subscript " $n$ " represents the number of residues contained in the fragments and thus designates the position of cleavage. Sometimes additional loss of a purine/pyrimidine base $\left(\mathrm{B}_{n}\right)$ is indicated by parenthesis with the identity of the base (if possible). For example, the fragment $\mathrm{a}_{4}-\mathrm{B}_{4}(\mathrm{~A})$ indicates the cleavage of the bond between ribose carbon and the oxygen of the phosphodiester group at position 3, with the additional loss of adenosine base at the same position. ESIMS/MS spectra of the oligonucleotides are generally dominated by $\mathrm{a}_{n}, \mathrm{a}_{n}-\mathrm{B}_{n}, \mathrm{~d}_{n}$, and $\mathrm{w}_{n}$-ions. Other types of fragments are also possible by some complex rearrangement type reaction. Several fragmentation pathways have been proposed to explain the formation of the complimentary ions in gas phase by the precursor oligonucleotides [209-213]. Scheme 5 shows the typical mechanisms [213] of the formation of $\mathrm{a}_{n}, \mathrm{a}_{n}-\mathrm{B}_{n}, \mathrm{~d}_{n}$, and $\mathrm{w}_{n}$-ions from the oligonucleotide anion upon CID.

8.6. CID of Lipids. Lipids are a broad group of naturally occurring hydrophobic organic molecules, which includes fatty acyls, glycerolipids, glycerophospholipids, sphingolipids, sterol lipids, prenol lipids, saccharolipids, and polyketides [215]. Mass spectrometry plays a key role in the structural elucidation and quantification of these molecules. It is beyond the scope here to discuss details about the CID of all classes of lipids. Here we would only discuss about the CID of two typical lipid molecules, for example, fatty acids and bile acids. Fatty acids are long hydrocarbon chain of varying length and varying degree of unsaturation, terminated by a carboxylic acid functional group. Bile acids are derived from cholesterol, and they contain a $5 \beta$ steroid ring made up of four fused cycles bearing a side-chain attached to the C-17 carbon atom of the cycle, terminated by a carboxylic group (see Figure 22). They differ from each other by the number and position of the hydroxyl/keto groups and by the presence of unsaturation in the cycle. The bile acids can exist as free carboxylic acids or amide conjugates of the carboxylic groups with glycine $\left(\mathrm{NH}_{2} \mathrm{CH}_{2} \mathrm{CO}_{2} \mathrm{H}\right)$ or taurine $\left(\mathrm{NH}_{2} \mathrm{CH}_{2} \mathrm{CH}_{2} \mathrm{SO}_{3} \mathrm{H}\right)$.

The fragmentation of fatty acids and bile acids is believed to occur via mechanisms that do not involve the charged group directly and thus termed as charge-remote fragmentation (CRF) mechanisms [162, 214, 216, 217]. A typical example of the CRF of a pseudomolecular anion has been shown in Scheme 6, which either involves a simple homolytic cleavage [218] or a $1,4-\mathrm{H}_{2}$ elimination [216] to produce distonic radical anion or terminally unsaturated anion.

When fatty acids are electrosprayed in negative ion mode, they produce $[\mathrm{M}-\mathrm{H}]^{-}$ions in gas phase. Upon collisional activation, the CRF of the chain in different positions occurs. According to the nature of the bond, which is broken, different symbols of the product ions are used [214]. When a regular $\mathrm{C}-\mathrm{C}$ bond is broken, this is represented by $\mathrm{C}$, a vinyl bond by $\mathrm{V}$, an allyl bond by $\mathrm{A}$, a homoallyl bond by $\mathrm{H}$, and a double bond by D. A subscript to the right of the capital letter (e.g., $\mathrm{C}_{n}$ ) indicates the number of the carbon atoms remaining in the corresponding charged fatty acid fragment. A prime symbol to the left of the capital letter (product ion symbol) indicates that the product ion is deficient in one hydrogen atom relative to a fragment ion formed by homolytic cleavage at the same site of a hypothetical precursor molecule, and $\mathrm{M}^{-\bullet}\left([\mathrm{M}-\mathrm{H}]^{-}\right.$is deficient one hydrogen relative to $\mathrm{M}^{-\bullet}$ ). Multiple hydrogen deficiencies are denoted by multiple prime symbols to the left of the letter [214]. Figure 21 shows the fragmentation characteristic of a saturated fatty acid (stearic acid) and an unsaturated fatty acid (oleic acid) under high energy collision conditions [214]. Both the fatty acids show their unique backbone fragmentation pattern.

Similarly the charge remote ring cleavage of the bile acids also occurs, resulting in ring opening, loss of neutral ethylene, and double-bond formation on the product ions. Griffiths et al. have developed a systematic nomenclature (see Figure 22) to interpret the fragment ions produced by the CID of the bile acids $[217,219]$. The rings are labeled as (a), (b), (c), (d) from left to right (see Figure 22), and the corresponding capital letter is used to indicate which ring is opened and broken in the cross-ring cleavage. The subscript $(1,2$, and 3$)$ to the right side of the capital letter indicates the cross-ring cleavage site on that ring. Again the "prime" symbol to the left of the letter is used to keep track of hydrogen deficiencies as discussed above. 

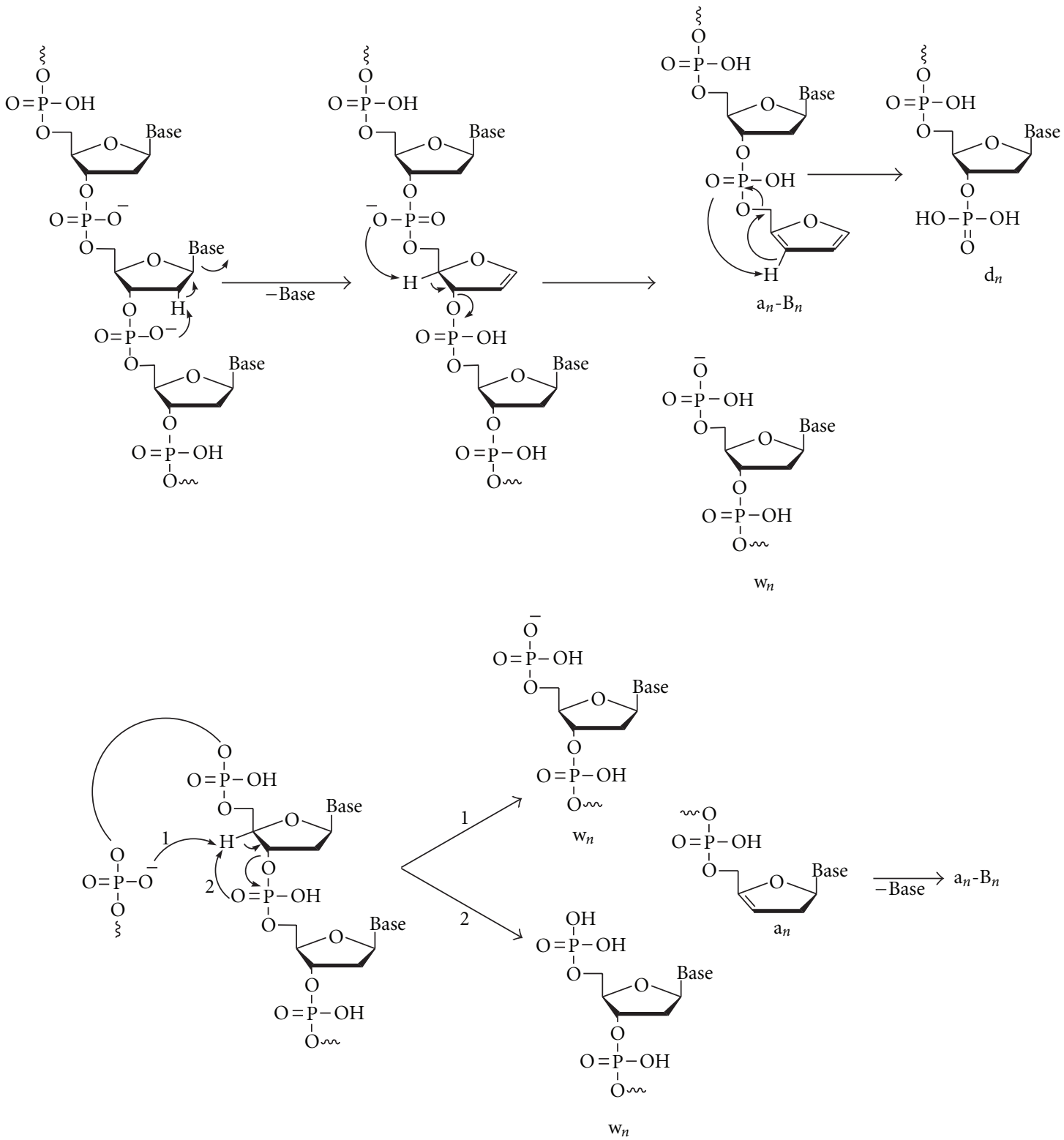

Scheme 5: The fragmentation mechanism of the oligonucleotide in two different ways. The mechanism in the upper panel shows the necessity of a charge proximate to the cleavage site. The mechanism in the lower panel does not require the charge proximate.

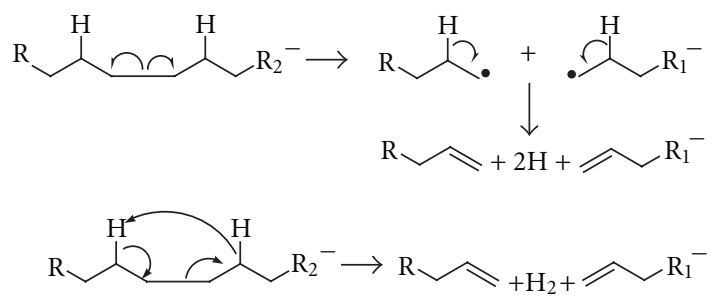

Scheme 6: The charge remote fragmentation (CRF) mechanism for the formation of distonic ions (anions) and terminally unsaturated ions (anions).

\section{Application of ESI-MS}

After the discovery of the ESI-MS, its application areas rapidly expanded from large macromolecules to small organic and inorganic molecules. Nowadays the ion signals in the ESI-mass spectra are providing a clear and deep perception about the analytes properties far beyond the conventional mass and structural properties of the analytes. Here we will discuss in brief about certain applications of the ESI-MS.

9.1. Protein Identification and Characterization. Since mass is a very specific property of a molecule, determination of the molecular weight with high precision allows to solve many problems in proteomics. Over the past twenty years, ESImass spectrometry has emerged as a powerful tool in the life science to determine the identity [220-222], quantity $[223,224]$, and structural properties $[6,225-227]$ of the protein molecules. Mass spectrometry is a very fast process to verify the structure and purity of the proteins and peptides 


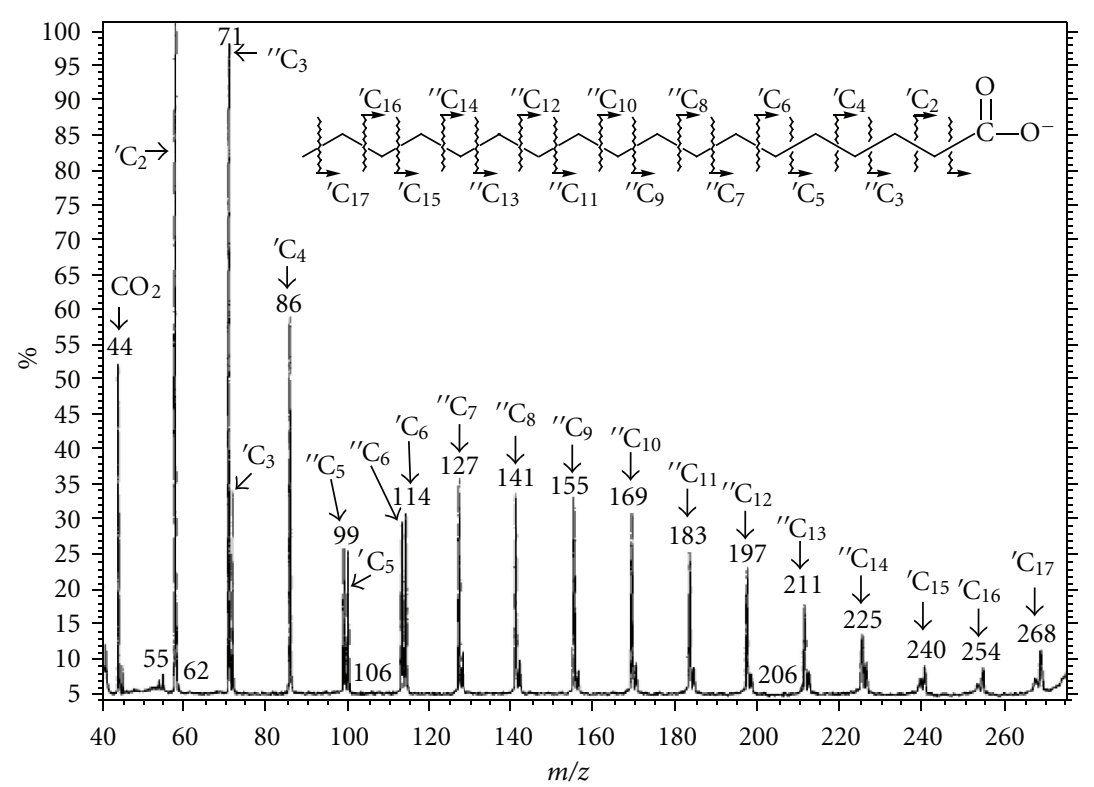

(a)

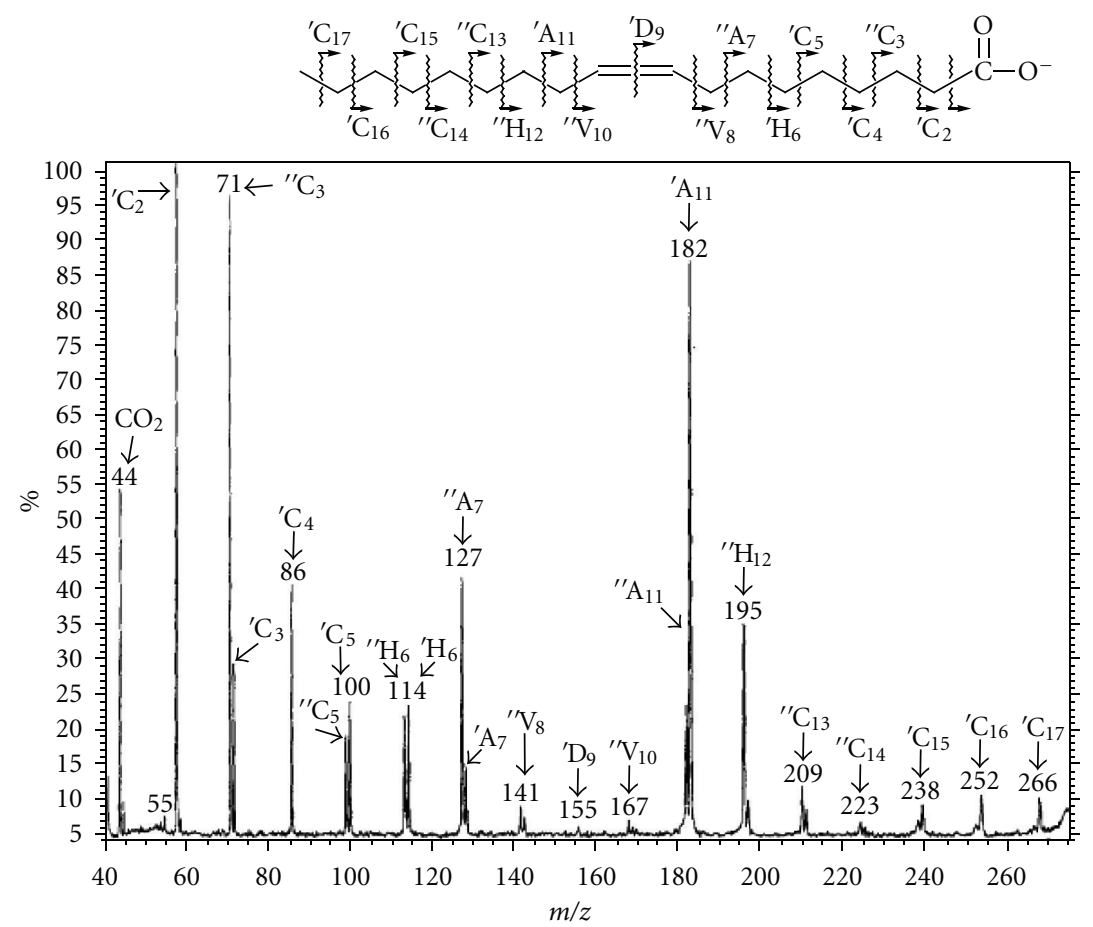

(b)

Figure 21: $400 \mathrm{eV}\left(E_{\text {lab }}\right)$ CID spectra of stearic acid (a) and oleic acid (b) pseudomolecular anion. (Reprinted with permission from Rapid Communication in Mass Spectrometry [214], Copyright 1996, John Wiley and Sons).

$[222,228]$. Classically the determination of the primary structure of the protein (i.e., the amino acid sequence) requires a chemical approach called Edman degradation method [229]. But this technique is time consuming, and a large quantity of the protein sample is also required. But after the discovery of LC-ESI-MS, the mass spectrometry is the most efficient way of sequencing a protein $[107,160$, 230, 231]. In this MS method, the protein is digested by an endopeptidase (e.g., trypsin, chymotrypsin, pepsin, etc.), which cut the protein into small peptide/polypeptide fragments very specifically. Then the digest mixture is passed through the high-performance liquid chromatography where the collection of peptide fragments is separated. At the end of the column the individual peptide fragment is electrosprayed in vacuum, where they are trapped and allowed to undergo collision activation to produce MS/MS spectra as discussed 


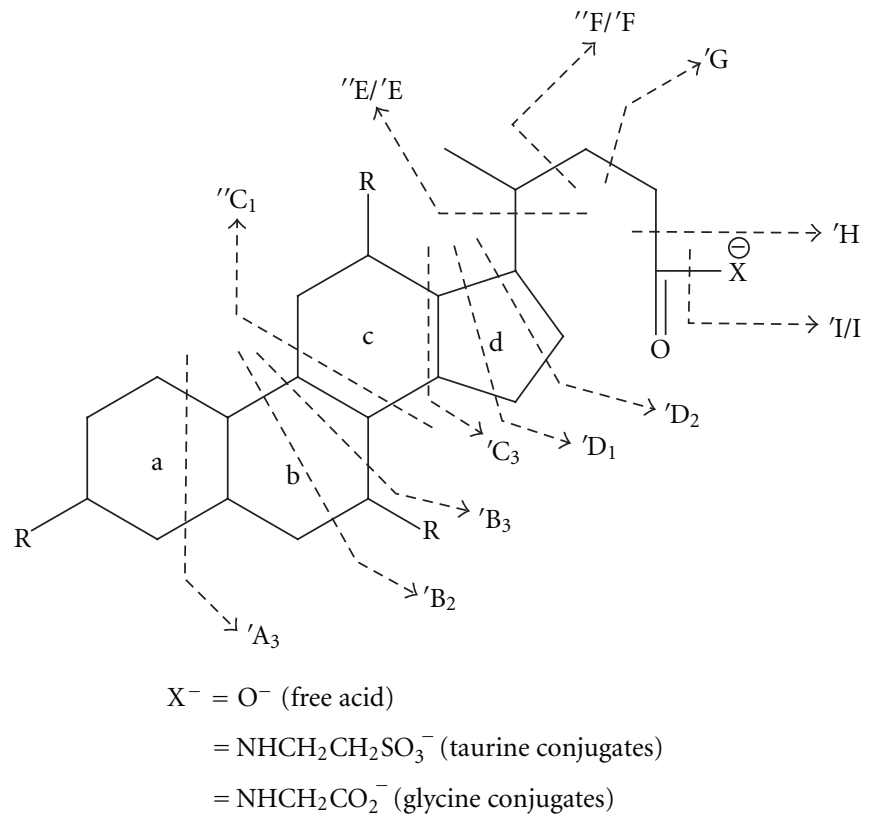

FIGURE 22: The charge remote fragmentation of bile acids (metabolites of cholesterol) with the nomenclature of different fragments.

above [160, 231]. The resulting MS/MS spectra are nothing but the mass fingerprints of the ladder-like product ions of the peptide of a particular sequence. The MS/MS spectra of the peptides are usually assigned with the help of various bioinformatic tools that implement sequencing algorithms based on peptide fragmentation chemistry as discussed before $[160,231,232]$. Thus the peptide mass fingerprinting (PMF) helps to identify the amino acid sequence of the whole proteins. The process is repeated using different digestion enzymes, and the overlaps of the resulting sequences are used to construct a sequence of the protein. When the identification of the proteins is solely based on the sequence data obtained from the tandem mass analysis, it is called "de novo sequencing" [232], and the corresponding procedure (as discussed above) of the protein analysis is called "bottomup" approach $[233,234]$.

Sometimes intact charged protein generated by ESI is introduced into the mass analyzer and are subjected to gasphase fragmentation, and this type of approach is referred to as the "top-down" strategy of protein analysis [235].

Although the ESI-MS technique is not sensitive to probe the local conformation of the polypeptide chain, that is, the secondary structure of the protein, the technique can successfully interpret the three-dimensional conformation of the proteins [76]. As discussed already that the charge state distribution actually represents the three dimensional folding or the tertiary structure of the proteins [76]. This property makes ESI-MS an excellent method, complimentary to CD (circular dichroism), to characterize the protein conformational change. Hence an increasing interest based on ESIMS is continuously developing to study the protein folding process.

ESI-MS can also successfully detect the posttranslational modifications (PTMs) $[236,237]$ and the mutation [238] of the proteins as those processes lead to the change of protein masses. Not only does the total mass change, but also the position or point of the PTM or mutation can be determined by tandem mass spectrometric experiments $[222,239]$. Recently, using tandem mass spectrometric technique, we have identified the reactive lysine residues of cytochrome c [240]. We found that the lysine residues, which are in the turn or loop region of the protein, are more reactive to succinylation compared to those which are in the helical region. It has been proposed that the lower reactivity of the lysine residues present in the helical regions might be due to the higher rigidity of the helical region than that of the turn or loop region [240]. In another study [241], using tandem mass spectrometry we have determined the molecular basis of the PTM involving covalent attachment of the heme with a glutamic acid of the protein matrix in the Cytochrome P450 enzyme.

Disulphide bonds (a kind of PTM) play important roles in the structure and biological activity of the cystinyl proteins. So the determination of the disulphide bond linkage between two adjacent or closely spaced cysteine residues is an integral part of the structural characterization of the proteins. Several mass spectrometry-based strategies have been developed to map the disulphide bond linkages in the proteins [242-247]. Most of the time, the protein of interest is cleaved enzymatically in its nonreduced states, and then the resulting disulphide-linked peptides are separated, identified, and characterized by LC-MS technique. Then the data is compared with the similar experiments performed on the disulphide-reduced protein of the interest [243]. This comparison study can locate the disulphide linkages in the folded proteins. Sometimes chemical cleavage at disulphide residues followed by chemical derivatization is also performed for the 
mass spectrometric study to identify the disulphide linkages in the proteins [247].

9.2. Studying Noncovalent Interaction. Since ESI is a sufficiently soft ionization technique, the noncovalent complexes of the analytes formed in solution can representatively, transferred to the gas phase when appropriate instrumental conditions are used [225, 248-250]. Mainly a collection of weak interactions such as Van der Waals forces, hydrophobic forces, and hydrogen bonding or salt bridges (electrostatic interactions) are responsible for the analyte association in solution. When the analyte is transformed in the gas-phase via ESI, probably most of those interactions are retained, and some of those interactions become more prominent in the gas phase compared to solution and thus provide the structural integrity in the gas phase [251-253]. Generally the propensities of the ionic interactions become more in the gas phase compared to solution [251-253]. For example, a recent ESI-MS study of the protonated and deprotonated gaseous ions of a single chain antibody-trisaccharide complex has showen several specific intermolecular H-bonds in the gas phase [254]. Likewise a recent report, shown that, in the presence of $\mathrm{K}^{+}, \mathrm{Rb}^{+}$, and $\mathrm{Cs}^{+}$, uracil, thymine, and their homologues form self-assembled quintet structures that are stabilized by hydrogen bonding and ion-dipole interactions in the gas phase [255]. ESI-MS has allowed the observation of a large number of biomolecular noncovalent complexes such as protein-protein [256, 257], protein-metal ion [258], protein-drug [259], and protein-nucleic acid [260] complexes. Since proteins provide a large number of functional groups for the noncovalent interaction with the partner molecule(s), the resultant noncovalent forces are large enough to retain the association during their transfer from condensed to the gas phase. But, in small molecules for example, in small peptides, this number of noncovalently interacting atoms with proper orientation for the intermolecular interaction is less and it is sometimes very difficult to probe their association in solution by ESI technique. Recently we have shown the formation of noncovalent dimers of the lysine containing basic peptides by ESI-MS [253], which demonstrated that the intermolecular electrostatic/Hbonding network is mainly responsible for the dimer formation of those small peptides in the gas phase. ESI-mass spectrometry also evolved as a valuable tool for the determination of the association/dissociation constants for several proteinligand complexes [261]. Although the gas-phase studies on the proterin-ligand complexes have been primarily focused on the complexes, which are stabilized by the ionic interaction or $\mathrm{H}$-bonding, the nonpolar intermolecular interaction between protein (bovine $\beta$-lactoglobulin) and ligand (fatty acids) in vacuum has also been reported lately [262]. The corresponding interaction strength of the nonpolar proteinligand complexes has also been quantified.

It is very difficult to ionize the hydrophobic proteins by ESI because of their inherent insolubility in the buffers compatible with electrospray. For this reason the ESI-mass spectrometry has not been applied to intact membrane protein complexes. But recently Barrera et al. have been successful to transfer some hydrophobic membrane protein complexes in vacuum via ESI by encapsulation in a solution phase detergent micelle [263].

The ESI-MS has also been used to study the complexes between polyether (e.g., crown ethers) and protonated peptides [264, 265]. The protonated amine functional groups make hydrogen bonds with the oxygen atoms of the crown ethers in those complexes. The energy-variable collisioninduced dissociation was carried out to analyze the strengths of noncovalent interactions of protonated peptide/polyether complexes [264, 265].

9.3. In Clinical Laboratory. Since ESI-MS is a sensitive, robust, and reliable tool for studying the femtomole samples in microlitre volumes, it has become an increasingly important technique in the clinical laboratory for structural study or quantitative measurement of metabolites in a complex biological sample [266]. For example, HPLC/ESI-MS is useful to a great extent than other conventional techniques in screening for inborn errors of amino acid [267, 268], fatty acid [269], purine [270], pyrimidine [270] metabolism, and diagnosis of galactosaemia [271] and peroxisomal [272, 273] disorders. Because of the preservation of the noncovalent interaction in gas phase, ESI-MS has nurtured a new and improved approach (versus electrophoresis) for identification and quantification of haemoglobin variants [274]. With the understanding of glycohaemoglobin structure, an IFCC reference method for glycohaemoglobin assay has been established using ESI-MS [275]. It also represents a promising strategy for the standardisation of HbAlc in diabetic monitoring [276]. With its other applications such as in therapeutic drug monitoring and identification of biomarkers $[277,278]$, ESI-MS will continue to exert a more important influence in the clinical laboratory in near future.

\subsection{Probing Molecular Dynamics: H/D-Exchange Experi-} ments. The application of the ESI-MS is not only restricted to the structural characterization, but it has also been extended recently to the study of the molecular dynamics. For this type of application, the analyte ions produced by the ESI-ion source are trapped and subjected to the ion-molecule reaction (H/D exchange) with some gaseous deuterated molecules possessing exchangeable deuterium (e.g., $\mathrm{CH}_{3} \mathrm{OD}$, $\mathrm{ND}_{3}$, etc.) for well-defined reaction intervals in the collision cell [279]. As a result the H/D-exchange between analyte and the deuterated molecules occurs in the gas phase and thus provides some critical information regarding the molecular motion in the noncovalent complexes. For example, the $H / D$ exchange reactions have been applied to uncover the tumbling motion of ammonium guests bound inside the cavity of resorcinarene hosts [280]. Very recently a highly dynamic motion of the crown ethers along the oligolysine peptide chains has been probed by H/D-exchange experiments in the gas phase [281]. The authors suggested this phenomenon as the wire dance on the molecular level. It has been observed that the crown ethers (guest molecules) can move directly between different binding sites of the oligolysine (a multitopic host) without intermediate dissociation. Furthermore, the exchange experiments unambiguously revealed the zwitterionic structure of the crown ether/oligolysine complexes, 
highlighting the success of the gas-phase experiments for investigating noncovalent interactions [281].

The gas-phase folding and unfolding of the protein (protein dynamics) can also be monitored by the H/D-exchange experiments [282, 283]. Valuable information regarding the protein conformation in vacuum has also come out by the gas-phase isotope exchange experiments [138, 284, 285]. Similarly several ion-molecule reactions in gas-phase have been used for the covalent modification of the gaseous analyte [286].

9.5. Monitoring Chemical Reactions and Studying Reactive Intermediates. The applications of ESI-MS have also been explored in synthetic organic and organometallic chemistry to study the reactive intermediates and the mechanisms [287292]. For example, catalytic intermediate of the Suzuki coupling reaction [289] and the Heck reaction mechanism [291] has been studied by ESI-MS. Raney nickel-catalyzed coupling reaction of 2-bromo-6-methylpyridine was studied, and a reactive dimer of the intermediate $\mathrm{Ni}[\mathrm{II}]$ complex of $6,6^{\prime}$-dimethyl-2,2'-bipyridine was detected [293]. Desorption electrospray ionization mass spectrometry (DESI-MS) has been used for monitoring solid-state organic reaction in ambient air, specifically the Bayer-Villiger type reactions involving the oxidation of ketones by $\mathrm{m}$-chloroperbenzoic acid in solid state [294]. The 1-adamantyl radicals have been identified as a reactive intermediate in several organic syntheses. Recently a tert-adamantyl peroxyl radical has been trapped in gas phase using ESI-MS, and its unusual structure and reactivity has been investigated [295]. Many other types of the reaction mechanisms investigated by the ESI-MS technique have recently been reviewed by Eberlin [296].

9.6. Chemical Imaging. Desorption electrospray ionization mass spectrometry (DESI-MS) is relatively a new ambient surface analysis method. The development of imaging mass spectrometry by DESI has been described recently [297299], and its application to high-throughput biological tissue imaging was also demonstrated [298]. In this technique the spatial distribution (on the tissue surface) as well as structural identification of the molecule of interest can be accomplished successfully [298]. Chemical imaging by DESI has been applied to label-free detection of drugs and metabolites in tissue [298]. DESI-MS imaging is advantage in a number of ways over the conventional whole-body autoradiography approach: (1) no radioactive label is required and (2) it allows simultaneous detection of the parent drug compound and metabolites in tissue [300]. DESI also holds the advantages of speed and specificity inherent in the mass spectrometric experiment. Chemical imaging by DESI-MS is still, however, in its early childhood. The ongoing research activities in this area address the questions concerning sensitivity, compound-specific ionization yields, tissue-specific ion suppression, and effects of solvent composition on ionization yields. An insight on these issues would immensely widen the horizon of applications of this technique in assessing more complex and quantitative information on the samples that would have important medical and pharmaceutical implications.

\section{Future Prospects and Outlook}

The development of electrospray ionization mass spectrometry has enabled us to solve a wide range of biochemical and mechanistic problems as discussed above. Perhaps it is one of the instruments that has continuously evolved over the last three decades both in application and modification of instrument design. For example, the transition of source design from microspray to nanospray has improved the sensitivity. Introduction of high-resolution mass analyzer (FT-ICR) amended the accuracy and redefined the applicability.

Yet in several aspects, the understanding of the ESI-MS remains vague to date. One of the major issues is the exact mechanism of ion formation. How is the gas-phase ion formation guided mechanistically? Is the perception of CRM and IEM enough to interpret the ion formation? It is still unclear about the analyte behavior (structure and dynamics) inside the charged droplets produced by ES process. If the proteins change their structure inside the charged droplet, then the charge state distribution (CSD) should reflect the instantaneous conformation of the protein inside the charged droplet not in the original solution. Again, as discussed in the present review, the CSD is not influenced by a specific parameter but governed by multiple parameters. So the precise understanding of the cumulative effect of those different parameters on the protein CSD would no doubt help to earn more quantitative insights about structural and chemical behavior of the proteins.

So far a little attention was invoked on the detector characterization and improvement compared to that of the ion source and mass analyzer. So, the characterization and improvement of the detector would likely be the next step in the development of mass spectrometry which would enable us to give the answer whether the ion signal intensity is governed by the molecular conformation of the analyte or not.

The application of the ESI-MS got a noteworthy dimension in biochemistry laboratories after its success in protein sequencing. The sequencing is based on the idea and information of gas-phase ion fragmentation chemistry of the peptides in the tandem mass spectrometry. But the tandem mass spectra of the peptides are mostly dominated by anomalous fragment ions than the "sequence informative ions." So the characterization of those anomalous fragments and accordingly the modification of sequencing algorithms would facilitate the sequencing of proteins/peptides more precisely and rapidly using mass-spectrometric technique.

\section{Acknowledgments}

Authors are thankful to Mr. Abhishek Acharya, Max Planck Institute for Biophysics, Germany, for his help. The financial support for this endeavor was provided by Tata Institute of Fundamental Research, Department of Atomic Energy, Government of India. 


\section{References}

[1] J. J. Thomson, Rays of Positive Electricity and Their Applications to Chemical Analysis, Longmans Green, London, UK, 1913.

[2] M. Grayson, "John Bennett Fenn: a curious road to the prize," Journal of The American Society for Mass Spectrometry, vol. 22, no. 8, pp. 1301-1308, 2011.

[3] M. Barber, R. S. Bordoli, R. D. Sedgwick, and A. N. Tyler, "Fast atom bombardment of solids (F.A.B.): a new ion source for mass spectrometry," Journal of the Chemical Society, Chemical Communications, no. 7, pp. 325-327, 1981.

[4] J. B. Fenn, M. Mann, C. K. Meng, S. F. Wong, and C. M. Whitehouse, "Electrospray ionization for mass spectrometry of large biomolecules," Science, vol. 246, no. 4926, pp. 64-71, 1989.

[5] M. Przybylski and M. O. Glocker, "Electrospray mass spectrometry of biomacromolecular complexes with noncovalent interactions-New analytical perspectives for supramolecular chemistry and molecular recognition processes," Angewandte Chemie, vol. 35, no. 8, pp. 807-826, 1996.

[6] B. Domon and R. Aebersold, "Mass spectrometry and protein analysis," Science, vol. 312, no. 5771, pp. 212-217, 2006.

[7] J. B. Fenn, "Electrospray wings for molecular elephants (Nobel lecture)," Angewandte Chemie, vol. 42, no. 33, pp. 3871-3894, 2003.

[8] Z. Ouyang, Z. Takáts, T. A. Blake et al., "Preparing protein microarrays by soft-landing of mass-selected ions," Science, vol. 301, no. 5638, pp. 1351-1354, 2003.

[9] B. Gologan, Z. Takáts, J. Alvarez et al., "Ion soft-landing into liquids: protein identification, separation, and purification with retention of biological activity," Journal of the American Society for Mass Spectrometry, vol. 15, no. 12, pp. 1874-1884, 2004.

[10] S. R. Wilson and Y. Wu, "Applications of electrospray ionization mass spectrometry to neutral organic molecules including fullerenes," Journal of the American Society for Mass Spectrometry, vol. 4, no. 7, pp. 596-603, 1993.

[11] C. E. C. A. Hop and R. Bakhtiar, "Electrospray ionization mass spectrometry. Part III: applications in inorganic chemistry and synthetic polymer chemistry," Journal of Chemical Education, vol. 73, no. 8, pp. A162-A169, 1996.

[12] M. J. Keith-Roach, "A review of recent trends in electrospray ionisation-mass spectrometry for the analysis of metalorganic ligand complexes," Analytica Chimica Acta, vol. 678, no. 2, pp. 140-148, 2010.

[13] I. Leito, K. Herodes, M. Huopolainen et al., "Towards the electrospray ionization mass spectrometry ionization efficiency scale of organic compounds," Rapid Communications in Mass Spectrometry, vol. 22, no. 3, pp. 379-384, 2008.

[14] M. Oss, A. Kruve, K. Herodes, and I. Leito, "Electrospray ionization efficiency scale of organic compound," Analytical Chemistry, vol. 82, no. 7, pp. 2865-2872, 2010.

[15] A. G. Baily, Electrostatic Spraying of Liquids, John Wiley \& Sons, New York, NY, USA, 1988.

[16] M. Dole, L. L. Mack, R. L. Hines et al., "Molecular beams of macroions," The Journal of Chemical Physics, vol. 49, no. 5, pp. 2240-2249, 1968.

[17] L. L. Mack, P. Kralik, A. Rheude, and M. Dole, "Molecular beams of macroions. II," The Journal of Chemical Physics, vol. 52, no. 10, pp. 4977-4986, 1970.

[18] M. Yamashita and J. B. Fenn, "Electrospray ion source. Another variation on the free-jet theme," Journal of Physical Chemistry, vol. 88, no. 20, pp. 4451-4459, 1984.
[19] M. Yamashita and J. B. Fenn, "Negative ion production with the electrospray ion source," Journal of Physical Chemistry, vol. 88, no. 20, pp. 4671-4675, 1984.

[20] C. M. Whitehouse, R. N. Dreyer, M. Yamashita, and J. B. Fenn, "Electrospray interface for liquid chromatographs and mass spectrometers," Analytical Chemistry, vol. 57, no. 3, pp. 675-679, 1985.

[21] A. P. Bruins, "Mass spectrometry with ion sources operating at atmospheric pressure," Mass Spectrometry Reviews, vol. 10, no. 1, pp. 53-77, 1991.

[22] P. Kebarle and L. Tang, "From ions in solution to ions in the gas phase: the mechanism of electrospray mass spectrometry," Analytical Chemistry, vol. 65, no. 22, pp. 972A-986A, 1993.

[23] M. Karas, U. Bahr, and T. Dülcks, "Nano-electrospray ionization mass spectrometry: addressing analytical problems beyond routine," Fresenius' Journal of Analytical Chemistry, vol. 366, no. 6-7, pp. 669-676, 2000.

[24] J. F. Anacleto, S. Pleasance, and R. K. Boyd, "Calibration of ion spray mass spectra using cluster ions," Organic Mass Spectrometry, vol. 27, pp. 660-666, 1992.

[25] C. E. C. A. Hop, "Generation of high molecular weight cluster ions by electrospray ionization; implications for mass calibration," Journal of Mass Spectrometry, vol. 31, pp. 1314-1316, 1996.

[26] A. P. Bruins, T. R. Covey, and J. D. Henion, "Ion spray interface for combined liquid chromatography/atmospheric pressure ionization mass spectrometry," Analytical Chemistry, vol. 59, no. 22, pp. 2642-2646, 1987.

[27] T. R. Covey, A. P. Bruins, and J. D. Henion, "Comparison of thermospray and ion spray mass spectrometry in an atmospheric pressure ion source," Organic Mass Spectrometry, vol. 23, pp. 178-186, 1988.

[28] M. G. Ikonomou, A. T. Blades, and P. Kebarle, "Electrosprayion spray: a comparison of mechanisms and performance," Analytical Chemistry, vol. 63, no. 18, pp. 1989-1998, 1991.

[29] J. F. Banks, J. P. Quinn, and C. M. Whilehouse, "LC/ESI-MS determination of proteins using conventional liquid chromatography and ultrasonically assisted electrospray," Analytical Chemistry, vol. 66, no. 21, pp. 3688-3695, 1994.

[30] J. F. Banks, S. Shen, C. M. Whitehouse, and J. B. Fenn, "Ultrasonically assisted electrospray ionization for LC/MS determination of nucleosides from a transfer RNA digest," Analytical Chemistry, vol. 66, no. 3, pp. 406-414, 1994.

[31] Z. Takáts, J. M. Wiseman, B. Gologan, and R. G. Cooks, "Electrosonic spray ionization. A gentle technique for generating folded proteins and protein complexes in the gas phase and for studying ion-molecule reactions at atmospheric pressure," Analytical Chemistry, vol. 76, no. 14, pp. 4050-4058, 2004.

[32] M. Wilm and M. Mann, "Analytical properties of the nanoelectrospray ion source," Analytical Chemistry, vol. 68, no. 1, pp. 1-8, 1996.

[33] E. D. Hoffmann and V. Stroobant, Mass Spectrometry Principles and Applications, John Wiley \& Sons, Chichester, UK, 2nd edition, 2001.

[34] J. H. Gross, Mass Spectrometry, Springer, Heidelberg, Germany, 2004.

[35] R. E. March, "An introduction to quadrupole ion trap mass spectrometry," Journal of Mass Spectrometry, vol. 32, no. 4, pp. 351-369, 1997.

[36] J. S. Allen, "An improved electron multiplier particle counter," Review of Scientific Instruments, vol. 18, no. 10, pp. 739749, 1947. 
[37] H. E. Stanton, W. A. Chupka, and M. G. Inghram, "Electron multipliers in mass spectrometry; effect of molecular structure," Review of Scientific Instruments, vol. 27, no. 2, p. 109, 1956.

[38] I. J. Amster, "Fourier transform mass spectrometry," Journal of Mass Spectrometry, vol. 31, no. 12, pp. 1325-1337, 1996.

[39] J. B. Fenn, "Ion formation from charged droplets: roles of geometry, energy, and time," Journal of the American Society for Mass Spectrometry, vol. 4, no. 7, pp. 524-535, 1993.

[40] J. F. J. Todd, "Recommendations for nomenclature and symbolism for mass spectroscopy," Pure and Applied Chemistry, vol. 63, pp. 1541-1566, 1991.

[41] T. R. Covey, R. F. Bonner, B. I. Shushan, and J. Henion, "The determination of protein, oligonucleotide and peptide molecular weights by ion-spray mass spectrometry," Rapid Communications in Mass Spectrometry, vol. 2, no. 11, pp. 249-256, 1988.

[42] J. R. Chapman, R. T. Gallagher, E. C. Barton, J. M. Curtis, and P. J. Derrick, "Advantages of high-resolution and high-mass range magnetic-sector mass spectrometry for electrospray ionization," Organic Mass Spectrometry, vol. 27, pp. 195-203, 1992.

[43] M. Mann, C. K. Meng, and J. B. Fenn, "Interpreting mass spectra of multiply charged ions," Analytical Chemistry, vol. 61, no. 15, pp. 1702-1708, 1989.

[44] M. Labowsky, C. Whitehouse, and J. B. Fenn, "Three-dimensional deconvolution of multiply charged spectra," Rapid Communications in Mass Spectrometry, vol. 7, pp. 71-84, 1993.

[45] G. Wang and R. B. Cole, "Effect of solution intic strength on analyte charge state distributions in positive and negative ion electrospray mass spectrometry," Analytical Chemistry, vol. 66, no. 21, pp. 3702-3708, 1994.

[46] R. Guevremont, K. W. M. Siu, J. C. Y. Le Blanc, and S. S. Berman, "Are the electrospray mass spectra of proteins related to their aqueous solution chemistry?" Journal of the American Society for Mass Spectrometry, vol. 3, no. 3, pp. 216224, 1992.

[47] M. A. Kelly, M. M. Vestling, C. C. Fenselau, and P. B. Smith, "Electrospray analysis of proteins: a comparison of positiveion and negative-ion mass spectra at high and low $\mathrm{pH}$," Organic Mass Spectrometry, vol. 27, pp. 1143-1147, 1992.

[48] G. Wang and R. B. Cole, "Disparity between solutionphase equilibria and charge state distributions in positive-ion electrospray mass spectrometry," Organic Mass Spectrometry, vol. 29, pp. 419-427, 1994.

[49] J. C. Y. Le Blanc, J. Wang, R. Guevremont, and K. W. M. Siu, "Electrospray mass spectra of protein cations formed in basic solutions," Organic Mass Spectrometry, vol. 29, pp. 587-593, 1994.

[50] J. A. Loo, C. G. Edmonds, H. R. Udseth, and R. D. Smith, "Effect of reducing disulfide-containing proteins on electrospray ionization mass spectra," Analytical Chemistry, vol. 62, no. 7, pp. 693-698, 1990.

[51] R. D. Smith, J. A. Loo, R. R. Ogorzalek Loo, M. Busman, and H. R. Udseth, "Principles and practice of electrospray ionization-mass spectrometry for large polypeptides and proteins," Mass Spectrometry Reviews, vol. 10, no. 5, pp. 359451, 1991.

[52] M. Cloupeau and B. Prunet-Foch, "Electrostatic spraying of liquids: main functioning," Journal of Electrostatics, vol. 25, pp. 165-184, 1990.
[53] R. B. Cole, "Some tenets pertaining to electrospray ionization mass spectrometry," Journal of Mass Spectrometry, vol. 35, no. 7, pp. 763-772, 2000.

[54] P. Kebarle and M. Peschke, "On the mechanisms by which the charged droplets produced by electrospray lead to gas phase ions," Analytica Chimica Acta, vol. 406, no. 1, pp. 11-35, 2000.

[55] N. B. Cech and C. G. Enke, "Practical implications of some recent studies in electrospray ionization fundamentals," Mass Spectrometry Reviews, vol. 20, no. 6, pp. 362-387, 2001.

[56] A. T. Blades, M. G. Ikonomou, and P. Kebarle, "Mechanism of electrospray mass spectrometry. Electrospray as an electrolysis cell," Analytical Chemistry, vol. 63, no. 19, pp. 2109-2114, 1991.

[57] G. Diehl and U. Karst, "On-line electrochemistry-MS and related techniques," Analytical and Bioanalytical Chemistry, vol. 373, no. 6, pp. 390-398, 2002.

[58] R. B. Cole, Electrospray and MALDI Mass Spectrometry, John Wiley \& Sons, New Jersey, NJ, USA, 2010.

[59] G. Taylor, "Disintegration of water drops in an electric field," Proceedings of the Royal Society of London A, vol. 280, pp. 383397, 1964.

[60] M. S. Wilm and M. Mann, "Electrospray and Taylor-Cone theory, Dole's beam of macromolecules at last?" International Journal of Mass Spectrometry and Ion Processes, vol. 136, no. 2-3, pp. 167-180, 1994.

[61] J. Fernandez De La Mora, "Electrospray ionization of large multiply charged species proceeds via Dole's charged residue mechanism," Analytica Chimica Acta, vol. 406, no. 1, pp. 93104, 2000.

[62] L. Rayleigh, "On the equilibrium of liquid conducting masses charged with electricity," Philosophical Magazine, pp. 184186, 1882.

[63] J. V. Iribarne and B. A. Thomson, "On the evaporation of small ions from charged droplets," The Journal of Chemical Physics, vol. 64, no. 6, pp. 2287-2294, 1976.

[64] A. Gomez and K. Tang, "Charge and fission of droplets in electrostatic sprays," Physics of Fluids, vol. 6, no. 1, pp. 404414, 1994.

[65] D. B. Hager, N. J. Dovichi, J. Klassen, and P. Kebarle, "Droplet electrospray mass spectrometry," Analytical Chemistry, vol. 66, no. 22, pp. 3944-3949, 1994.

[66] D. Duft, T. Achtzehn, R. Müller, B. A. Huber, and T. Leisner, "Coulomb fission: rayleigh jets from levitated microdroplets," Nature, vol. 421, no. 6919, p. 128, 2003.

[67] M. G. Ikonomou, A. T. Blades, and P. Kebarle, "Investigations of the electrospray interface for liquid chromatography/mass spectrometry," Analytical Chemistry, vol. 62, no. 9, pp. 957967, 1990.

[68] G. Schmelzeisen-Redeker, L. Bütfering, and F. W. Röllgen, "Desolvation of ions and molecules in thermospray mass spectrometry," International Journal of Mass Spectrometry and Ion Processes, vol. 90, no. 2, pp. 139-150, 1989.

[69] S. Nguyen and J. B. Fenn, "Gas-phase ions of solute species from charged droplets of solutions," Proceedings of the $\mathrm{Na}$ tional Academy of Sciences of the United States of America, vol. 104, no. 4, pp. 1111-1117, 2007.

[70] B. E. Winger, K. J. Light-Wahl, R. R. Ogorzalek Loo, H. R. Udseth, and R. D. Smith, "Observation and implications of high mass-to-charge ratio ions from electrospray ionization mass spectrometry," Journal of the American Society for Mass Spectrometry, vol. 4, no. 7, pp. 536-545, 1993. 
[71] L. P. Tolić, G. A. Anderson, R. D. Smith, H. M. Brothers, R. Spindler, and D. A. Tomalia, "Electrospray ionization Fourier transform ion cyclotron resonance mass spectrometric characterization of high molecular mass Starburst dendrimers," International Journal of Mass Spectrometry and Ion Processes, vol. 165-166, pp. 405-418, 1997.

[72] S. J. Valentine, J. G. Anderson, A. D. Ellington, and D. E. Clemmer, "Disulfide-intact and-reduced lysozyme in the gas phase: conformations and pathways of folding and unfolding," Journal of Physical Chemistry B, vol. 101, no. 19, pp. 3891-3900, 1997.

[73] B. A. Thomson and J. V. Iribarne, "Field induced ion evaporation from liquid surfaces at atmospheric pressure," The Journal of Chemical Physics, vol. 71, no. 11, pp. 44514463, 1979.

[74] P. Kebarle, "A brief overview of the present status of the mechanisms involved in electrospray mass spectrometry," Journal of Mass Spectrometry, vol. 35, no. 7, pp. 804-817, 2000.

[75] Z. Olumee, J. H. Callahan, and A. Vertes, "Droplet dynamics changes in electrostatic sprays of methanol-Water mixtures," Journal of Physical Chemistry A, vol. 102, no. 46, pp. 9154-9160, 1998.

[76] I. A. Kaltashov and R. R. Abzalimov, "Do ionic charges in ESI MS provide useful information on macromolecular structure?" Journal of the American Society for Mass Spectrometry, vol. 19, no. 9, pp. 1239-1246, 2008.

[77] I. A. Kaltashov and A. Mohimen, "Estimates of protein surface areas in solution by electrospray ionization mass spectrometry," Analytical Chemistry, vol. 77, no. 16, pp. 53705379, 2005.

[78] H. Prakash and S. Mazumdar, "Direct correlation of the crystal structure of proteins with the maximum positive and negative charge states of gaseous protein ions produced by electrospray ionization," Journal of the American Society for Mass Spectrometry, vol. 16, no. 9, pp. 1409-1421, 2005.

[79] R. Grandori, "Origin of the conformation dependence of protein charge-state distributions in electrospray ionization mass spectrometry," Journal of Mass Spectrometry, vol. 38, no. 1, pp. 11-15, 2003.

[80] L. Konermann and D. J. Douglas, "Acid-induced unfolding of cytochrome $\mathrm{c}$ at different methanol concentrations: electrospray ionization mass spectrometry specifically monitors changes in the tertiary structure," Biochemistry, vol. 36, no. 40, pp. 12296-12302, 1997.

[81] L. Konermann and D. J. Douglas, "Unfolding of proteins monitored by electrospray ionization mass spectrometry: a comparison of positive and negative ion modes," Journal of the American Society for Mass Spectrometry, vol. 9, no. 12, pp. 1248-1254, 1998.

[82] A. K. Frimpong, R. R. Abzalimov, S. J. Eyles, and I. A. Kaltashov, "Gas-phase interference-free analysis of protein ion charge-state distributions: detection of small-scale conformational transitions accompanying pepsin inactivation," Analytical Chemistry, vol. 79, no. 11, pp. 4154-4161, 2007.

[83] V. J. Nesatyy, "On the conformation-dependent neutralization theory and charging of individual proteins and their non-covalent complexes in the gas phase," Journal of Mass Spectrometry, vol. 39, no. 1, pp. 93-97, 2004.

[84] R. Grandori, "Origin of the conformation dependence of protein charge-state distributions in electrospray ionization mass spectrometry," Journal of Mass Spectrometry, vol. 38, no. 1, pp. 11-15, 2003.
[85] U. H. Verkerk, M. Peschke, and P. Kebarle, "Effect of buffer cations and of $\mathrm{H}_{3} \mathrm{O}^{+}$on the charge states of native proteins. Significance to determinations of stability constants of protein complexes," Journal of Mass Spectrometry, vol. 38, no. 6, pp. 618-631, 2003.

[86] R. R. Julian, R. Hodyss, and J. L. Beauchamp, "Salt bridge stabilization of charged zwitterionic arginine aggregates in the gas phase," Journal of the American Chemical Society, vol. 123, no. 15, pp. 3577-3583, 2001.

[87] P. D. Schnier, D. S. Gross, and E. R. Williams, "On the maximum charge state and proton transfer reactivity of peptide and protein ions formed by electrospray ionization," Journal of the American Society for Mass Spectrometry, vol. 6, no. 11, pp. 1086-1097, 1995.

[88] J. R. Chapman, Mass Spectrometry of Protein and Peptides, Humana Press, New Jersey, NJ, USA, 2000.

[89] T. B. McMahon and G. Ohanessian, "An experimental and $\mathrm{ab}$ initio study of the nature of the binding in gas-phase complexes of sodium ions," Chemistry A, vol. 6, no. 16, pp. 2931-2941, 2000.

[90] S. Hoyau, K. Norrman, T. B. McMahon, and G. Ohanessian, "A quantitative basis for a scale of $\mathrm{Na}^{+}$affinities of organic and small biological molecules in the gas phase," Journal of the American Chemical Society, vol. 121, no. 38, pp. 8864$8875,1999$.

[91] U. H. Verkerk and P. Kebarle, "Ion-ion and ion-molecule reactions at the surface of proteins produced by nanospray. Information on the number of acidic residues and control of the number of ionized acidic and basic residues," Journal of the American Society for Mass Spectrometry, vol. 16, no. 8, pp. 1325-1341, 2005.

[92] H. Prakash, B. T. Kansara, and S. Mazumdar, "Effects of salts on the charge-state distribution and the structural basis of the most-intense charge-state of the gaseous protein ions produced by electrospray ionization," International Journal of Mass Spectrometry, vol. 289, no. 2-3, pp. 84-91, 2010.

[93] N. Felitsyn, M. Peschke, and P. Kebarle, "Origin and number of charges observed on multiply-protonated native proteins produced by ESI," International Journal of Mass Spectrometry, vol. 219, no. 1, pp. 39-62, 2002.

[94] M. Peschke, A. Blades, and P. Kebarle, "Charged states of proteins. Reactions of doubly protonated alkyldiamines with $\mathrm{NH}_{3}$ : solvation or deprotonation. Extension of two proton cases to multiply protonated globular proteins observed in the gas phase," Journal of the American Chemical Society, vol. 124, no. 38, pp. 11519-11530, 2002.

[95] W. Z. Shou and W. Naidong, "Simple means to alleviate sensitivity loss by trifluoroacetic acid (TFA) mobile phases in the hydrophilic interaction chromatography-electrospray tandem mass spectrometric (HILIC-ESI/MS/MS) bioanalysis of basic compounds," Journal of Chromatography B, vol. 825, no. 2, pp. 186-192, 2005.

[96] A. T. Iavarone, J. C. Jurchen, and E. R. Williams, "Effects of solvent on the maximum charge state and charge state distribution of protein ions produced by electrospray ionization," Journal of the American Society for Mass Spectrometry, vol. 11, no. 11, pp. 976-985, 2000.

[97] R. R. Ogorzalek Loo, B. E. Winger, and R. D. Smith, "Proton transfer reaction studies of multiply charged proteins in a high mass-to-charge ratio quadrupole mass spectrometer," Journal of the American Society for Mass Spectrometry, vol. 5, no. 12, pp. 1064-1071, 1994. 
[98] B. E. Winger, K. J. Light-Wahl, and S. Richard, "Gas-phase proton transfer reactions involving multiply charged cytochrome c ions and water under thermal conditions," Journal of the American Society for Mass Spectrometry, vol. 3, no. 6, pp. 624-630, 1992.

[99] J. D. Carbeck, J. C. Severs, J. Gao, Q. Wu, R. D. Smith, and G. M. Whitesides, "Correlation between the charge of proteins in solution and in the gas phase investigated by protein charge ladders, capillary electrophoresis, and electrospray ionization mass spectrometry," Journal of Physical Chemistry B, vol. 102, no. 51, pp. 10596-10601, 1998.

[100] A. T. Iavarone and E. R. Williams, "Mechanism of charging and supercharging molecules in electrospray ionization," Journal of the American Chemical Society, vol. 125, no. 8, pp. 2319-2327, 2003.

[101] A. T. Iavarone, J. C. Jurchen, and E. R. Williams, "Supercharged protein and peptide ions formed by electrospray ionization," Analytical Chemistry, vol. 73, no. 7, pp. 1455-1460, 2001.

[102] J. A. Loo, R. R. Loo, H. R. Udseth, C. G. Edmonds, and R. D. Smith, "Solvent-induced conformational changes of polypeptides probed by electrospray-ionization mass spectrometry," Rapid Communications in Mass Spectrometry, vol. 5, no. 3, pp. 101-105, 1991.

[103] R. B. Cole and A. K. Harrata, "Solvent effect on analyte charge state, signal intensity, and stability in negative ion electrospray mass spectrometry; implications for the mechanism of negative ion formation," Journal of the American Society for Mass Spectrometry, vol. 4, pp. 546-556, 1993.

[104] H. J. Sterling and E. R. Williams, "Origin of supercharging in electrospray ionization of noncovalent complexes from aqueous solution," Journal of the American Society for Mass Spectrometry, vol. 20, no. 10, pp. 1933-1943, 2009.

[105] H. J. Sterling, M. P. Daly, G. K. Feld et al., "Effects of supercharging reagents on noncovalent complex structure in electrospray ionization from aqueous solutions," Journal of the American Society for Mass Spectrometry, vol. 21, no. 10, pp. 1762-1774, 2010.

[106] S. H. Lomeli, I. X. Peng, S. Yin, R. R. Ogorzalek Loo, and J. A. Loo, "New reagents for increasing ESI multiple charging of proteins and protein complexes," Journal of the American Society for Mass Spectrometry, vol. 21, no. 1, pp. 127-131, 2010.

[107] D. F. Hunt, J. R. Yates III, and J. Shabanowitz, "Protein sequencing by tandem mass spectrometry," Proceedings of the $\mathrm{Na}$ tional Academy of Sciences of the United States of America, vol. 83, no. 17, pp. 6233-6237, 1986.

[108] J. A. Loo, J. P. Quinn, S. I. Ryu, K. D. Henry, M. W. Senko, and F. W. McLafferty, "High-resolution tandem mass spectrometry of large biomolecules," Proceedings of the National Academy of Sciences of the United States of America, vol. 89, no. 1, pp. 286-289, 1992.

[109] A. T. Iavarone and E. R. Williams, "Collisionally activated dissociation of supercharged proteins formed by electrospray ionization," Analytical Chemistry, vol. 75, no. 17, pp. 45254533, 2003.

[110] X. Han, M. Jin, K. Breuker, and F. W. McLafferty, "Extending top-down mass spectrometry to proteins with masses great than 200 kilodaltons," Science, vol. 314, no. 5796, pp. 109$112,2006$.

[111] S. A. McLuckey and J. L. Stephenson, "Ion/ion chemistry of high-mass multiply charged ions," Mass Spectrometry Reviews, vol. 17, no. 6, pp. 369-407, 1998.
[112] S. J. Pitteri and S. A. McLuckey, "Recent developments in the ion/ion chemistry of high-mass multiply charged ions," Mass Spectrometry Reviews, vol. 24, no. 6, pp. 931-958, 2005.

[113] E. R. Williams, "Proton transfer reactivity of large multiply charged ions," Journal of Mass Spectrometry, vol. 31, no. 8, pp. 831-842, 1996.

[114] A. Kharlamova and S. A. McLuckey, "Negative electrospray droplet exposure to gaseous bases for the manipulation of protein charge state distributions," Analytical Chemistry, vol. 83, no. 1, pp. 431-437, 2011.

[115] A. Kharlamova, B. M. Prentice, T. Y. Huang, and S. A. McLuckey, "Electrospray droplet exposure to gaseous acids for the manipulation of protein charge state distributions," Analytical Chemistry, vol. 82, no. 17, pp. 7422-7429, 2010.

[116] C. J. Krusemark, B. L. Frey, P. J. Belshaw, and L. M. Smith, "Modifying the charge state distribution of proteins in electrospray ionization mass spectrometry by chemical derivatization," Journal of the American Society for Mass Spectrometry, vol. 20, no. 9, pp. 1617-1625, 2009.

[117] B. L. Frey, C. J. Krusemark, A. R. Ledvina, J. J. Coon, P. J. Belshaw, and L. M. Smith, "Ion-ion reactions with fixedcharge modified proteins to produce ions in a single, very high charge state," International Journal of Mass Spectrometry, vol. 276, no. 2-3, pp. 136-143, 2008.

[118] L. Tang and P. Kebarle, "Dependence of ion intensity in electrospray mass spectrometry on the concentration of the analytes in the electrosprayed solution," Analytical Chemistry, vol. 65, no. 24, pp. 3654-3667, 1993.

[119] G. Wang and R. B. Cole, "Mechanistic interpretation of the dependence of charge state distributions on analyte concentrations in electrospray ionization mass spectrometry," Analytical Chemistry, vol. 67, no. 17, pp. 2892-2900, 1995.

[120] L. Tang and P. Kebarle, "Effect of the conductivity of the electrosprayed solution on the electrospray current. Factors determining analyte sensitivity in electrospray mass spectrometry," Analytical Chemistry, vol. 63, no. 23, pp. 2709-2715, 1991.

[121] C. G. Enke, "A predictive model for matrix and analyte effects in electrospray ionization of singly-charged ionic analytes," Analytical Chemistry, vol. 69, no. 23, pp. 4885-4893, 1997.

[122] T. L. Constantopoulos, G. S. Jackson, and C. G. Enke, "Effects of salt concentration on analyte response using electrospray ionization mass spectrometry," Journal of the American Society for Mass Spectrometry, vol. 10, no. 7, pp. 625-634, 1999.

[123] Y. Li and R. B. Cole, "Shifts in peptide and protein charge state distributions with varying spray tip orifice diameter in nanoelectrospray fourier transform ion cycltron resonance mass spectrometry," Analytical Chemistry, vol. 75, no. 21, pp. 5739-5746, 2003.

[124] W. M. A. Niessen, "State-of-the-art in liquid chromatography-mass spectrometry," Journal of Chromatography A, vol. 856, pp. 179-197, 1999.

[125] R. D. Voyksner and H. Lee, "Improvements in LC/electrospray ion trap mass spectrometry performance using an offaxis nebulizer," Analytical Chemistry, vol. 71, no. 7, pp. 14411447, 1999.

[126] V. Gabelica, E. De Pauw, and M. Karas, "Influence of the capillary temperature and the source pressure on the internal energy distribution of electrosprayed ions," International Journal of Mass Spectrometry, vol. 231, no. 2-3, pp. 189-195, 2004. 
[127] M. Busman, A. L. Rockwood, and R. D. Smith, "Activation energies for gas-phase dissociations of multiply charged ions from electrospray ionization mass spectrometry," Journal of Physical Chemistry, vol. 96, no. 6, pp. 2397-2400, 1992.

[128] M. J. Van Stipdonk, M. P. Ince, B. A. Perera, and J. A. Martin, "Cluster ions derived from sodium and potassium tetrafluoroborate and their collision induced dissociation in an ion trap mass spectrometer," Rapid Communications in Mass Spectrometry, vol. 16, no. 5, pp. 355-363, 2002.

[129] R. D. Smith, J. A. Loo, C. J. Barinaga, C. G. Edmonds, and H. R. Udseth, "Collisional activation and collisionactivated dissociation of large multiply charged polypeptides and proteins produced by electrospray ionization," Journal of the American Society for Mass Spectrometry, vol. 1, no. 1, pp. 53-65, 1990.

[130] B. A. Thomson, "Declustering and fragmentation of protein ions from an electrospray ion source," Journal of the American Society for Mass Spectrometry, vol. 8, no. 10, pp. 1053-1058, 1997.

[131] D. S. Ashton, C. R. Beddell, D. J. Cooper, B. N. Green, and R. W. A. Oliver, "Mechanism of production of ions in electrospray mass spectrometry," Organic Mass Spectrometry, vol. 28, pp. 721-728, 1993.

[132] R. D. Smith, K. J. Light-Wahl, B. E. Winger, and J. A. Loo, "Preservation of non-covalent associations in electrospray ionization mass spectrometry: multiply charged polypeptide and protein dimers," Organic Mass Spectrometry, vol. 27, pp. 811-821, 1992.

[133] G. J. Van Berkel, F. Zhou, and J. T. Aronson, "Changes in bulk solution $\mathrm{pH}$ caused by the inherent controlled-current electrolytic process of an electrospray ion source," International Journal of Mass Spectrometry and Ion Processes, vol. 162, no. 1-3, pp. 55-67, 1997.

[134] S. Zhou, A. G. Edwards, K. D. Cook, and G. J. Van Berkel, "Investigation of the electrospray plume by laser-induced fluorescence spectroscopy," Analytical Chemistry, vol. 71, no. 4, pp. 769-776, 1999.

[135] C. L. Gatlin and F. Tureček, "Acidity determination in droplets formed by electrospraying methanol-water solutions," Analytical Chemistry, vol. 66, no. 5, pp. 712-718, 1994.

[136] S. E. Rodriguez-Cruz, J. T. Khoury, and J. H. Parks, "Protein fluorescence measurements within electrospray droplets," Journal of the American Society for Mass Spectrometry, vol. 12, no. 6, pp. 716-725, 2001.

[137] K. Breuker and F. W. McLafferty, "Stepwise evolution of protein native structure with electrospray into the gas phase, $10^{-12}$ to $10^{2} \mathrm{~s}$," Proceedings of the National Academy of Sciences of the United States of America, vol. 105, no. 47, pp. 1814518152, 2008.

[138] T. D. Wood, R. A. Chorush, F. M. Wampler, D. P. Little, P. B. O'Connor, and F. W. McLafferty, "Gas-phase folding and unfolding of cytochrome c cations," Proceedings of the National Academy of Sciences of the United States of America, vol. 92, no. 7, pp. 2451-2454, 1995.

[139] S. Banerjee, H. Prakash, and S. Mazumdar, "Evidence of molecular fragmentation inside the charged droplets produced by electrospray process," Journal of the American Society for Mass Spectrometry, vol. 22, no. 10, pp. 1707-1717, 2011.

[140] A. M. Gañán-Calvo, "The surface charge in electrospraying: its nature and its universal scaling laws," Journal of Aerosol Science, vol. 30, no. 7, pp. 863-872, 1999.

[141] Oxford English Dictionary, Oxford University Press, 2nd edition, 1989
[142] F. W. McLafferty, Tandem Mass Spectrometry, John Wiley \& Sons, New York, NY, USA, 1983.

[143] S. A. McLuckey, "Principles of collisional activation in analytical mass spectrometry," Journal of the American Society for Mass Spectrometry, vol. 3, no. 6, pp. 599-614, 1992.

[144] A. L. McCormack, J. L. Jones, and V. H. Wysocki, "Surfaceinduced dissociation of multiply protonated peptides," Journal of the American Society for Mass Spectrometry, vol. 3, no. 8, pp. 859-862, 1992.

[145] R. A. Chorush, D. P. Little, S. C. Beu, T. D. Wood, and F. W. McLafferty, "Surface-induced dissociation of multiplyprotonated proteins," Analytical Chemistry, vol. 67, no. 6, pp. 1042-1046, 1995.

[146] D. P. Little, J. P. Speir, M. W. Senko, P. B. O’Connor, and F. W. McLafferty, "Infrared multiphoton dissociation of large multiply charged ions for biomolecule sequencing," Analytical Chemistry, vol. 66, no. 18, pp. 2809-2815, 1994.

[147] W. D. Price, P. D. Schnier, and E. R. Williams, "Tandem mass spectrometry of large biomolecule ions by blackbody infrared radiative dissociation," Analytical Chemistry, vol. 68, no. 5, pp. 859-866, 1996.

[148] R. C. Dunbar and T. B. McMahon, "Activation of unimolecular reactions by ambient blackbody radiation," Science, vol. 279, no. 5348, pp. 194-197, 1998.

[149] M. S. Thompson, W. Cui, and J. P. Reilly, "Fragmentation of singly charged peptide ions by photodissociation at $\lambda=$ 157 nm," Angewandte Chemie, vol. 43, no. 36, pp. 4791-4794, 2004.

[150] Z. Guan, N. L. Kelleher, P. B. O’Connor, D. J. Aaserud, D. P. Little, and F. W. McLafferty, "193 nm photodissociation of larger multiply-charged biomolecules," International Journal of Mass Spectrometry and Ion Processes, vol. 157-158, pp. 357364, 1996.

[151] R. A. Zubarev, N. L. Kelleher, and F. W. McLafferty, "Electron capture dissociation of multiply charged protein cations. A nonergodic process," Journal of the American Chemical Society, vol. 120, no. 13, pp. 3265-3266, 1998.

[152] J. E. P. Syka, J. J. Coon, M. J. Schroeder, J. Shabanowitz, and D. F. Hunt, "Peptide and protein sequence analysis by electron transfer dissociation mass spectrometry," Proceedings of the National Academy of Sciences of the United States of America, vol. 101, no. 26, pp. 9528-9533, 2004.

[153] B. A. Budnik, K. F. Haselmann, and R. A. Zubarev, "Electron detachment dissociation of peptide di-anions: an electronhole recombination phenomenon," Chemical Physics Letters, vol. 342, no. 3-4, pp. 299-302, 2001.

[154] R. B. Cody, "Electron impact excitation of ions from organics: an alternative to collision induced dissociation," Analytical Chemistry, vol. 51, no. 4, pp. 547-551, 1979.

[155] R. W. Vachet and G. L. Glish, "Effects of heavy gases on the tandem mass spectra of peptide ions in the quadrupole ion trap," Journal of the American Society for Mass Spectrometry, vol. 7, no. 12, pp. 1194-1202, 1996.

[156] R. Boyd and A. Somogyi, "The mobile proton hypothesis in fragmentation of protonated peptides: a perspective," Journal of the American Society for Mass Spectrometry, vol. 21, pp. 1275-1278, 2010.

[157] X. J. Tang, P. Thibault, and R. K. Boyd, "Fragmentation reactions of multiply-protonated peptides and implications for sequencing by tandem mass spectrometry with lowenergy collision-induced dissociation," Analytical Chemistry, vol. 65, no. 20, pp. 2824-2834, 1993. 
[158] R. S. Bordoli and R. H. Bateman, "The effect of collision energy, target gas and target gas purity on the high energy collision induced product ion spectrum of renin substrate," International Journal of Mass Spectrometry and Ion Processes, vol. 122, pp. 243-254, 1992.

[159] W. J. Griffiths, A. P. Jonsson, S. Liu, D. K. Rai, and Y. Wang, "Electrospray and tandem mass spectrometry in biochemistry," Biochemical Journal, vol. 355, no. 3, pp. 545-561, 2001.

[160] M. Kinter and N. E. Sherman, Protein Sequencing and Identification Using Tandem Mass Spectrometry, Wiley-Interscience, New York, NY, USA, 2000.

[161] V. H. Wysocki, G. Cheng, Q. Zhang, K. A. Herrmann, R. L. Beardsley, and A. E. Hilderbrand, in Principles of Mass Spectrometry Applied to Biomolecules, pp. 277-300, John Wiley \& Sons, 2006.

[162] M. L. Gross, "Charge-remote fragmentations: method, mechanism and applications," International Journal of Mass Spectrometry and Ion Processes, vol. 118-119, pp. 137-165, 1992.

[163] K. Biemann and A. M. James, in Methods in Enzymology, vol. 193, pp. 455-479, Academic Press, 1990.

[164] B. Paizs and S. Suhai, "Towards understanding the tandem mass spectra of protonated oligopeptides. 1: mechanism of amide bond cleavage," Journal of the American Society for Mass Spectrometry, vol. 15, no. 1, pp. 103-113, 2004.

[165] H. H. Hill, C. H. Hill, G. R. Asbury, C. Wu, L. M. Matz, and T. Ichiye, "Charge location on gas phase peptides," International Journal of Mass Spectrometry, vol. 219, no. 1, pp. 23-37, 2002.

[166] C. Afonso, F. Modeste, P. Breton, F. Fournier, and J. C. Tabet, "Proton affinities of the commonly occuring L-amino acids by using electrospray ionization-ion trap mass spectrometry," European Journal of Mass Spectrometry, vol. 6, no. 5, pp. 443-449, 2000.

[167] C. Bleiholder, S. Suhai, and B. Paizs, "Revising the proton affinity scale of the naturally occurring $\alpha$-amino acids," Journal of the American Society for Mass Spectrometry, vol. 17, no. 9, pp. 1275-1281, 2006.

[168] V. H. Wysocki, G. Tsaprailis, L. L. Smith, and L. A. Breci, "Mobile and localized protons: a framework for understanding peptide dissociation," Journal of Mass Spectrometry, vol. 35, no. 12, pp. 1399-1406, 2000.

[169] A. R. Dongre, J. L. Jones, A. Somogyi, and V. H. Wysocki, "Influence of peptide composition, gas-phase basicity, and chemical modification on fragmentation efficiency: evidence for the mobile proton model," Journal of the American Chemical Society, vol. 118, no. 35, pp. 8365-8374, 1996.

[170] A. G. Harrison and T. Yalcin, "Proton mobility in protonated amino acids and peptides," International Journal of Mass Spectrometry and Ion Processes, vol. 165-166, pp. 339-347, 1997.

[171] I. P. Csonka, B. Paizs, G. Lendvay, and S. Suhai, "Proton mobility in protonated peptides: a joint molecular orbital and RRKM study," Rapid Communications in Mass Spectrometry, vol. 14, no. 6, pp. 417-431, 2000.

[172] B. Paizs and S. Suhai, "Theoretical study of the main fragmentation pathways for protonated glycylglycine," Rapid Communications in Mass Spectrometry, vol. 15, no. 8, pp. 651-663, 2001.

[173] B. Palzs and S. Suhal, "Fragmentation pathways of protonated peptides," Mass Spectrometry Reviews, vol. 24, no. 4, pp. 508-548, 2005.

[174] P. Roepstorff and J. Fohlman, "Proposal for a common nomenclature for sequence ions in mass spectra of peptides," Biomedical Mass Spectrometry, vol. 11, no. 11, p. 601, 1984.
[175] K. Biemann, "Contributions of mass spectrometry to peptide and protein structure," Biomedical and Environmental Mass Spectrometry, vol. 16, no. 1-12, pp. 99-111, 1988.

[176] K. D. Ballard and S. J. Gaskell, "Sequential mass spectrometry applied to the study of the formation of "internal" fragment ions of protonated peptides," International Journal of Mass Spectrometry and Ion Processes, vol. 111, no. C, pp. 173-189, 1991.

[177] K. Ambihapathy, T. Yalcin, H. W. Leung, and A. G. Harrison, "Pathways to immonium ions in the fragmentation of protonated peptides," Journal of Mass Spectrometry, vol. 32, no. 2, pp. 209-215, 1997.

[178] S. Sun, C. Yu, Y. Qiao et al., "Deriving the probabilities of water loss and ammonia loss for amino acids from tandem mass spectra," Journal of Proteome Research, vol. 7, no. 1, pp. 202-208, 2008.

[179] J. E. McClellan, S. T. Quarmby, and R. A. Yost, "Parent and neutral loss monitoring on a quadrupole ion trap mass spectrometer: screening of acylcarnitines in complex mixtures," Analytical Chemistry, vol. 74, no. 22, pp. 5799-5806, 2002.

[180] A. G. Harrison, A. B. Young, C. Bleiholder, S. Suhai, and B. Paizs, "Scrambling of sequence information in collisioninduced dissociation of peptides," Journal of the American Chemical Society, vol. 128, no. 32, pp. 10364-10365, 2006.

[181] A. G. Harrison and A. B. Young, "Fragmentation of protonated oligoalanines: amide bond cleavage and beyond," Journal of the American Society for Mass Spectrometry, vol. 15, no. 12, pp. 1810-1819, 2004.

[182] T. Yalcin, C. Khouw, I. G. Csizmadia, M. R. Peterson, and A. G. Harrison, "Why are B ions stable species in peptide spectra?" Journal of the American Society for Mass Spectrometry, vol. 6, no. 12, pp. 1165-1174, 1995.

[183] H. Nair, A. Somogyi, and V. H. Wysocki, "Effect of alkyl substitution at the amide nitrogen on amide bond cleavage: electrospray ionization/surface-induced dissociation fragmentation of substance P and two alkylated analogs," Journal of Mass Spectrometry, vol. 31, no. 10, pp. 1141-1148, 1996.

[184] R. W. Vachet, B. M. Bishop, B. W. Erickson, and G. L. Glish, "Novel peptide dissociation: gas-phase intramolecular rearrangement of internal amino acid residues," Journal of the American Chemical Society, vol. 119, no. 24, pp. 5481-5488, 1997.

[185] J. V. Olsen and M. Mann, "Improved peptide identification in proteomics by two consecutive stages of mass spectrometric fragmentation," Proceedings of the National Academy of Sciences of the United States of America, vol. 101, no. 37, pp. 13417-13422, 2004.

[186] Tang Xue Jun and R. K. Boyd, "Rearrangements of doubly charged acylium ions from lysyl and ornithyl peptides," Rapid Communications in Mass Spectrometry, vol. 8, no. 9, pp. 678686, 1994.

[187] J. Yaqüe, A. Paradela, M. Ramos et al., "Peptide rearrangement during quadrupole ion trap fragmentation: added complexity to MS/MS spectra," Analytical Chemistry, vol. 75, no. 6, pp. 1524-1535, 2003.

[188] C. Bleiholder, S. Osburn, T. D. Williams et al., "Sequencescrambling fragmentation pathways of protonated peptides," Journal of the American Chemical Society, vol. 130, no. 52, pp. 17774-17789, 2008.

[189] C. Jia, W. Qi, and Z. He, "Cyclization reaction of peptide fragment Ions during multistage collisionally activated decomposition: an inducement to lose internal amino-acid residues," Journal of the American Society for Mass Spectrometry, vol. 18, no. 4, pp. 663-678, 2007. 
[190] A. G. Harrison, "Peptide sequence scrambling through cyclization of b5 Ions," Journal of the American Society for Mass Spectrometry, vol. 19, no. 12, pp. 1776-1780, 2008.

[191] S. Molesworth, S. Osburn, and M. Van Stipdonk, "Influence of amino acid side chains on apparent selective opening of cyclic b5 ions," Journal of the American Society for Mass Spectrometry, vol. 21, no. 6, pp. 1028-1036, 2010.

[192] L. Mouls, J. L. Aubagnac, J. Martinez, and C. Enjalbal, "Low energy peptide fragmentations in an ESI-Q-Tof type mass spectrometer," Journal of Proteome Research, vol. 6, no. 4, pp. 1378-1391, 2007.

[193] L. Yu, Y. Tan, Y. Tsai, D. R. Goodlett, and N. C. Polfer, "On the relevance of peptide sequence permutations in shotgun proteomics studies," Journal of Proteome Research, vol. 10, no. 5, pp. 2409-2416, 2011.

[194] A. A. Goloborodko, M. V. Gorshkov, D. M. Good, and R. A. Zubarev, "Sequence scrambling in shotgun proteomics is negligible," Journal of the American Society for Mass Spectrometry, vol. 22, no. 7, pp. 1121-1124, 2011.

[195] D. Pu and C. J. Cassady, "Negative ion dissociation of peptides containing hydroxyl side chains," Rapid Communications in Mass Spectrometry, vol. 22, no. 2, pp. 91-100, 2008.

[196] J. H. Bowie, C. S. Brinkworth, and S. Dua, "Collisioninduced fragmentations of the (M-H)-parent anions of underivatized peptides: an aid to structure determination and some unusual negative ion cleavages," Mass Spectrometry Reviews, vol. 21, no. 2, pp. 87-107, 2002.

[197] A. G. Harrison and A. B. Young, "Fragmentation of deprotonated N-benzoylpeptides: formation of deprotonated oxazolones," Journal of the American Society for Mass Spectrometry, vol. 15, no. 4, pp. 446-456, 2004.

[198] N. L. Clipston, J. Jai-nhuknan, and C. J. Cassady, "A comparison of negative and positive ion time-of-flight postsource decay mass spectrometry for peptides containing basic residues," International Journal of Mass Spectrometry, vol. 222, no. 1-3, pp. 363-381, 2003.

[199] A. L. McCormack, A. Somogyi, A. R. Dongre, and V. H. Wysocki, "Fragmentation of protonated peptides: surfaceinduced dissociation in conjunction with a quantum mechanical approach," Analytical Chemistry, vol. 65, no. 20, pp. 2859-2872, 1993.

[200] G. E. Reid, R. J. Simpson, and R. A. J. O’Hair, “Leaving group and gas phase neighboring group effects in the side chain losses from protonated serine and its derivatives," Journal of the American Society for Mass Spectrometry, vol. 11, no. 12, pp. 1047-1060, 2000.

[201] R. J. Ferrier, Carbohydrate Chemistry, vol. 33, Royal Society of Chemistry, Cambridge, UK, 2002.

[202] B. Domon and C. E. Costello, "A systematic nomenclature for carbohydrate fragmentations in FAB-MS/MS spectra of glycoconjugates," Glycoconjugate Journal, vol. 5, no. 4, pp. 397-409, 1988.

[203] J. Lemoine, B. Fournet, D. Despeyroux, K. R. Jennings, R. Rosenberg, and E. de Hoffmann, "Collision-induced dissociation of alkali metal cationized and permethylated oligosaccharides: influence of the collision energy and of the collision gas for the assignment of linkage position," Journal of the American Society for Mass Spectrometry, vol. 4, no. 3, pp. 197-203, 1993.

[204] D. J. Harvey, "Collision-induced fragmentation of underivatized N-linked carbohydrates ionized by electrospray," Journal of Mass Spectrometry, vol. 35, no. 10, pp. 1178-1190, 2000.
[205] A. Pfenninger, M. Karas, B. Finke, and B. Stahl, "Structural analysis of underivatized neutral human milk oligosaccharides in the negative ion mode by nano-electrospray $\mathrm{M}^{S n}$ (Part 1: methodology)," Journal of the American Society for Mass Spectrometry, vol. 13, no. 11, pp. 1331-1340, 2002.

[206] W. Chai, V. Piskarev, and A. M. Lawson, "Negative-ion electrospray mass spectrometry of neutral underivatized oligosaccharides," Analytical Chemistry, vol. 73, no. 3, pp. 651657, 2001.

[207] D. Garozzo, M. Giuffrida, G. Impallomeni, A. Ballistreri, and G. Mon taudo, "Determination of linkage position and identification of the reducing end in linear oligosaccharides by negative ion fast atom bombardment mass spectrometry," Analytical Chemistry, vol. 62, no. 3, pp. 279-286, 1990.

[208] S. A. McLuckey, G. J. Van Berker, and G. L. Glish, “Tandem mass spectrometry of small, multiply charged oligonucleotides," Journal of the American Society for Mass Spectrometry, vol. 3, no. 1, pp. 60-70, 1992.

[209] E. Nordhoff, M. Karas, R. Cramer et al., "Direct mass spectrometric sequencing of low-picomole amounts of oligodeoxynucleotides with up to 21 bases by matrix-assisted laser desorption/ionization mass spectrometry," Journal of Mass Spectrometry, vol. 30, no. 1, pp. 99-112, 1995.

[210] J. P. Barry, P. Vouros, A. Van Schepdael, and S. J. Law, "Mass and sequence verification of modified oligonucleotides using electrospray tandem mass spectrometry," Journal of Mass Spectrometry, vol. 30, no. 7, pp. 993-1006, 1995.

[211] M. G. Bartlett, J. A. McCloskey, S. Manalili, and R. H. Griffey, "The effect of backbone charge on the collision-induced dissociation of oligonucleotides," Journal of Mass Spectrometry, vol. 31, no. 11, pp. 1277-1283, 1996.

[212] S. A. McLuckey and S. Habibi-Goudarzi, "Decompositions of multiply charged oligonucleotide anions," Journal of the American Chemical Society, vol. 115, no. 25, pp. 1208512095, 1993.

[213] R. L. Hettich and E. A. Stemmler, "Investigation of oligonucleotide fragmentation with matrix-assisted laser desorption/ ionization fourier-transform mass spectrometry and sustained off-resonance irradiation," Rapid Communications in Mass Spectrometry, vol. 10, no. 3, pp. 321-327, 1996.

[214] W. J. Griffiths, Y. Yang, J. A. Lindgren, and J. Sjövall, "Charge remote fragmentation of fatty acid anions in $400 \mathrm{eV}$ collisions with xenon atoms," Rapid Communications in Mass Spectrometry, vol. 10, no. 1, pp. 21-28, 1996.

[215] E. Fahy, S. Subramaniam, H. A. Brown et al., "A comprehensive classification system for lipids," Journal of Lipid Research, vol. 46, no. 5, pp. 839-861, 2005.

[216] K. B. Tomer, F. W. Crow, and M. L. Gross, "Location of double bond position in unsaturated fatty acids by negative ion MS/MS," Journal of the American Chemical Society, vol. 105, no. 16, pp. 5487-5488, 1983.

[217] W. J. Griffiths, "Tandem mass spectrometry in the study of fatty acids, bile acids, and steroids," Mass Spectrometry Reviews, vol. 22, no. 2, pp. 81-152, 2003.

[218] V. H. Wysocki and M. M. Ross, "Charge-remote fragmentation of gas-phase ions: mechanistic and energetic considerations in the dissociation of long-chain functionalized alkanes and alkenes," International Journal of Mass Spectrometry and Ion Processes, vol. 104, no. 3, pp. 179-211, 1991.

[219] W. J. Griffiths, A. Brown, R. Reimendal, Y. Yang, J. Zhang, and J. Sjövall, "A comparison of fast-atom bombardment and electrospray as methods of ionization in the study of 
sulphated- and sulphonated-lipids by tandem mass spectrometry," Rapid Communications in Mass Spectrometry, vol. 10, no. 10, pp. 1169-1174, 1996.

[220] P. Roepstorff, "Mass spectrometry in protein studies from genome to function," Current Opinion in Biotechnology, vol. 8, no. 1, pp. 6-13, 1997.

[221] J. R. Yates, "Mass spectrometry and the age of the proteome," Journal of Mass Spectrometry, vol. 33, no. 1, pp. 1-19, 1998.

[222] D. J. C. Pappin, P. Hojrup, and A. J. Bleasby, "Rapid identification of proteins by peptide-mass fingerprinting," Current Biology, vol. 3, no. 6, pp. 327-332, 1993.

[223] B. M. Mayr, O. Kohlbacher, K. Reinert et al., "Absolute myoglobin quantitation in serum by combining twodimensional liquid chromatography-electrospray ionization mass spectrometry and novel data analysis algorithms," Journal of Proteome Research, vol. 5, no. 2, pp. 414-421, 2006.

[224] Y. Oda, K. Huang, F. R. Cross, D. Cowburn, and B. T. Chait, "Accurate quantitation of protein expression and site-specific phosphorylation," Proceedings of the National Academy of Sciences of the United States of America, vol. 96, no. 12, pp. 6591-6596, 1999.

[225] J. A. Loo, "Electrospray ionization mass spectrometry: a technology for studying noncovalent macromolecular complexes," International Journal of Mass Spectrometry, vol. 200, no. 1-3, pp. 175-186, 2000.

[226] E. T. J. Van den Bremer, W. Jiskoot, R. James et al., "Probing metal ion binding and conformational properties of the colicin E9 endonuclease by electrospray ionization time-offlight mass spectrometry," Protein Science, vol. 11, no. 7, pp. 1738-1752, 2002.

[227] S. K. Chowdhury, V. Katta, and B. T. Chait, "Probing conformational changes in proteins by mass spectrometry," Journal of the American Chemical Society, vol. 112, no. 24, pp. 90129013, 1990.

[228] J. S. Andersen, B. Svensson, and P. Roepstorff, "Electrospray ionization and matrix assisted laser desorption/ionization mass spectrometry: powerful analytical tools in recombinant protein chemistry," Nature Biotechnology, vol. 14, no. 4, pp. 449-457, 1996.

[229] H. D. Niall and S. N. T. C. H. W. Hirs, in Methods in Enzymology, vol. 27, pp. 942-1010, Academic Press, 1973.

[230] J. A. Loo, C. G. Edmonds, and R. D. Smith, "Primary sequence information from intact proteins by electrospray ionization tandem mass spectrometry," Science, vol. 248, no. 4952, pp. 201-204, 1990.

[231] K. Biemann, "Sequencing of peptides by tandem mass spectrometry and high-energy collision-induced dissociation," Methods in Enzymology, vol. 193, pp. 455-479, 1990.

[232] J. A. Taylor and R. S. Johnson, "Sequence database searches via de Novo peptide sequencing by tandem mass spectrometry," Rapid Communications in Mass Spectrometry, vol. 11, no. 9, pp. 1067-1075, 1997.

[233] A. Armirotti, "Bottom-up proteomics," Current Analytical Chemistry, vol. 5, no. 2, pp. 116-130, 2009.

[234] H. Zhong, Y. Zhang, Z. Wen, and L. Li, "Protein sequencing by mass analysis of polypeptide ladders after controlled protein hydrolysis," Nature Biotechnology, vol. 22, no. 10, pp. 1291-1296, 2004.

[235] G. E. Reid and S. A. McLuckey, “"Top down” protein characterization via tandem mass spectrometry," Journal of Mass Spectrometry, vol. 37, no. 7, pp. 663-675, 2002.

[236] M. Mann and O. N. Jensen, "Proteomic analysis of posttranslational modifications," Nature Biotechnology, vol. 21, no. 3, pp. 255-261, 2003.
[237] M. A. Freitas, A. R. Sklenar, and M. R. Parthun, "Application of mass spectrometry to the identification and quantification of histone post-translational modifications," Journal of Cellular Biochemistry, vol. 92, no. 4, pp. 691-700, 2004.

[238] H. Oberacher, C. G. Huber, and P. J. Oefner, "Mutation scanning by ion-pair reversed-phase high-performance liquid chromatography-electrospray ionization mass spectrometry (ICEMS)," Human Mutation, vol. 21, no. 1, pp. 86-95, 2003.

[239] L. Zhang, E. E. Eugeni, M. R. Parthun, and M. A. Freitas, "Identification of novel histone post-translational modifications by peptide mass fingerprinting," Chromosoma, vol. 112, no. 2, pp. 77-86, 2003.

[240] H. Prakash and S. Mazumdar, "Succinylation of cytochrome c investigated by electrospray ionization mass spectrometry: reactive lysine residues," International Journal of Mass Spectrometry, vol. 281, no. 1-2, pp. 55-62, 2009.

[241] S. Goyal, M. S. Deshpande, and S. Mazumdar, "Structural design of the active site for covalent attachment of the heme to the protein matrix: atudies on a thermostable cytochrome P450," Biochemistry, vol. 50, no. 6, pp. 1042-1052, 2011.

[242] T. Y. Yen, H. Yan, and B. A. Macher, "Characterizing closely spaced, complex disulfide bond patterns in peptides and proteins by liquid chromatography/electrospray ionization tandem mass spectrometry," Journal of Mass Spectrometry, vol. 37, no. 1, pp. 15-30, 2002.

[243] D. L. Smith, Z. Zhou, and A. M. James, in Methods in Enzymology, vol. 193, pp. 1296-1291, Academic Press, 1990.

[244] M. Scigelova, P. S. Green, A. E. Giannakopulos et al., "A practical protocol for the reduction of disulfide bonds in proteins prior to analysis by mass spectrometry," European Journal of Mass Spectrometry, vol. 7, pp. 29-34, 2001.

[245] S. Y. Gauthier, C. M. Kay, B. D. Sykes, V. K. Walker, and P. L. Davies, "Disulfide bond mapping and structural characterization of spruce budworm antifreeze protein," European Journal of Biochemistry, vol. 258, no. 2, pp. 445-453, 1998.

[246] M. Zhang and I. A. Kaltashov, "Mapping of protein disulfide bonds using negative ion fragmentation with a broadband precursor selection," Analytical Chemistry, vol. 78, no. 14, pp. 4820-4829, 2006.

[247] J. Wu, "Disulfide bond mapping by cyanylation-induced cleavage and mass spectrometry," Methods in Molecular Biology, vol. 446, pp. 1-20, 2008.

[248] R. D. Smith and K. J. Light-Wahl, "The observation of noncovalent interactions in solution by electrospray ionization mass spectrometry: promise, pitfalls and prognosis," Biological Mass Spectrometry, vol. 22, no. 9, pp. 493-501, 1993.

[249] T. D. Veenstra, "Electrospray ionization mass spectrometry in the study of biomolecular non-covalent interactions," Biophysical Chemistry, vol. 79, no. 2, pp. 63-79, 1999.

[250] B. N. Pramanik, P. L. Bartner, U. A. Mirza, Y. H. Liu, and A. K. Ganguly, "Electrospray ionization mass spectrometry for the study of non-covalent complexes: an emerging technology," Journal of Mass Spectrometry, vol. 33, no. 10, pp. 911-920, 1998.

[251] S. Y. Sheu, D. Y. Yang, H. L. Selzle, and E. W. Schlag, "Energetics of hydrogen bonds in peptides," Proceedings of the National Academy of Sciences of the United States of America, vol. 100, no. 22, pp. 12683-12687, 2003.

[252] M. F. Jarrold, "Peptides and proteins in the vapor phase," Annual Review of Physical Chemistry, vol. 51, pp. 179-207, 2000.

[253] S. Banerjee and S. Mazumdarc, "Non-covalent dimers of the lysine containing protonated peptide ions in gaseous state: electrospray ionizationmass spectrometric study," Journal of Mass Spectrometry, vol. 45, no. 10, pp. 1212-1219, 2010. 
[254] E. N. Kitova, M. Seo, P. N. Roy, and J. S. Klassen, "Elucidating the intermolecular interactions within a desolvated proteinligand complex. An experimental and computational study," Journal of the American Chemical Society, vol. 130, no. 4, pp. 1214-1226, 2008.

[255] B. Qiu, J. Liu, Z. Qin, G. Wang, and H. Luo, "Quintets of uracil and thymine: a novel structure of nucleobase selfassembly studied by electrospray ionization mass spectrometry," Chemical Communications, no. 20, pp. 2863-2865, 2009.

[256] J. A. Loo, "Studying noncovalent protein complexes by electrospray ionization mass spectrometry," Mass Spectrometry Reviews, vol. 16, no. 1, pp. 1-23, 1997.

[257] D. Lafitte, A. J. R. Heck, T. J. Hill, K. Jumel, S. E. Harding, and P. J. Derrick, "Evidence of noncovalent dimerization of calmodulin," European Journal of Biochemistry, vol. 261, no. 1, pp. 337-344, 1999.

[258] J. A. Loo, "Probing protein-metal ion interactions by electrospray ionization mass spectrometry: enolase and nucleocapsid protein," International Journal of Mass Spectrometry, vol. 204, no. 1-3, pp. 113-123, 2001.

[259] K. Benkestock, P. O. Edlund, and J. Roeraade, "Electrospray ionization mass spectrometry as a tool for determination of drug binding sites to human serum albumin by noncovalent interaction," Rapid Communications in Mass Spectrometry, vol. 19, no. 12, pp. 1637-1643, 2005.

[260] H. Steen and N. Jensen, "Analysis of protein-nucleic acid interactions by photochemical cross-linking and mass spectrometry," Mass Spectrometry Reviews, vol. 21, no. 3, pp. 163$182,2002$.

[261] A. Tjernberg, S. Carnö, F. Oliv et al., "Determination of dissociation constants for protein-ligand complexes by electrospray ionization mass spectrometry," Analytical Chemistry, vol. 76, no. 15, pp. 4325-4331, 2004.

[262] L. Liu, D. Bagal, E. N. Kitova, P. D. Schnier, and J. S. Klassen, "Hydrophobic protein-ligand interactions preserved in the gas phase," Journal of the American Chemical Society, vol. 131, no. 44, pp. 15980-15981, 2009.

[263] N. P. Barrera, N. Di Bartolo, P. J. Booth, and C. V. Robinson, "Micelles protect membrane complexes from solution to vacuum," Science, vol. 321, no. 5886, pp. 243-246, 2008.

[264] M. C. Crowe and J. S. Brodbelt, "Evaluation of noncovalent interactions between peptides and polyether compounds via energy-variable collisionally activated dissociation," Journal of the American Society for Mass Spectrometry, vol. 14, no. 10, pp. 1148-1157, 2003.

[265] W. M. David and J. S. Brodbelt, "Threshold dissociation energies of protonated amine/polyether complexes in a quadrupole ion trap," Journal of the American Society for Mass Spectrometry, vol. 14, no. 4, pp. 383-392, 2003.

[266] C. S. Ho, C. W. K. Lam, M. H. M. Chan et al., "Electrospray ionisation mass spectrometry: principles and clinical applications," Clinical Biochemistry Review, vol. 24, pp. 3-12, 2003.

[267] M. S. Rashed, M. P. Bucknall, D. Little et al., "Screening blood spots for inborn errors of metabolism by electrospray tandem mass spectrometry with a microplate batch process and a computer algorithm for automated flagging of abnormal profiles," Clinical Chemistry, vol. 43, no. 7, pp. 1129-1141, 1997.

[268] D. H. Chace, J. E. Sherwin, S. L. Hillman, F. Lorey, and G. C. Cunningham, "Use of phenylalanine-to-tyrosine ratio determined by tandem mass spectrometry to improve newborn screening for phenylketonuria of early discharge specimens collected in the first 24 hours," Clinical Chemistry, vol. 44, no. 12, pp. 2405-2409, 1998.
[269] D. H. Chace, J. C. DiPerna, B. L. Mitchell, B. Sgroi, L. F. Hofman, and E. W. Naylor, "Electrospray tandem mass spectrometry for analysis of acylcarnitines in dried postmortem blood specimens collected at autopsy from infants with unexplained cause of death," Clinical Chemistry, vol. 47, no. 7, pp. 1166-1182, 2001.

[270] T. Ito, A. B. P. Van Kuilenburg, A. H. Bootsma et al., "Rapid screening of high-risk patients for disorders of purine and pyrimidine metabolism using HPLC-electrospray tandem mass spectrometry of liquid urine or urine-soaked filter paper strips," Clinical Chemistry, vol. 46, no. 4, pp. 445-452, 2000.

[271] U. G. Jensen, N. J. Brandt, E. Christensen, F. Skovby, B. Nørgaard-Pedersen, and H. Simonsen, "Neonatal screening for galactosemia by quantitative analysis of hexose monophosphates using tandem mass spectrometry: a retrospective study," Clinical Chemistry, vol. 47, no. 8, pp. 1364-1372, 2001.

[272] D. W. Johnson, "A rapid screening procedure for the diagnosis of peroxisomal disorders: quantification of very longchain fatty acids, as dimethylaminoethyl esters, in plasma and blood spots, by electrospray tandem mass spectrometry," Journal of Inherited Metabolic Disease, vol. 23, no. 5, pp. 475486, 2000.

[273] A. H. Bootsma, H. Overmars, A. Van Rooij et al., "Rapid analysis of conjugated bile acids in plasma using electrospray tandem mass spectrometry: application for selective screening of peroxisomal disorders," Journal of Inherited Metabolic Disease, vol. 22, no. 3, pp. 307-310, 1999.

[274] B. J. Wild, B. N. Green, E. K. Cooper et al., "Rapid identification of hemoglobin variants by electrospray ionization mass spectrometry," Blood Cells, Molecules, and Diseases, vol. 27, no. 3, pp. 691-704, 2001.

[275] W. Hoelzel and K. Miedema, "Development of a reference system for the international standardization of HbAlc/glycohemoglobin determinations," Journal of the International Federation of Clinical Chemistry, vol. 9, no. 2, pp. 62-67, 1996.

[276] U. Krishnamurti and M. W. Steffes, "Glycohemoglobin: a primary predictor of the development or reversal of complications of diabetes mellitus," Clinical Chemistry, vol. 47, no. 7, pp. 1157-1165, 2001.

[277] S. K. Manna, A. D. Patterson, Q. Yang et al., "UPLCMS-based urine metabolomics reveals indole-3-lactic acid and phenyllactic acid as conserved biomarkers for alcoholinduced liver disease in the Ppara-null mouse model," Journal of Proteome Research, vol. 10, no. 9, pp. 4120-4133, 2011.

[278] S. K. Manna, A. D. Patterson, Q. Yang et al., "Identification of noninvasive biomarkers for alcohol-induced liver disease using urinary metabolomics and the ppara-null mouse," Journal of Proteome Research, vol. 9, no. 8, pp. 4176-4188, 2010.

[279] C. Lifshitz and J. Laskin, Principles of Mass Spectrometry Applied to Biomolecules, John Wiley \& Sons, 2006.

[280] E. Kalenius, D. Moiani, E. Dalcanale, and P. Vainiotalo, "Measuring H-bonding in supramolecular complexes by gas phase ion-molecule reactions," Chemical Communications, no. 37, pp. 3865-3867, 2007.

[281] D. P. Weimann, H. D. F. Winkler, J. A. Falenski, B. Koksch, and C. A. Schalley, "Highly dynamic motion of crown ethers along oligolysine peptide chains," Nature Chemistry, vol. 1, no. 7, pp. 573-577, 2009.

[282] T. E. Wales and J. R. Engen, "Hydrogen exchange mass spectrometry for the analysis of protein dynamics," Mass Spectrometry Reviews, vol. 25, no. 1, pp. 158-170, 2006. 
[283] Y. Hamuro, S. J. Coales, M. R. Southern, J. F. Nemeth-Cawley, D. D. Stranz, and P. R. Griffin, "Rapid analysis of protein structure and dynamics by hydrogen/deuterium exchange mass spectrometry," Journal of Biomolecular Techniques, vol. 14, no. 3, pp. 171-182, 2003.

[284] B. E. Winger, K. J. Light-Wahl, A. L. Rockwood, and R. D. Smith, "Probing qualitative conformation differences of multiply protonated gas-phase proteins via hydrogen/deuterium isotopic exchange with water-d2," Journal of the American Chemical Society, vol. 114, no. 14, pp. 5897-5898, 1992.

[285] F. Wang, M. A. Freitas, A. G. Marshall, and B. D. Sykes, "Gasphase memory of solution-phase protein conformation: H/D exchange and Fourier transform ion cyclotron resonance mass spectrometry of the N-terminal domain of cardiac troponin C," International Journal of Mass Spectrometry, vol. 192, no. 1-3, pp. 319-325, 1999.

[286] H. Han and S. A. McLuckey, "Selective covalent bond formation in polypeptide ions via gas-phase ion/ion reaction chemistry," Journal of the American Chemical Society, vol. 131, no. 36, pp. 12884-12885, 2009.

[287] R. Qian, J. Zhou, S. Yao, H. Wang, and Y. Guo, in Reactive Intermediates, pp. 113-131, Wiley-VCH, 2010.

[288] V. M. Williams, J. R. Kong, B. J. Ko et al., "ESI-MS, DFT, and synthetic studies on the $\mathrm{H}_{2}$-mediated coupling of acetylene: insertion of $\mathrm{C}=\mathrm{X}$ bonds into rhodacyclopentadienes and Brønsted acid cocatalyzed hydrogenolysis of organorhodium intermediates," Journal of the American Chemical Society, vol. 131, no. 44, pp. 16054-16062, 2009.

[289] A. O. Aliprantis and J. W. Canary, "Observation of catalytic intermediates in the Suzuki reaction by electrospray mass spectrometry," Journal of the American Chemical Society, vol. 116, no. 15, pp. 6985-6986, 1994.

[290] L. S. Santos, C. H. Pavam, W. P. Almeida, F. Coelho, and M. N. Eberlin, "Probing the mechanism of the Baylis-Hillman reaction by electrospray ionization mass and tandem mass spectrometry," Angewandte Chemie, vol. 43, no. 33, pp. 43304333, 2004.

[291] A. A. Sabino, A. H. L. Machado, C. R. D. Correia, and M. N. Eberlin, "Probing the mechanism of the Heck reaction with arene diazonium salts by electrospray mass and tandem mass spectrometry," Angewandte Chemie, vol. 43, no. 19, pp. 25142518, 2004.

[292] H. Guo, R. Qian, Y. Liao, S. Ma, and Y. Guo, "ESI-MS studies on the mechanism of $\operatorname{Pd}(0)$-catalyzed three-component tandem double addition-cyclization reaction," Journal of the American Chemical Society, vol. 127, no. 37, pp. 1306013064, 2005.

[293] S. R. Wilson and Y. Wu, "A study of nickel-catalyzed coupling reactions by electrospray ionization mass spectrometry," Organometallics, vol. 12, no. 4, pp. 1478-1480, 1993.

[294] Y. Xie, L. F. He, S. C. Lin et al., "Desorption electrospray ionization mass spectrometry for monitoring the kinetics of baeyer-villiger solid-state organic reactions," Journal of the American Society for Mass Spectrometry, vol. 20, no. 11, pp. 2087-2092, 2009.

[295] D. G. Harman and S. J. Blanksby, "Trapping of a tert-adamantyl peroxyl radical in the gas phase," Chemical Communications, no. 8, pp. 859-861, 2006.

[296] M. N. Eberlin, "Electrospray ionization mass spectrometry: a major tool to investigate reaction mechanisms in both solution and the gas phase," European Journal of Mass Spectrometry, vol. 13, no. 1, pp. 19-28, 2007.
[297] V. Kertesz and G. J. V. Berkel, "Chemical imaging with desorption electrospray ionization mass spectrometry," Methods in Molecular Biology, vol. 656, pp. 231-241, 2010.

[298] J. M. Wiseman, D. R. Ifa, Y. Zhu et al., "Desorption electrospray ionization mass spectrometry: imaging drugs and metabolites in tissues," Proceedings of the National Academy of Sciences of the United States of America, vol. 105, no. 47, pp. 18120-18125, 2008.

[299] D. R. Ifa, J. M. Wiseman, Q. Song, and R. G. Cooks, "Development of capabilities for imaging mass spectrometry under ambient conditions with desorption electrospray ionization (DESI)," International Journal of Mass Spectrometry, vol. 259, no. 1-3, pp. 8-15, 2007.

[300] J. M. Wiseman and B. C. Laughlin, "Desorption electrospray ionization (DESI) mass spectrometry: a brief introduction and overview," Current Separations and Drug Development, vol. 22, pp. 11-14, 2007. 


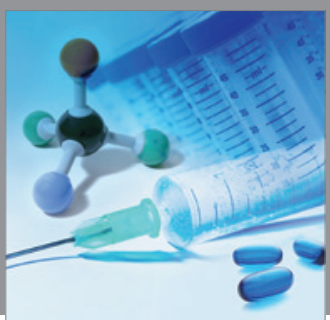

International Journal of

Medicinal Chemistry

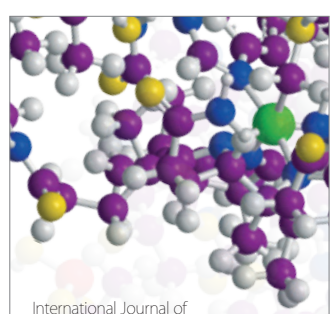

Carbohydrate Chemistry

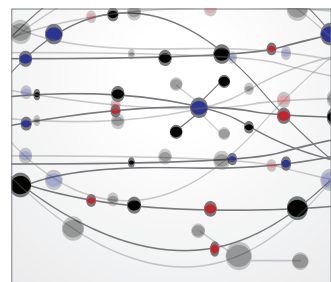

The Scientific World Journal
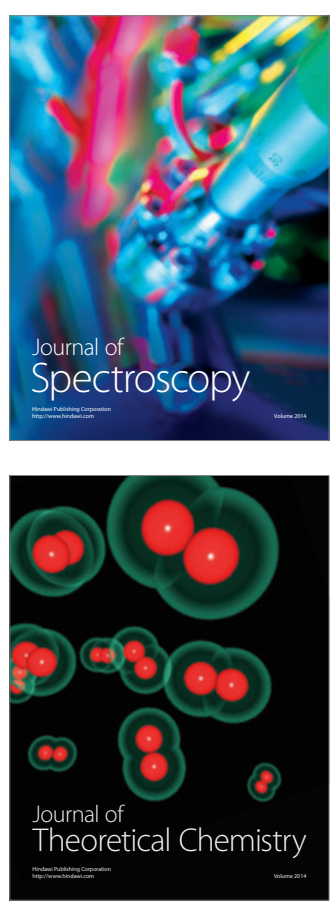
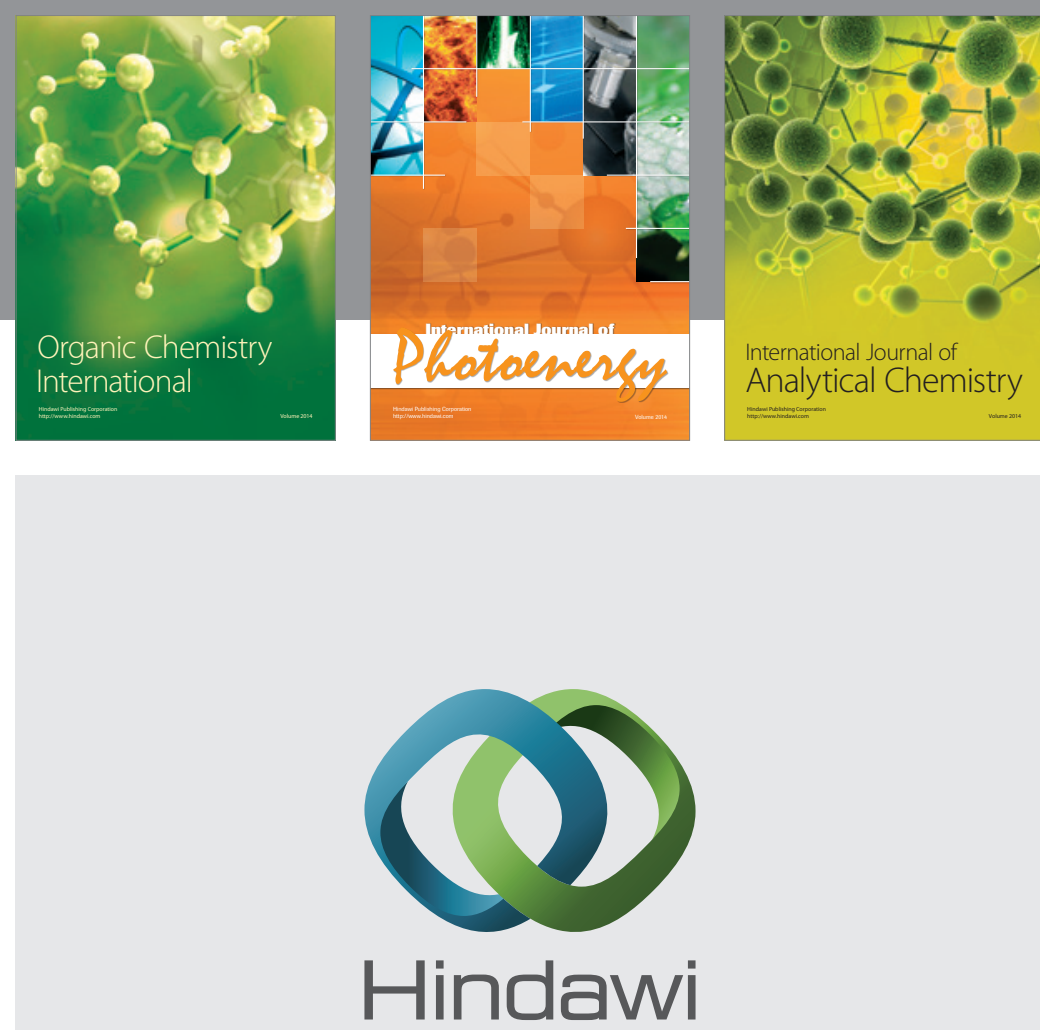

Submit your manuscripts at

http://www.hindawi.com
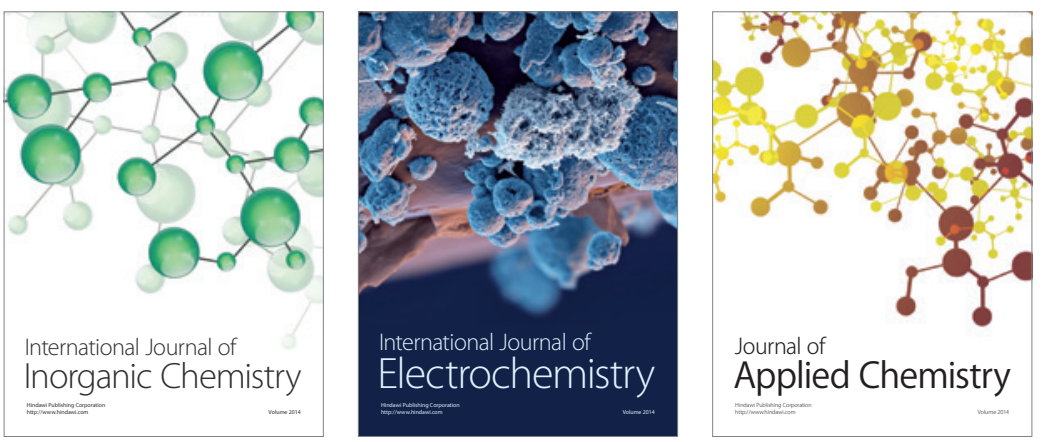

Journal of

Applied Chemistry
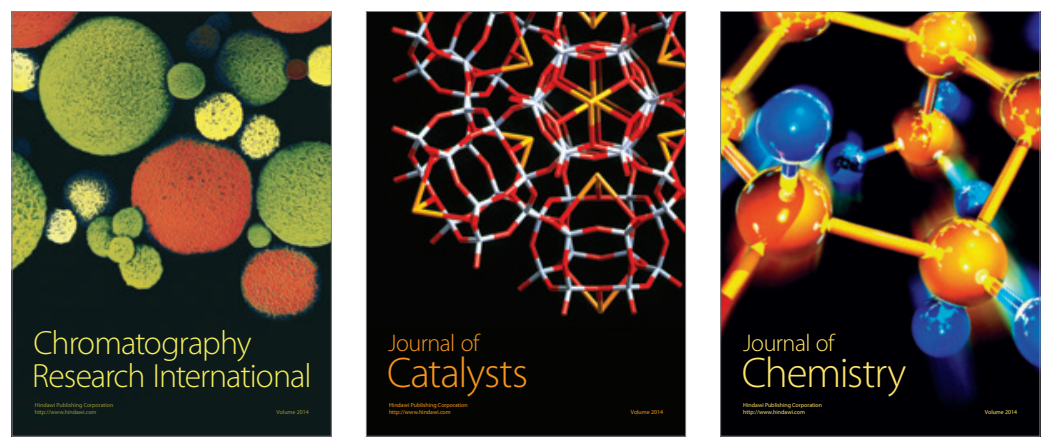
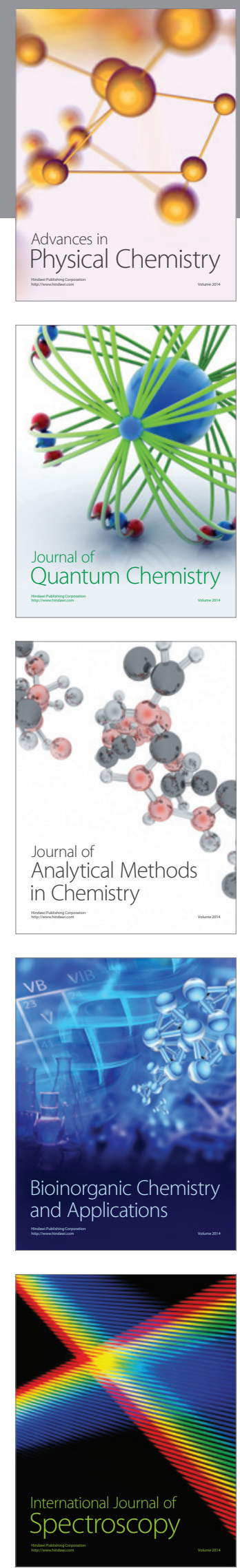